November 2000

\title{
Chain-Limiting Operation of Fischer-Tropsch Reactor
}

\author{
Technical Progress Report
}

\author{
Apostolos A. Nikolopoulos \\ Santosh K. Gangwal
}

Work Performed Under

Contract No.: DE-FG26-99FT40680

Prepared for

US Department of Energy

National Energy Technology Laboratory

P.O. Box 10940

Pittsburgh, PA 15236-0940

USA

Prepared by

Research Triangle Institute

P.O. Box 12194

Research Triangle Park, NC 27709-2194

USA 


\title{
Chain-Limiting Operation of Fischer-Tropsch Reactor
}

\author{
Technical Progress Report
}

Reporting Period Start Date: $\quad$ September 30, 1999

Reporting Period End Date: $\quad$ September 30, 2000

Apostolos A. Nikolopoulos and Santosh K. Gangwal

Date of Report:

November 2000

DOE Award No.:

DE-FG26-99FT40680

\author{
Research Triangle Institute \\ 3040 Cornwallis Rd. \\ P.O. Box 12194 \\ Research Triangle Park, NC 27709-2194 \\ USA \\ and \\ Syntroleum Corporation \\ 6024 South $166^{\text {th }}$ East Avenue \\ Tulsa, OK 74146-6821 \\ USA
}




\section{DISCLAIMER}

This report was prepared as an account of work sponsored by an agency of the United States Government. Neither the United States Government nor any agency thereof, nor any of their employees, makes any warranty, express or implied, or assumes any legal liability or responsibility for the accuracy, completeness, or usefulness of any information, apparatus, product, or process disclosed, or represents that its use would not infringe privately owned rights. Reference herein to any specific commercial product, process, or service by trade name, trademark, manufacturer, or other wise does not necessarily constitute or imply its endorsement, recommendation, or favoring by the United States Government or any agency thereof. The views and opinions of authors expressed herein do not necessarily state or reflect those of the United States Government or any agency thereof. 


\begin{abstract}
The use of pulsing to limit the chain growth of the hydrocarbon products of the FischerTropsch (FT) synthesis in order to to maximize the yield of diesel-range $\left(\mathrm{C}_{10}-\mathrm{C}_{20}\right)$ products was examined on three high-chain-growth-probability $(\boldsymbol{\alpha} \geq 0.9) \mathrm{FT}$ catalysts. On a Co- $\mathrm{ZrO}_{2} / \mathrm{SiO}_{2} \mathrm{FT}$ synthesis catalyst the application of $\mathrm{H}_{2}$ pulsing causes significant increase in $\mathrm{CO}$ conversion, and only an instantaneous increase in undesirable selectivity to $\mathrm{CH}_{4}$. Increasing the frequency of $\mathrm{H}_{2}$ pulsing enhances the selectivity to $\mathrm{C}_{10}-\mathrm{C}_{20}$ compounds but the chain-growth probability $\boldsymbol{\alpha}$ remains essentially unaffected. Increasing the duration of $\mathrm{H}_{2}$ pulsing results in enhancing the maximum obtained $\mathrm{CO}$ conversion and the instantaneous selectivity to $\mathrm{CH}_{4}$. An optimum set of $\mathrm{H}_{2}$ pulse parameters (pulse frequency and duration) is required for maximizing the yield of desirable diesel-range $\mathrm{C}_{10}-\mathrm{C}_{20}$ products.

On a high- $\boldsymbol{\alpha} \mathrm{Fe} / \mathrm{K} / \mathrm{Cu} / \mathrm{SiO}_{2} \mathrm{FT}$ synthesis catalyst $\mathrm{H}_{2}$ pulsing enhances the yield of $\mathrm{C}_{10}-\mathrm{C}_{20}$ but at the same time decreases the catalyst activity ( $\mathrm{CO}$ conversion) and increases the selectivity to $\mathrm{CH}_{4}$. On the other hand, pulsing with $\mathrm{CO}$ also increases the yield of $\mathrm{C}_{10}-\mathrm{C}_{20}$ but has no impact on the selectivity to $\mathrm{CH}_{4}$ or $\mathrm{CO}_{2}$ and decreases catalytic activity only moderately.

In contrast to these catalysts, $\mathrm{H}_{2}$ pulsing on a high- $\boldsymbol{\alpha} \mathrm{Ru} /$ alumina FT synthesis catalyst has only minimal effect on activity and product distribution, showing enhanced activity towards methanation and water-gas-shift at the expense of FT synthesis. However, these observations are based on experiments performed at a significantly lower reaction pressure (ca. 26 atm) and higher reaction temperature $\left(210-250^{\circ} \mathrm{C}\right)$ than those commonly used for supported-Ru FT catalysts (typically $100-1000 \mathrm{~atm}, 160-170^{\circ} \mathrm{C}$ ).
\end{abstract}




\section{TABLE OF CONTENTS}

Section Page

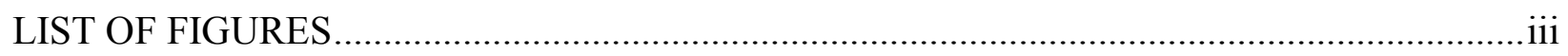

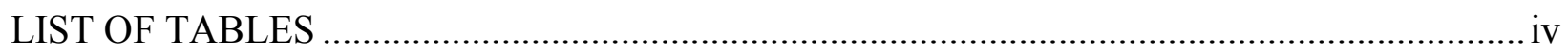

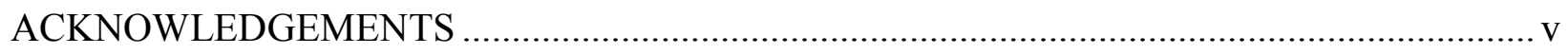

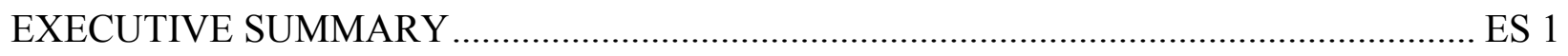

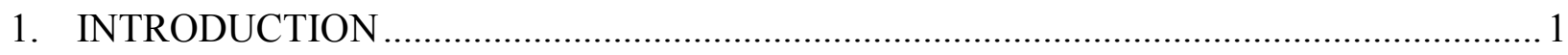

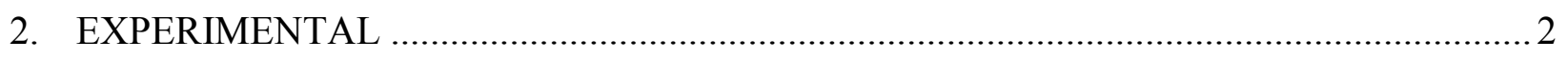

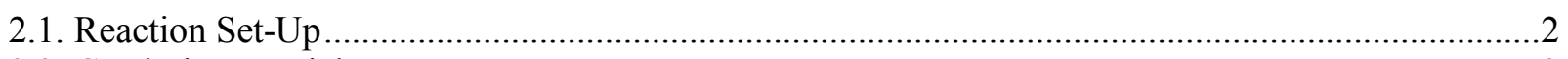

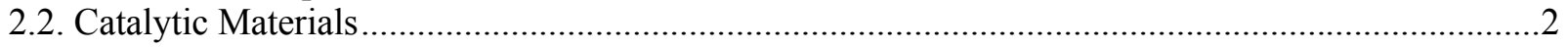

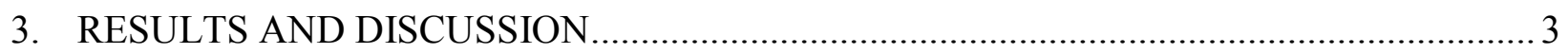

3.1. FT Reaction on $\alpha$-Alumina .........................................................................................

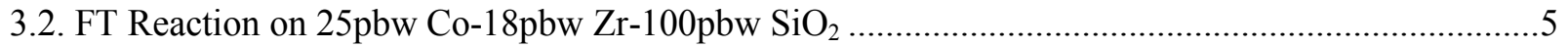

3.3. FT Reaction on $\mathrm{Fe} / \mathrm{K} / \mathrm{Cu} / \mathrm{SiO}_{2}$ catalyst (HPR-43) ……………............................................13

3.4. Fixed bed (RTI) and CSTR data (Syntroleum Corp.) of catalyst HPR-43 .....................................19

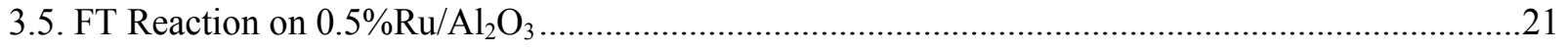

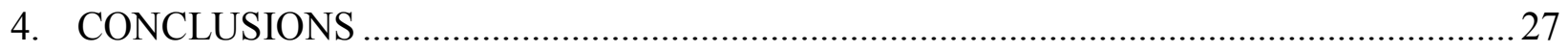

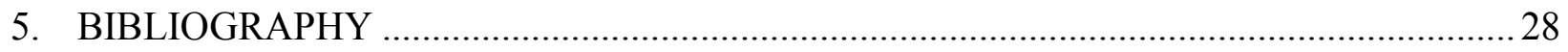

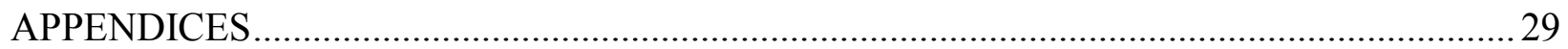

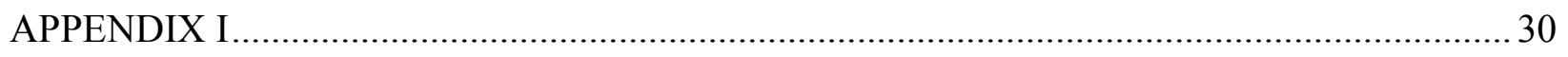

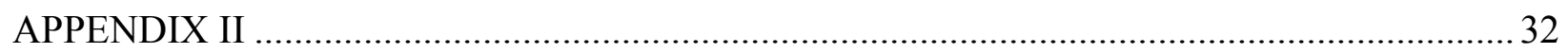




\section{LIST OF FIGURES}

\section{Section}

Figure 1.1. Product distribution ( $\alpha$-plot) for FT synthesis 1

Figure 3.1.1. CO conversion on $\alpha$-alumina $@ 208^{\circ} \mathrm{C}$;

$\mathrm{P}=300$ psig; $\mathrm{SV}=6000 \mathrm{~h}^{-1}$. 3

Figure 3.1.2. Effect of $\mathrm{H}_{2}$ pulse ( 1 min per 1 hour) on outlet $\mathrm{H}_{2}: \mathrm{CO}$ ratio @ $270^{\circ} \mathrm{C} ; \mathrm{P}=300$ psig; $\mathrm{SV}=6000 \mathrm{~h}^{-1}$. 4

Figure 3.2.1. Effect of $\mathrm{H}_{2}$ pulse frequency on $\mathrm{CO}$ conversion of $\mathrm{Co}-\mathrm{ZrO}_{2} / \mathrm{SiO}_{2} @ 300$ psig and $6000 \mathrm{~h}^{-1}$. 7

Figure 3.2.2. Effect of $\mathrm{H}_{2}$ pulse frequency on $\mathrm{C}_{1}$ selectivity of $\mathrm{Co}-\mathrm{ZrO}_{2} / \mathrm{SiO}_{2} @ 300$ psig and $6000 \mathrm{~h}^{-1}$. 7

Figure 3.2.3. Effect of $\mathrm{H}_{2}$ pulse frequency on product yield of $\mathrm{Co}-\mathrm{ZrO}_{2} / \mathrm{SiO}_{2} @ 300$ psig and $6000 \mathrm{~h}^{-1}$. .8

Figure 3.2.4. Effect of $\mathrm{H}_{2}$ pulse duration on outlet $\mathrm{H}_{2}: \mathrm{CO}$ ratio of $\mathrm{Co}-\mathrm{ZrO}_{2} / \mathrm{SiO}_{2} @ 300$ psig and $6000 \mathrm{~h}^{-1}$. 9

Figure 3.2.5. Effect of $\mathrm{H}_{2}$ pulse duration on $\mathrm{CO}$ conversion of $\mathrm{Co}-\mathrm{ZrO}_{2} / \mathrm{SiO}_{2} @ 300$ psig and $6000 \mathrm{~h}^{-1}$.

Figure 3.2.6. Effect of $\mathrm{H}_{2}$ pulse duration on $\mathrm{C}_{1}$ selectivity of $\mathrm{Co}-\mathrm{ZrO}_{2} / \mathrm{SiO}_{2} @ 300$ psig and $6000 \mathrm{~h}^{-1}$. 10

Figure 3.2.7. Effect of $\mathrm{H}_{2}$ pulse duration on product distribution ( $\alpha$-plot) of $\mathrm{Co}-\mathrm{ZrO}_{2} / \mathrm{SiO}_{2} @ 300$ psig and $6000 \mathrm{~h}^{-1}$.

Figure 3.2.3. Effect of $\mathrm{H}_{2}$ pulse duration on product yield of Co- $\mathrm{ZrO}_{2} / \mathrm{SiO}_{2} @ 300$ psig and $6000 \mathrm{~h}^{-1}$. 12

Figure 3.3.1. Effect of $\mathrm{H}_{2}$ pulse on outlet $\mathrm{H}_{2}$ : $\mathrm{CO}$ ratio of HPR-43@300psig and 6000 h $^{-1}$. 14

Figure 3.3.2. Effect of $\mathrm{H}_{2}$ pulse on $\mathrm{CO}$ conversion of HPR-43@300psig and 6000 h $^{-1}$. 14

Figure 3.3.3. Effect of $\mathrm{H}_{2}$ pulse on $\mathrm{C}_{1}$ selectivity of HPR-43@300 psig and 6000 h $^{-1}$.

Figure 3.3.4. Effect of $\mathrm{H}_{2}$ pulse on product distribution of HPR-43@300psig and 6000 h $^{-1}$. 16

Figure 3.3.5. Effect of $24 \% \mathrm{CO}_{2} / \mathrm{N}_{2}$ pulse on product distribution of HPR-43@300psig and 6000 h $^{-1}$. .16 
Figure 3.3.6. Effect of $\mathrm{CO}$ pulse on outlet $\mathrm{H}_{2}$ : $\mathrm{CO}$ ratio of HPR-43@300psig and 6000 h $^{-1}$.

Figure 3.3.7. Effect of $\mathrm{CO}$ pulse on $\mathrm{CO}$ conversion of HPR-43@300psig and 6000 h $^{-1}$. 18

Figure 3.3.8. Effect of $\mathrm{CO}$ pulse on $\mathrm{C}_{1}$ selectivity of HPR-43@300psig and 6000 h $^{-1}$. .18

Figure 3.3.9. Effect of $\mathrm{CO}$ pulse on product distribution of HPR-43@300psig and 6000 h $^{-1}$.

Figure 3.4.1. \% CO conversion and rate ( $\mathrm{cc} \mathrm{CO} / \mathrm{cc}$ cat $/ \mathrm{h})$

from CSTR run of RTI catalyst HPR-43

Figure 3.5.1. Effect of $\mathrm{H}_{2}$ pulse on outlet $\mathrm{H}_{2}$ : $\mathrm{CO}$ ratio of $\mathrm{Ru} / \mathrm{Al}_{2} \mathrm{O}_{3} @ 400$ psig and $3000 \mathrm{~h}^{-1}$.

Figure 3.5.2. Effect of $\mathrm{H}_{2}$ pulse on $\mathrm{CO}$ conversion of $\mathrm{Ru} / \mathrm{Al}_{2} \mathrm{O}_{3} @ 400$ psig and $3000 \mathrm{~h}^{-1}$.

Figure 3.5.3. Effect of $\mathrm{H}_{2}$ pulse on $\mathrm{C}_{1}$ selectivity of $\mathrm{Ru} / \mathrm{Al}_{2} \mathrm{O}_{3} @ 400$ psig and $3000 \mathrm{~h}^{-1}$.

Figure 3.5.4. Effect of activation process on $\mathrm{CO}$ conversion of $\mathrm{Ru} / \mathrm{Al}_{2} \mathrm{O}_{3} @ 400$ psig and $3000 \mathrm{~h}^{-1}$.

Figure 3.5.5. Effect of temperature on rate of $\mathrm{CO}$ consumption of $\mathrm{Ru} / \mathrm{Al}_{2} \mathrm{O}_{3} @ 400$ psig and $3000 \mathrm{~h}^{-1}$.

Figure 3.5.6. Effect of $\mathrm{H}_{2}$ pulse on $\mathrm{CO}$ conversion of $\mathrm{Ru} / \mathrm{Al}_{2} \mathrm{O}_{3} @ 400$ psig and $3000 \mathrm{~h}^{-1}$. .25

Figure 3.5.7. Effect of $\mathrm{H}_{2}$ pulse on $\mathrm{C}_{1}$ selectivity of $\mathrm{Ru} / \mathrm{Al}_{2} \mathrm{O}_{3} @ 400$ psig and $3000 \mathrm{~h}^{-1}$. .26

\section{LIST OF TABLES}

Section

Page

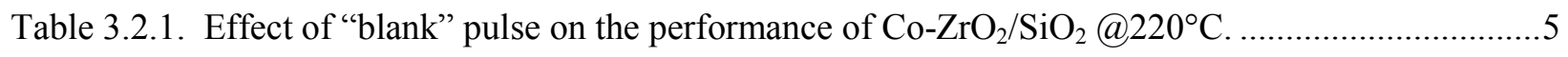

Table 3.2.2. Effect of inert (N2) pulse on the performance of $\mathrm{Co}-\mathrm{ZrO} 2 / \mathrm{SiO} 2 @ 224^{\circ} \mathrm{C}$..........................6

Table 3.4.1. Fixed bed and CSTR data of catalyst HPR-43 ..................................................................20 


\section{ACKNOWLEDGEMENTS}

This research was supported by National Energy Technology Laboratory (NETL) of the US Department of Energy under Grant No. DE-FG26-99FT40680. Donald Krastman is the Contracting Officer's Representative at NETL. Dr. James J. Spivey managed a major portion of the first year effort for the Grant at RTI before leaving for NCSU in July 2000. The authors would also like to thank Paul Schubert and Cemal Ercan of Syntroleum and Gary Howe and David Carter of RTI for their technical contributions. Valuable suggestions on the research were provided by Ram Srivastava of Parsons, and Mike Novak, John Shen, and John Winslow of DOE. 


\section{EXECUTIVE SUMMARY}

\section{$\underline{\text { Objective }}$}

The objective of this research project is to limit the chain growth of Fiscer-Tropsch (FT) products by removing the growing hydrocarbons from the catalyst surface. The present research work focuses on investigating the effect of pulsing on the activity and product distribution of high- $\boldsymbol{\alpha}$ FT synthesis catalysts, in an attempt to limit chain growth to $\mathrm{C}_{20}$ hydrocarbons, thus maximizing the desirable diesel-range $\mathrm{C}_{10}-\mathrm{C}_{20}$ yield.

This investigation involves periodic substitution of the reactant $\left(\mathrm{H}_{2}+\mathrm{CO}\right)$ flow by an equal flow of a selected "pulse" gas (typically $\mathrm{H}_{2}$ ) and monitoring the resulting changes in productivity and product distribution of a particular FT synthesis catalyst. The evaluation of various FT catalysts is based on maximizing the $\mathrm{C}_{10}-\mathrm{C}_{20}$ product yield. Optimization of the pulse sequence characteristics (frequency, duration, gas type, and gas concentration) is also within the scope of this research.

\section{Summary of Results}

Four materials were examined for evaluating the chain-limiting concept on FT synthesis in terms of activity and product selectivity. These were:

- a high-purity, low-surface-area $\left(0.2-\mathrm{m}^{2} / \mathrm{g}\right) \alpha$-alumina (SA 5397, Norton), which was an "inert" material and was also used for diluting the other examined FT catalysts,

- a high-a ( 0.9) 25pbw Co-18pbw Zr-100pbw $\mathrm{SiO}_{2}$ catalyst, synthesized at RTI,

- a very-high- $\alpha(\sim 0.95) \mathrm{Fe} / \mathrm{K} / \mathrm{Cu} / \mathrm{SiO}_{2}$ catalyst, synthesized by the Hampton University, RTI, University of Pittsburgh team under another DOE contract (DE-FG22-96PC96217), and

- a very-high- $\alpha$ ( 0.95 or more) $0.5 \mathrm{wt} \% \mathrm{Ru} /$ alumina catalyst (synthesized at North Carolina State University, in sub-contract to RTI).

Preliminary FT synthesis runs were performed on the $\alpha$-alumina catalyst at 208 and $270^{\circ} \mathrm{C}$, so as to establish a "blank" activity in the absence of a metal-supported FT catalyst. This $\alpha$ alumina catalyst exhibited no measurable activity for FT synthesis at $208^{\circ} \mathrm{C}$ and $270^{\circ} \mathrm{C}$; thus, its presence did not contribute to the activity measurements for the other examined catalysts.

The chain-limiting concept was examined on the $\mathrm{Co}-\mathrm{ZrO}_{2} / \mathrm{SiO}_{2}$ FT synthesis catalyst using a series of pulse runs of varying pulse gas, pulse frequency, and pulse duration. "Blank" pulse runs (i.e., involving a switch between two feed streams of the same composition) had no effect on the progress of FT synthesis in terms of activity and product distribution. Pulsing with an inert gas $\left(\mathrm{N}_{2}\right)$ gave only minimal variations in catalyst activity (as measured by $\mathrm{CO}$ conversion) and product yield for FT reaction.

Pulsing with reactant gas $\mathrm{H}_{2}$ resulted in a significant increase in $\mathrm{CO}$ conversion, along with an enhanced reaction exotherm, while only instantaneously increasing the selectivity to $\mathrm{CH}_{4}$. The activity decreased gradually until the next pulse, indicating a tendency to return to its steadystate value, whereas the selectivity to $\mathrm{CH}_{4}$ is quickly restored to its steady-state value. Thus, $\mathrm{H}_{2}$ pulsing increases catalytic activity while only briefly increasing the formation of $\mathrm{CH}_{4}$.

An increase in the $\mathrm{H}_{2}$ pulse frequency enhanced the selectivity to $\mathrm{C}_{10}-\mathrm{C}_{20}$ compounds (while maintaining or slightly decreasing the selectivity to $\mathrm{CH}_{4}$ ), but the chain-growth probability $\boldsymbol{\alpha}$ remained essentially unaffected. Increasing the $\mathrm{H}_{2}$ pulse duration increased the maximum 
obtained $\mathrm{CO}$ conversion as well as the instantaneous selectivity to $\mathrm{CH}_{4}$. The extent of the $\mathrm{CH}_{4}$ formation appears to be correlated to the increase in $\mathrm{H}_{2}$ concentration as caused by pulsing. The FT reaction, however, appears to have a different dependence on $\mathrm{H}_{2}$ concentration, since it progressed within a different time frame. An optimum set of pulse parameters (pulse frequency and duration) is required for maximizing the yield of desirable (diesel-range) $\mathrm{C}_{10}-\mathrm{C}_{20}$ products.

The effect of pulsing was also examined on a high- $\alpha \mathrm{Fe} / \mathrm{K} / \mathrm{Cu} / \mathrm{SiO}_{2} \mathrm{FT}$ catalyst at different reaction conditions than those applied for the $\mathrm{Co}-\mathrm{ZrO}_{2} / \mathrm{SiO}_{2}$ catalyst (moderately higher reaction temperature, and a $\mathrm{H}_{2}$ : $\mathrm{CO}$ ratio of 0.67 ). Pulsing with $\mathrm{H}_{2}$ increased the $\mathrm{C}_{10}-\mathrm{C}_{20}$ yield but also caused a significant decrease in catalyst activity ( $\mathrm{CO}$ conversion) and an undesirable increase in the selectivity to $\mathrm{CH}_{4}$. Pulsing with $\mathrm{CO}$ also enhanced the $\mathrm{C}_{10}-\mathrm{C}_{20}$ yield and had no measurable effect on the selectivity to $\mathrm{CH}_{4}$ and $\mathrm{CO}_{2}$, while causing only a moderate decrease in $\mathrm{CO}$ conversion. Pulsing with a $24 \% \mathrm{CO}_{2} / \mathrm{N}_{2}$ gas mixture had essentially no effect on the catalyst activity or product distribution ( $\boldsymbol{\alpha}$-value, $\mathrm{C}_{10}-\mathrm{C}_{20}$ yield).

In contrast, $\mathrm{H}_{2}$ pulsing had only minimal effect on the activity and product distribution of the examined $0.5 \% \mathrm{Ru} /$ alumina FT synthesis catalyst, which exhibited enhanced activity towards methanation and water-gas-shift reactions. This could be due to a lower reaction pressure (ca. 26 atm) and higher reaction temperature compared to those commonly used for supported-Ru FT catalysts (typically $100-1000 \mathrm{~atm}, 160-170^{\circ} \mathrm{C}$ ). Application of another reduction procedure produced a better-activated catalyst, exhibiting the same activity at lower temperatures, along with lower selectivity to undesirable compounds $\mathrm{CH}_{4}$ and $\mathrm{CO}_{2}$.

\section{$\underline{\text { Publications/Presentations }}$}

1. Two-page abstract entitled "Fischer-Tropsch Synthesis on a Co- $\mathrm{ZrO}_{2} / \mathrm{SiO}_{2}$ Catalyst: Effect of $H_{2}$ Pulsing", submitted for presentation in the $17^{\text {th }}$ North American Catalysis Society Meeting, to be held in Toronto, Canada, on June 3-8, 2001 (see Appendix I).

2. Six-page camera-ready manuscript entitled "Effect of Periodic Pulsed Operation on Product Selectivity in Fischer-Tropsch Synthesis on $\mathrm{Co}-\mathrm{ZrO}_{2} / \mathrm{SiO}_{2}$ ", submitted for oral presentation and publication in the Proceedings of the $6^{\text {th }}$ Natural Gas Conversion Symposium, to be held in Girdwood, Alaska, on June 17-21, 2001 (see Appendix II).

\section{$\underline{\text { Keywords }}$}

Chain-limiting

Cobalt

Diesel

Fischer-Tropsch synthesis

Iron

Pulsing

Ruthenium 


\section{INTRODUCTION}

The Fischer-Tropsch synthesis (FTS) can convert solid fuel- or natural gas-derived syngas $\left(\mathrm{CO}+\mathrm{H}_{2}\right)$ to liquid fuels and high-value products. The extensively reviewed Fischer-Tropsch (FT) reaction [1-3] produces a non-selective distribution of hydrocarbons $\left(\mathrm{C}_{1}-\mathrm{C}_{100+}\right)$ from syngas. FT catalysts are typically based on Group-VIII metals ( $\mathrm{Fe}, \mathrm{Co}, \mathrm{Ni}$, and $\mathrm{Ru}$ ), with $\mathrm{Fe}$ and Co most frequently used. The product distribution over these catalysts is generally governed by the Schultz-Flory-Anderson (SFA) polymerization kinetics [4].

Currently there is significant commercial interest in producing diesel-fuel range middle distillates $\left(\mathrm{C}_{10}-\mathrm{C}_{20}\right.$ paraffins $)$ from natural gas-derived syngas [5]. Increasing the selectivity of FTS to desired products such as diesel $\left(\mathrm{C}_{10}-\mathrm{C}_{20}\right)$ or gasoline $\left(\mathrm{C}_{5}-\mathrm{C}_{11}\right)$ by altering the SFA distribution is economically attractive. Use of bifunctional catalysts (FT-active metals on zeolite, e.g. ZSM-5) to produce high-octane gasoline-range hydrocarbons (explored in the past 2 decades), has been economically unsuccessful [6-9]. The zeolite cracking activity lowers the chain-growth probability $(\boldsymbol{\alpha})$, producing gasoline-range products in excess of $48 \mathrm{wt} \%$ of the total hydrocarbon, but it also produces a significant amount of undesirable $\mathrm{C}_{1}-\mathrm{C}_{4}$ gases (Figure 1).

The present emphasis has shifted towards maximizing the yield of high-cetane $\mathrm{C}_{10}-\mathrm{C}_{20}$ products from FTS. Increased worldwide demand for low-sulfur diesel has further stressed the importance of development of zero-sulfur FT-diesel products. An alternative approach to the use of bifunctional catalysts to alter selectivity is periodic FT reactor operation (pulsing) [3]. It entails alternatively switching between two predetermined input compositions over the FT catalyst to promote time-average rate, selectivity, and catalyst life [10-12]. Periodic pulsing of $\mathrm{H}_{2}$ has been examined so as to limit chain growth by removing the growing hydrocarbon chain from the catalyst surface [13-15]. Experimental studies have shown the potential to alter the SFA distribution [16,17]; they were performed, however, at conditions of limited industrial interest.

The chain-limiting concept using pulsing to maximize diesel yield is shown in a plot of

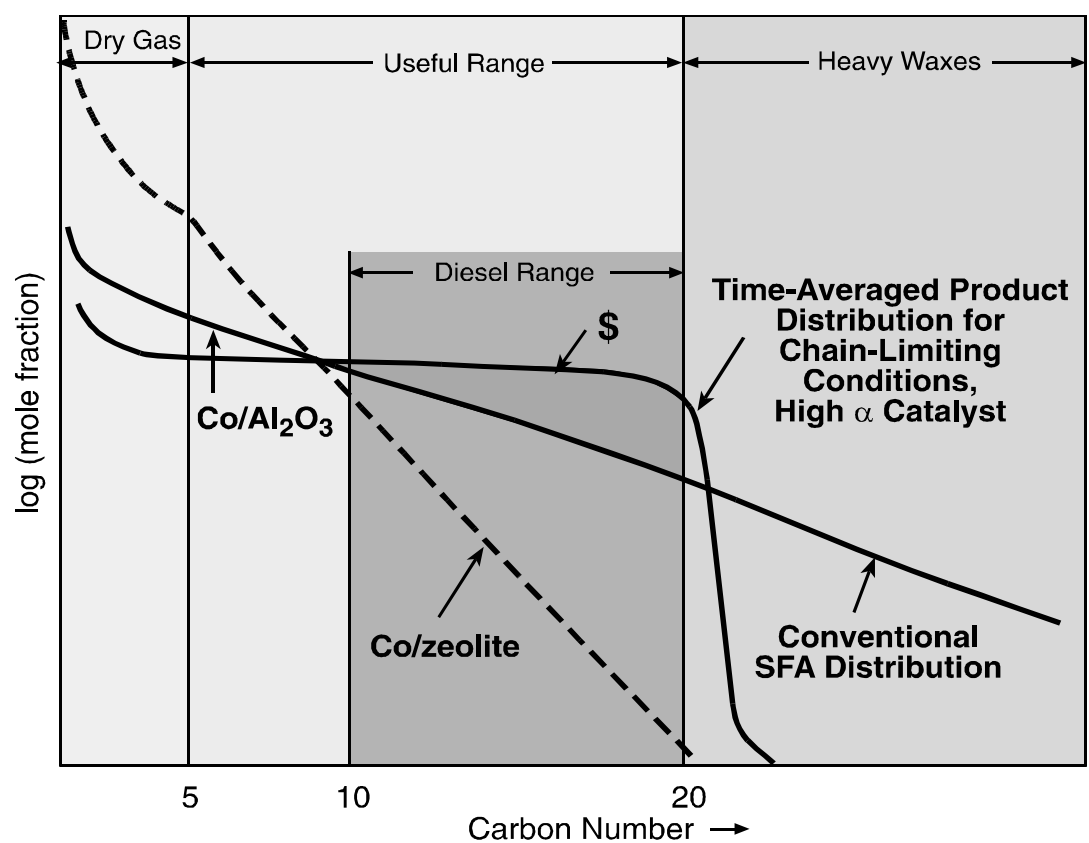
carbon number vs. mole fraction (Fig. 1). The slope of the curve is determined by the chain-growth probability, $\boldsymbol{\alpha}$. Periodic operation on a high- $\boldsymbol{\alpha}$ catalyst may result in removal of the growing chain from the surface at the desired $\mathrm{C}_{10}-\mathrm{C}_{20}$ length, thereby maximizing diesel yield without increasing the dry gas.

The objective of this study is to investigate the effect of pulsing on the activity and product distribution of high-a FT synthesis catalysts, in an attempt to maximize the $\mathrm{C}_{10^{-}}$ $\mathrm{C}_{20}$ product yield.

Figure 1.1. Product distribution ( $\alpha$-plot) for FT synthesis 


\section{EXPERIMENTAL}

\subsection{Reaction Set-Up}

The reaction system consisted of the gas-feed, a fixed-bed reactor, and a sampling/analysis system for the liquid and gaseous products. The feed system blended $\mathrm{CO} / \mathrm{Ar}, \mathrm{H}_{2}, \mathrm{~N}_{2}$, or other premixed gases in desired concentrations. The feed streams enter through the top of the reactor. Mass flow controllers (from Brooks) were used to control the flow rate of the feed streams. They operated in a fail-closed mode in order to stop the flow of the feed gases to the reactor in the event of a power/controller failure.

A time-programmable interface system (Carolina Instrumentation Co.) was used to control a series of actuated valves, so that a (reactant or inert) flow opened / closed automatically and independently of the others. Appropriate periodic switch of these valves offered the capability to perform various pulsing-type experiments with this configuration. Pulse time could be varied from 1 min to 48 hours. All valves automatically switched to their respective fail-safe position $\left(\mathrm{N}_{2}\right.$ open, all others closed) in the event of power failure.

A stainless-steel 3/8-in o.d. (0.305-in i.d.) downflow reactor was enclosed in a three-zone programmable furnace. A $90-\mu \mathrm{m}$ sintered stainless-steel frit, held in place by a welded cap, was placed at the bottom of the reactor. It supported the catalyst bed and prevented the removal of catalyst fines from the catalyst bed into the liquid product stream. A "dual-profile" internal bed thermocouple measured the bed temperature at two points: 1 inch from the top of the bed and 3 inches from the bottom of the bed.

The liquid products were collected and separated into a wax trap (waxes) maintained at $140^{\circ} \mathrm{C}$ and a water trap (oil + water) maintained at $25^{\circ} \mathrm{C}$. Two sets of these traps, positioned in parallel, enabled continuous operation. A Kammer back-pressure-control valve, located downstream of the traps, controlled the reactor and trap pressure.

An on-line GC-Carle (TCD) analyzed the permanent gases $\left(\mathrm{H}_{2}, \mathrm{CO}_{2}, \mathrm{Ar}, \mathrm{N}_{2}, \mathrm{CH}_{4}, \mathrm{CO}\right)$. Argon was used as internal standard. An on-line GC-FID (100-m Petrocol column, ramped from -25 to $\left.300^{\circ} \mathrm{C}\right)$ analyzed the light hydrocarbons $\left(\mathrm{C}_{1}-\mathrm{C}_{15}\right)$. A third off-line GC-FID (15-m SPB-1 capillary column, $0.1-\mu \mathrm{m}$, ramped from 50 to $350^{\circ} \mathrm{C}$ ) analyzed the composite wax and oil collected from the wax and water traps, respectively.

\subsection{Catalytic Materials}

The following catalysts were examined in terms of their activity and product selectivity with respect to the application of various pulse schemes:

a) a high-purity, low-surface-area $\left(0.2-\mathrm{m}^{2} / \mathrm{g}\right) \alpha$-alumina (SA 5397 , Norton), which was also used for diluting the other examined FT catalysts,

b) a high- $\boldsymbol{\alpha}(\sim 0.9) 25 \mathrm{pbw}$ Co-18pbw $\mathrm{Zr}-100 \mathrm{pbw} \mathrm{SiO}_{2}$ catalyst, synthesized at RTI,

c) a very-high- $\boldsymbol{\alpha}(\sim 0.95) \mathrm{Fe} / \mathrm{K} / \mathrm{Cu} / \mathrm{SiO}_{2}$ catalyst, synthesized by the Hampton University, RTI, University of Pittsburgh team under another DOE contract (DE-FG22-96PC96217), and

d) a potentially very-high- $\alpha$ ( 0.95 or more) $0.5 \mathrm{wt} \% \mathrm{Ru} /$ alumina catalyst (synthesized by Henry Lamb at North Carolina State University, in sub-contract to RTI). 


\section{RESULTS AND DISCUSSION}

\subsection{FT Reaction on $\alpha$-Alumina}

A preliminary FT reaction run was performed on a low-surface-area $\left(\sim 0.2 \mathrm{~m}^{2} / \mathrm{g}\right)$ high-purity $\alpha$-alumina sample (SA 5397, Norton). This alumina was used for diluting the other examined FT catalysts included in this report. The objective of this experiment was to establish a "blank-run" activity in the absence of a metal-supported FT catalyst.

The reactor was loaded with $17.7 \mathrm{cc}(28.32 \mathrm{~g})$ of $\alpha$-alumina. The sample was reduced in-situ under $\mathrm{H}_{2}$ at $350^{\circ} \mathrm{C}$ for $14 \mathrm{~h}$, and was cooled and pressurized to ca. 300 psig (19.4 atm). The FT reaction was started by feeding a $10 \% \mathrm{Ar} / \mathrm{CO}$ gas mix, thus establishing the following base reaction conditions:

$$
\begin{aligned}
& \text { Syngas }\left(\mathrm{H}_{2}+\mathrm{CO}\right)=50 \%, \mathrm{H}_{2}: \mathrm{CO}=2: 1\left(\text { i.e., } 33.3 \% \mathrm{H}_{2} \text { and } 16.7 \% \mathrm{CO}\right) \\
& \text { Inerts }\left(\mathrm{N}_{2}+\mathrm{Ar}\right)=50 \%\left(1.7 \% \mathrm{Ar}, 48.3 \% \mathrm{~N}_{2}\right) \\
& \mathrm{P}=300 \mathrm{psig}, \mathrm{F}=200 \mathrm{scc} / \mathrm{min}, \mathrm{SV}=6000 \mathrm{~h}^{-1} .
\end{aligned}
$$

The reaction temperature was stabilized at $208^{\circ} \mathrm{C}$, thus allowing the reaction to reach a "pseudo-steady state". Under these reaction conditions a moderate $(<10 \%) \mathrm{CO}$ conversion is observed initially (Figure 3.1.1). Then, the $\alpha$-alumina shows no FT activity, thus establishing a true "blank" run at $208^{\circ} \mathrm{C}$.

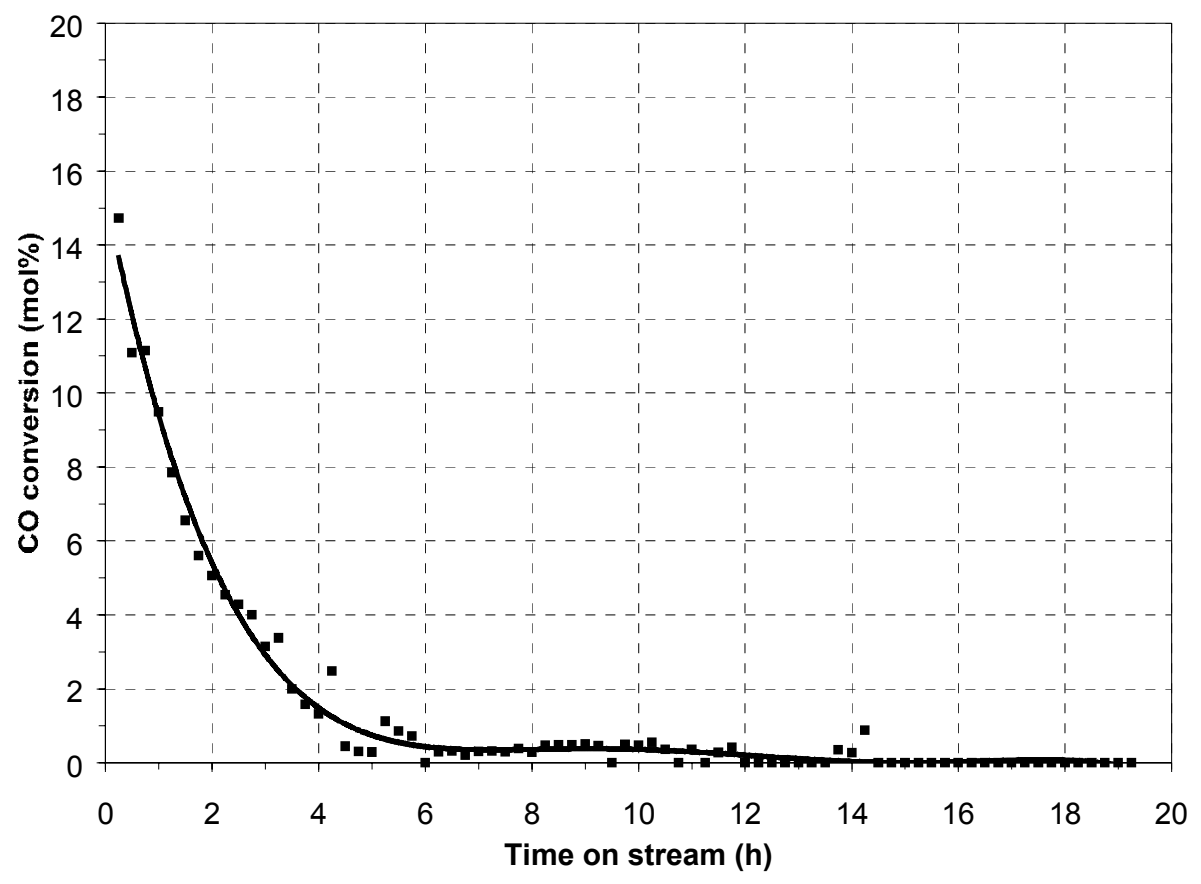

Figure 3.1.1. $\mathrm{CO}$ conversion on $\alpha$-alumina $@ 208^{\circ} \mathrm{C}$; $\mathrm{P}=300$ psig; $\mathrm{SV}=6000 \mathrm{~h}^{-1}$. 
The reaction $\mathrm{T}$ was then gradually increased to $270^{\circ} \mathrm{C}$ (maximum temperature for Fe-FT reaction). The observed $\mathrm{CO}$ conversion also remains essentially zero at this reaction temperature. After 4 hours on stream a 1-min $\mathrm{H}_{2}$ pulse per 1 hour was applied, so as to establish any background activity when pulses are used. Pulse runs involved substituting the reactant feed flow $\left(\mathrm{H}_{2}+\mathrm{CO} / \mathrm{Ar}\right)$ with an equal molar flow of a pulse gas. The total molar flow and the reaction pressure were kept constant between base and pulse runs. Seventeen such $\mathrm{H}_{2}$ pulses (in a period of 17 hours) were applied. The effect on the outlet $\mathrm{H}_{2}$ : $\mathrm{CO}$ ratio is shown in Figure 3.1.2.

Due to the 15-min analysis time of the permanent gases $\left(\mathrm{H}_{2}, \mathrm{CO}_{2}, \mathrm{Ar}, \mathrm{N}_{2}, \mathrm{CH}_{4}, \mathrm{CO}\right)$, only 4 data points could be obtained for every 1-hour pulse cycle. In order to better observe the effect of a given pulse, a "delay time" is defined as the time difference between the end of a pulse and the following GC data point. The need for applying a delay time arises from the fact that a step change in the reactant feed cannot be instantaneously detected due to the dead volume of the reaction/analysis system. A delay time of 5 min was used, i.e., the first 1-min $\mathrm{H}_{2}$ pulse was completed at 4 hours and 55 min on stream and the next data point was obtained at 5 hours on stream, as shown in Figure 3.

The results of Fig. 3.1.2 indicate that the applied $\mathrm{H}_{2}$ pulses cause an increase in the outlet $\mathrm{H}_{2}$ :CO ratio (up to ca. 2.4), but this ratio is moderately quickly restored to a value of ca. 2 . A minimal reactor pressure variation (ca. 3 psi, i.e., ca. $1 \%$ of the measured pressure) is observed during each pulse. The measured $\mathrm{CO}$ conversion is also essentially zero throughout this run, thus establishing a zero-activity baseline for the FT reaction at $270^{\circ} \mathrm{C}$ even under a typical $\mathrm{H}_{2}$ pulse sequence.

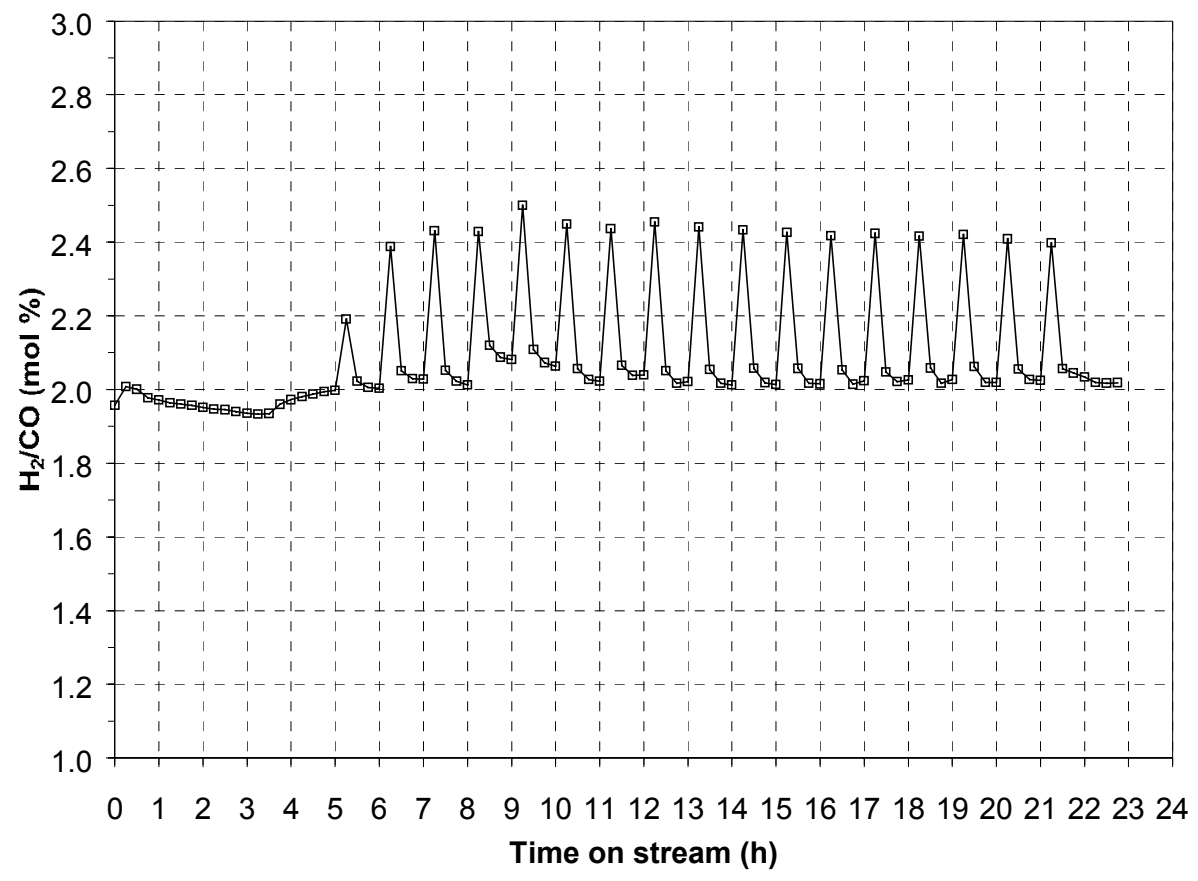

Figure 3.1.2. Effect of $\mathrm{H}_{2}$ pulse (1 min per 1 hour) on outlet $\mathrm{H}_{2}$ : $\mathrm{CO}$ ratio $@ 270^{\circ} \mathrm{C} ; \mathrm{P}=300 \mathrm{psig} ; \mathrm{SV}=6000 \mathrm{~h}^{-1}$. 


\subsection{FT Reaction on 25pbw Co-18pbw $\mathrm{Zr}-100 \mathrm{pbw} \mathrm{SiO}_{2}$}

A $25 \mathrm{pbw}$ Co-18pbw $\mathrm{Zr}-100 \mathrm{pbw} \mathrm{SiO}_{2}$ catalyst was synthesized by sequential incipient wetness impregnation of a high-purity, high-surface-area $\left(144-\mathrm{m}^{2} / \mathrm{g}\right)$ silica support (XS 16080, Norton) [18]. The support (crushed and sieved to a particle size of 100-150 $\mu \mathrm{m}$ ) was degassed in vacuum and heated to $80^{\circ} \mathrm{C}$. A zirconium tetrapropoxide $\left(\mathrm{Zr}\left(\mathrm{OCH}_{2} \mathrm{CH}_{2} \mathrm{CH}_{3}\right)_{4}\right)$ solution in 1propanol (Aldrich) was used for the incipient wetness impregnation, performed in two steps. After each impregnation step, the product was dried $\left(120^{\circ} \mathrm{C}, 2 \mathrm{~h}\right)$ and calcined in air $\left(500^{\circ} \mathrm{C}, 1\right.$ hour). The produced material had a nominal loading of $18 \mathrm{pbw} \mathrm{Zr} / \mathrm{silica}$.

Cobalt was impregnated on the zirconia/silica support using a cobalt nitrate hexahydrate precursor $\left(\mathrm{Co}\left(\mathrm{NO}_{3}\right)_{2} \cdot 6 \mathrm{H}_{2} \mathrm{O}\right.$, Aldrich). The hexahydrate was dissolved in water and the formed solution was added in a controlled manner to the zirconia/silica support, forming the catalyst with a nominal composition of $25 \mathrm{pbw} \mathrm{Co}-18 \mathrm{pbw} \mathrm{Zr}-100 \mathrm{pbw} \mathrm{SiO}_{2}$. Finally, the catalyst was calcined in air at $350^{\circ} \mathrm{C}$ for 1 hour.

The surface area of the $\mathrm{Co}-\mathrm{ZrO}_{2} / \mathrm{SiO}_{2}$ catalyst was measured (by BET method) to be $102 \pm 3$

$\mathrm{m}^{2} / \mathrm{g}$. Its pore volume was estimated at $0.40 \pm 0.01 \mathrm{cc} / \mathrm{g}$ (by mercury porosimetry). Its crystalline structure was examined by X-ray diffraction (XRD). The predominant phase was $\mathrm{Co}_{3} \mathrm{O}_{4}$, with no other $\mathrm{Co}-\mathrm{O}$ or $\mathrm{Zr}-\mathrm{O}$ crystalline phases or cobalt silicate present in the diffraction pattern.

A physical mixture of $2 \mathrm{cc}(1.55 \mathrm{~g})$ of the calcined $\mathrm{Co}-\mathrm{ZrO}_{2} / \mathrm{SiO}_{2}$ catalyst and $10 \mathrm{cc}(15.91 \mathrm{~g})$ of a low-surface-area $\left(0.2 \mathrm{~m}^{2} / \mathrm{g}\right) \alpha$-alumina (SA5397, Norton) was loaded into the reactor. The catalyst was reduced in-situ under $\mathrm{H}_{2}$ at $350^{\circ} \mathrm{C}$ for $14 \mathrm{~h}$, and was cooled and pressurized to ca. 300 psig $(19.4 \mathrm{~atm})$. The FT reaction was initiated by feeding a $10 \% \mathrm{Ar} / \mathrm{CO}$ gas mix, thus establishing the following base reaction conditions:

$$
\begin{aligned}
& \text { Syngas } \left.\left(\mathrm{H}_{2}+\mathrm{CO}\right)=50 \%, \mathrm{H}_{2}: \mathrm{CO}=2: 1 \text { (i.e., } 33.3 \% \mathrm{H}_{2} \text { and } 16.7 \% \mathrm{CO}\right) \\
& \text { Inerts }\left(\mathrm{N}_{2}+\mathrm{Ar}\right)=50 \%\left(1.7 \% \mathrm{Ar}, 48.3 \% \mathrm{~N}_{2}\right) \\
& \mathrm{P}=300 \mathrm{psig}, \mathrm{F}=200 \mathrm{scc} / \mathrm{min}, \mathrm{SV}=6000 \mathrm{~h}^{-1} .
\end{aligned}
$$

The reaction temperature was increased (by $0.5^{\circ} \mathrm{C} / \mathrm{h}$ or less) to $220^{\circ} \mathrm{C}$ and was stabilized at this value, thus allowing the reaction to reach a "pseudo-steady state". Pulse runs involved substituting the reactant feed flow $\left(\mathrm{H}_{2}+\mathrm{CO} / \mathrm{Ar}\right)$ with an equal molar flow of a pulse gas. The total molar flow and the reaction pressure were kept constant between base and pulse runs.

A "blank" pulse run (i.e., switching between two equal flows of $\mathrm{H}_{2} / \mathrm{CO} / \mathrm{Ar}$ reactant mix) was performed in order to identify the possible effect of the periodic pressure disturbance (directly related to the applied pulse) due to non-ideal switching of the actuated valves. This run produces no measurable variation on $\mathrm{CO}$ conversion, $\mathrm{H}_{2}: \mathrm{CO}$ ratio, or product distribution ( $\boldsymbol{\alpha}$-value, $\mathrm{C}_{10^{-}}$ $\mathrm{C}_{20}$ yield), as seen in Table 3.2.1. Therefore, pulse runs involving no variations in the feed composition have no effect on measurements of the progress of the FT reaction.

Table 3.2.1. Effect of "blank" pulse on the performance of $\mathrm{Co}-\mathrm{ZrO}_{2} / \mathrm{SiO}_{2} @ 220^{\circ} \mathrm{C}$.

\begin{tabular}{lccccccc}
\hline $\begin{array}{l}\text { Run } \\
\text { type }\end{array}$ & $\begin{array}{c}\text { Pulse } \\
\text { gas }\end{array}$ & $\begin{array}{c}\mathbf{T} \\
\left({ }^{\circ} \mathbf{C}\right)\end{array}$ & $\begin{array}{c}\mathbf{X}(\mathbf{C O}) \\
\mathbf{( \% )}\end{array}$ & $\begin{array}{c}\mathbf{S}\left(\mathbf{C H}_{\mathbf{4}}\right) \\
(\mathbf{m o l} \%)\end{array}$ & $\begin{array}{c}\text { Alpha } \\
(-)\end{array}$ & $\begin{array}{c}\mathbf{Y}(\mathbf{C H}) \\
(\mathbf{c c} / \mathbf{c c} / \mathbf{h})\end{array}$ & $\begin{array}{c}\mathbf{Y}\left(\mathbf{C}_{\mathbf{1 0}}-\mathbf{C}_{\mathbf{2 0}}\right) \\
(\mathbf{c c} / \mathbf{c c} / \mathbf{h})\end{array}$ \\
\hline Base run & - & 220 & 13.0 & 14.5 & 0.89 & 0.014 & 0.025 \\
\hdashline Blank pulse & $\mathrm{H}_{2}+\mathrm{CO} / \mathrm{Ar}$ & 220 & 13.0 & 15.0 & 0.89 & 0.014 & 0.021 \\
\hline
\end{tabular}


Table 3.2.2. Effect of inert (N2) pulse on the performance of $\mathrm{Co}-\mathrm{ZrO} 2 / \mathrm{SiO} 2 @ 224^{\circ} \mathrm{C}$.

\begin{tabular}{lccccccc}
\hline $\begin{array}{l}\text { Run } \\
\text { type }\end{array}$ & $\begin{array}{c}\text { Pulse } \\
\text { gas }\end{array}$ & $\begin{array}{c}\mathbf{T} \\
\left({ }^{\circ} \mathbf{C}\right)\end{array}$ & $\begin{array}{c}\mathbf{X}(\mathbf{C O}) \\
\mathbf{( \% )}\end{array}$ & $\begin{array}{c}\mathbf{S}\left(\mathbf{C H}_{\mathbf{4}}\right) \\
(\mathbf{m o l} \%)\end{array}$ & $\begin{array}{c}\text { Alpha } \\
(-)\end{array}$ & $\begin{array}{c}\mathbf{Y}\left(\mathbf{C H}_{\mathbf{4}}\right) \\
(\mathbf{c c} / \mathbf{c c} / \mathbf{h})\end{array}$ & $\begin{array}{c}\mathbf{Y}\left(\mathbf{C}_{\mathbf{1 0}}-\mathbf{C}_{\mathbf{2 0}}\right) \\
(\mathbf{c c} / \mathbf{c c} / \mathbf{h})\end{array}$ \\
\hline Base run & - & 224 & 15.0 & 14.5 & 0.89 & 0.016 & 0.027 \\
\hline Inert pulse & $\mathrm{N}_{2}$ & 224 & 15.0 & 14.5 & 0.89 & 0.018 & 0.022 \\
\hline Base run & - & 224 & 15.5 & 14.0 & 0.88 & 0.017 & 0.027 \\
\hline
\end{tabular}

A 1 -min $\mathrm{N}_{2}$ (inert) pulse per 1 hour (i.e., substituting the $\mathrm{H}_{2} / \mathrm{CO} / \mathrm{Ar}$ flow, which is $51.7 \%$ of the total, with an equal flow of $\mathrm{N}_{2}$ for 1 min every hour) was applied so as to examine the effect of inert pulsing on the reaction progress. The $\mathrm{N}_{2}$ pulse gives only minimal variations in activity ( $\mathrm{CO}$ conversion) or product selectivity ( $\boldsymbol{\alpha}$-value, $\mathrm{CH}_{4}$ yield, $\mathrm{C}_{10}-\mathrm{C}_{20}$ yield) as shown in Table 3.2.2, implying that short (1-min) disruptions in reactant flow do not substantially affect the FT reaction.

In contrast to the inert pulse, a 1-min $\mathrm{H}_{2}$ (reactant) pulse causes significant variations in $\mathrm{CO}$ conversion and $\mathrm{CH}_{4}$ selectivity. Effects of varying the $\mathrm{H}_{2}$ pulse frequency (1-min $\mathrm{H}_{2}$ per 1,2 , and 4 hours) on the $\mathrm{CO}$ conversion and the $\mathrm{C}_{1}\left(\mathrm{CH}_{4}\right.$ and $\left.\mathrm{CO}_{2}\right)$ selectivity are shown in the composite plots of Figures 3.2.1 and 3.2.2, respectively. These plots are composed of 10-hour segments of a series of sequential runs (typically lasting 48 hours, so as to collect sufficient amounts of oil + wax for the analysis), starting and ending with a base (no pulse) run. The data points correspond to measurements of the reactor effluent gas every 15 minutes.

A 1-min $\mathrm{H}_{2}$ pulse per 1-hour (10-20-hour segment in Figs. 3.2.1 and 3.2.2) causes a significant increase in $\mathrm{CO}$ conversion (from $16 \%$ to ca. $30 \%$ ). The measured temperature of the catalyst bed also increases to $226^{\circ} \mathrm{C}$, indicating a strong reaction exotherm. The conversion of $\mathrm{CO}$ decreases gradually until the next $\mathrm{H}_{2}$ pulse. A less-pronounced increase in $\mathrm{CO}$ conversion is also observed for the 1-min $\mathrm{H}_{2}$ pulse per 2-h and 4-h runs. The observed decrease in $\mathrm{CO}$ conversion after the pulse indicates that the activity tends to return to its steady state (comparing also the base runs before and after the 3 pulse runs). The measured changes in $\mathrm{CO}$ conversion cannot be attributed to variations in the inlet $\mathrm{CO}$ concentration since the conversion was based on comparing the inlet and outlet ratios of $\mathrm{CO}$ to the inert Ar (fed at a fixed ratio from a single gas cylinder).

The selectivity to $\mathrm{CH}_{4}$ is observed to increase instantaneously after each $\mathrm{H}_{2}$ pulse (from 13$14 \%$ to ca. $20 \%$ for all examined pulse runs). It is then quickly restored to its base value (Fig. 3.2.2). Thus, $\mathrm{H}_{2}$ pulsing increases catalytic activity while only briefly increasing the undesirable formation of $\mathrm{CH}_{4}$.

The effect of varying $\mathrm{H}_{2}$ pulse frequency on the desired $\mathrm{C}_{10}-\mathrm{C}_{20}$ yield vs. the undesired $\mathrm{CH}_{4}$ yield is shown in Figure 3.2.3. Pulse frequencies of $1,0.5$, and $0.25, \mathrm{~h}^{-1}$ correspond to a 1-min $\mathrm{H}_{2}$ pulse per 1, 2, and 4 hours, respectively. The zero pulse frequency corresponds to the average of the two no-pulse (base) runs before and after the 3 pulse runs.

Both $\mathrm{C}_{10}-\mathrm{C}_{20}$ and $\mathrm{CH}_{4}$ yields increase with $\mathrm{H}_{2}$-pulse frequency (and so does the yield of $\mathrm{C}_{21+}$ ), obviously due to the enhancement in catalytic activity caused by the pulsing (Fig. 3.2.1). As seen in Fig. 3.2.3, the effect of the 1-min $\mathrm{H}_{2}$ pulse per 1 hour compared to the (average) base run is to increase the $\mathrm{C}_{10}-\mathrm{C}_{20}$ yield by ca. $57 \%$, while the $\mathrm{CH}_{4}$ yield only increased by ca. $34 \%$. 


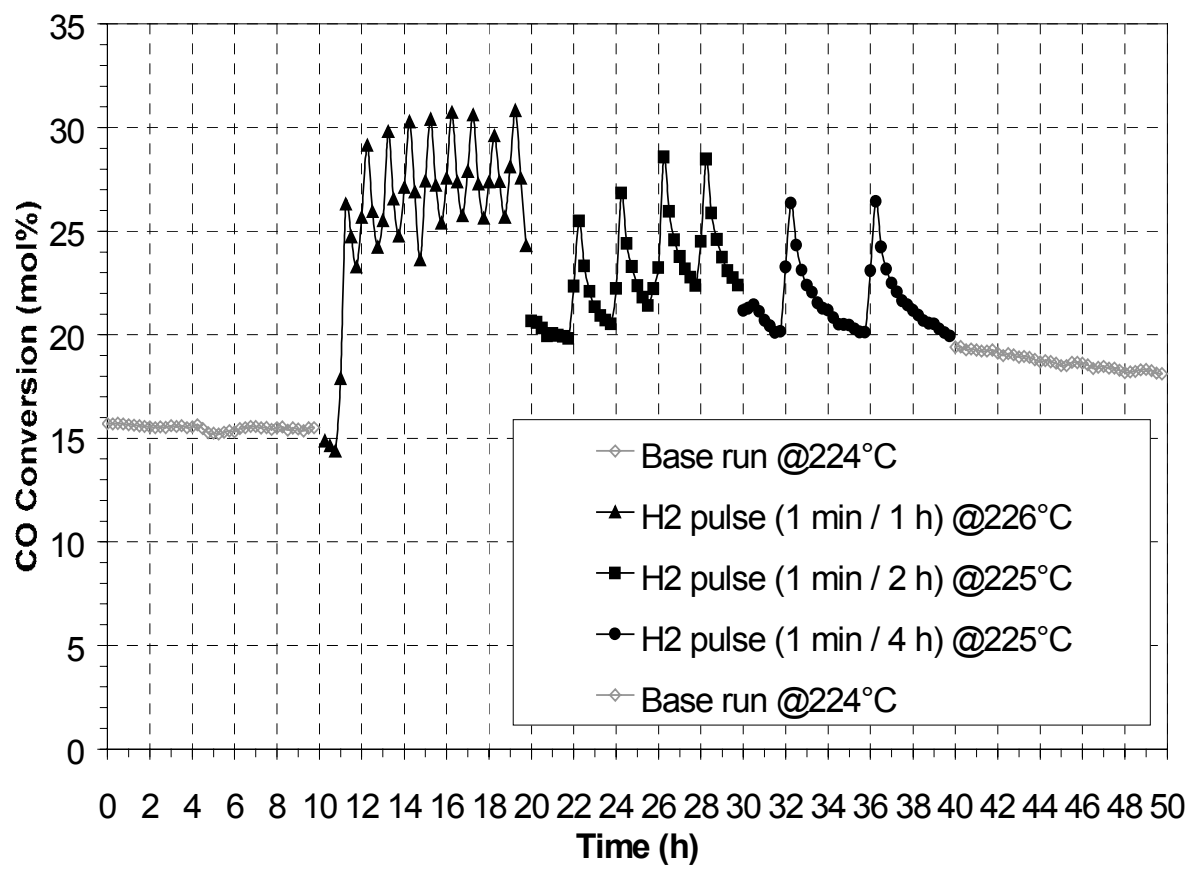

Figure 3.2.1. Effect of $\mathrm{H}_{2}$ pulse frequency on $\mathrm{CO}$ conversion of $\mathrm{Co}-\mathrm{ZrO}_{2} / \mathrm{SiO}_{2} @ 300$ psig and $6000 \mathrm{~h}^{-1}$.

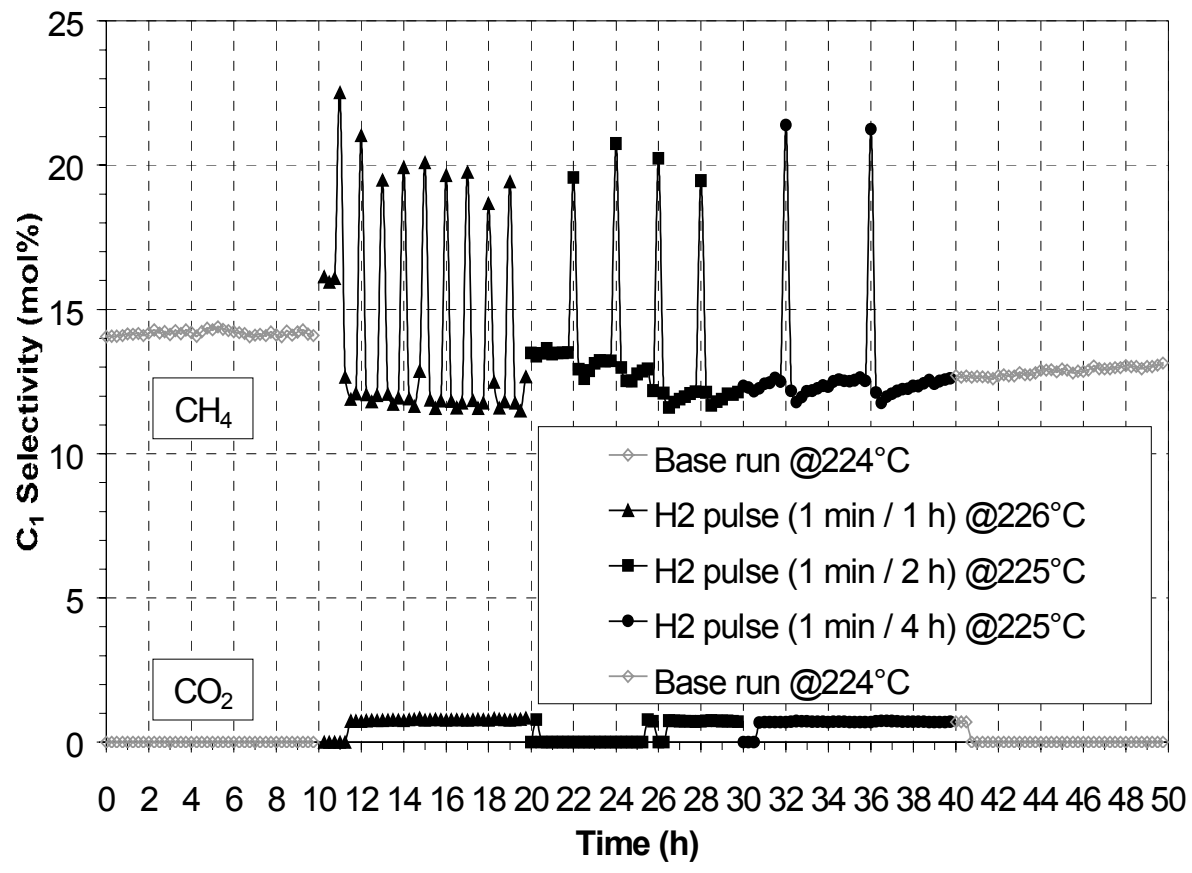

Figure 3.2.2. Effect of $\mathrm{H}_{2}$ pulse frequency on $\mathrm{C}_{1}$ selectivity of $\mathrm{Co}-\mathrm{ZrO}_{2} / \mathrm{SiO}_{2} @ 300$ psig and $6000 \mathrm{~h}^{-1}$. 


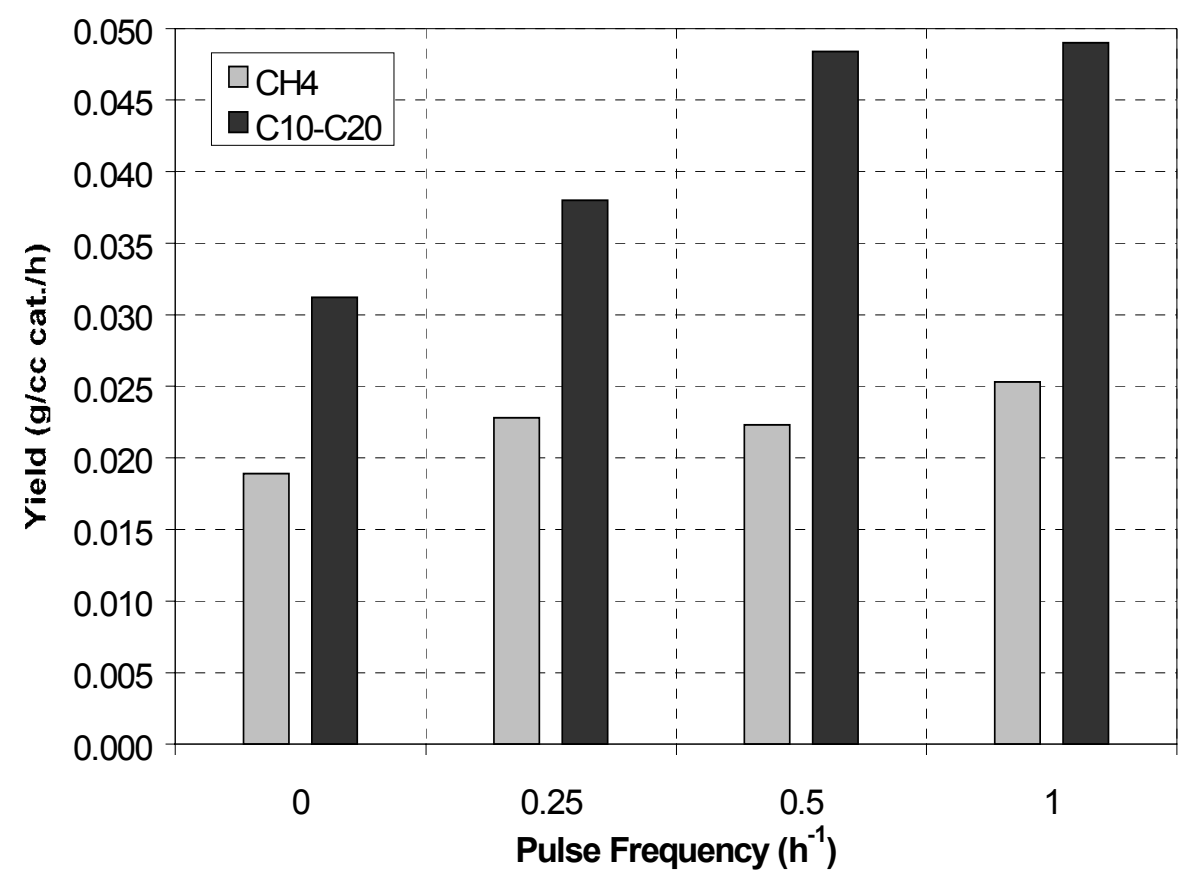

Figure 3.2.3. Effect of $\mathrm{H}_{2}$ pulse frequency on product yield of $\mathrm{Co}-\mathrm{ZrO}_{2} / \mathrm{SiO}_{2} @ 300$ psig and $6000 \mathrm{~h}^{-1}$.

Although this comparison entails a temperature change (from $224^{\circ} \mathrm{C}$ to $226^{\circ} \mathrm{C}$ ), the increase in the $\mathrm{C}_{10}-\mathrm{C}_{20}$ yield is more than what could be accounted for solely by a $2^{\circ} \mathrm{C}$ increase in reaction temperature.

The $\mathrm{CH}_{4}$ selectivity in the pulse runs (13-14\% on molar basis) is lower than that of the base runs (15.5\%), whereas the selectivity to $\mathrm{C}_{10}-\mathrm{C}_{20}$ and $\mathrm{C}_{21+}$ compounds is higher (28-32\% vs. $27 \%$, and $23-24 \%$ vs. $20 \%$, respectively). The $\boldsymbol{\alpha}$-values of the pulse runs (based on the molar fractions of $\mathrm{C}_{10}-\mathrm{C}_{65}$ products) are found to be essentially identical to that of the base runs $(0.890 \pm 0.005)$. Thus, the applied $\mathrm{H}_{2}$ pulsing apparently does not alter the SFA distribution.

Within the examined pulse frequency range, the greater difference between the yields of the desirable $\mathrm{C}_{10}-\mathrm{C}_{20}$ and the undesirable $\mathrm{CH}_{4}$ is obtained at the intermediate pulse frequency of 0.5 $\mathrm{h}^{-1}$ (1-min $\mathrm{H}_{2}$ per 2 hours). Also, upon extrapolating to higher $\mathrm{H}_{2}$-pulse frequencies, we could expect a stronger reaction exotherm and thus an increase in reaction temperature, which is known to cause a shift in FTS product distribution to lower molecular weight compounds and to enhance the methanation reaction [4]. Higher pulse frequencies would thus tend to increase the $\mathrm{CH}_{4}$ yield much more than the $\mathrm{C}_{10}-\mathrm{C}_{20}$ yield. An optimum $\mathrm{H}_{2}$-pulse frequency (depending on catalyst and reaction conditions) would therefore be required for maximizing the $\mathrm{C}_{10}-\mathrm{C}_{20}$ yield without substantially increasing the $\mathrm{CH}_{4}$ yield.

Another series of $\mathrm{H}_{2}$-pulse runs on the $\mathrm{Co}-\mathrm{ZrO}_{2} / \mathrm{SiO}_{2}$ catalyst examined the effect of $\mathrm{H}_{2}$ pulse duration on the outlet $\mathrm{H}_{2}$ : $\mathrm{CO}$ ratio, the activity, and product distribution, by varying the pulse duration $\left(1,2,4-\min\right.$ of $\left.\mathrm{H}_{2}\right)$ at a fixed pulse frequency $\left(0.5 \mathrm{~h}^{-1}\right)$. The results of this study are given in the plots of Figures 3.2.4, 3.2.5, and 3.2.6, respectively, composed of superimposed 10-hour segments of sequential runs (typically lasting 48 hours), starting and ending with a base (no pulse) run. 


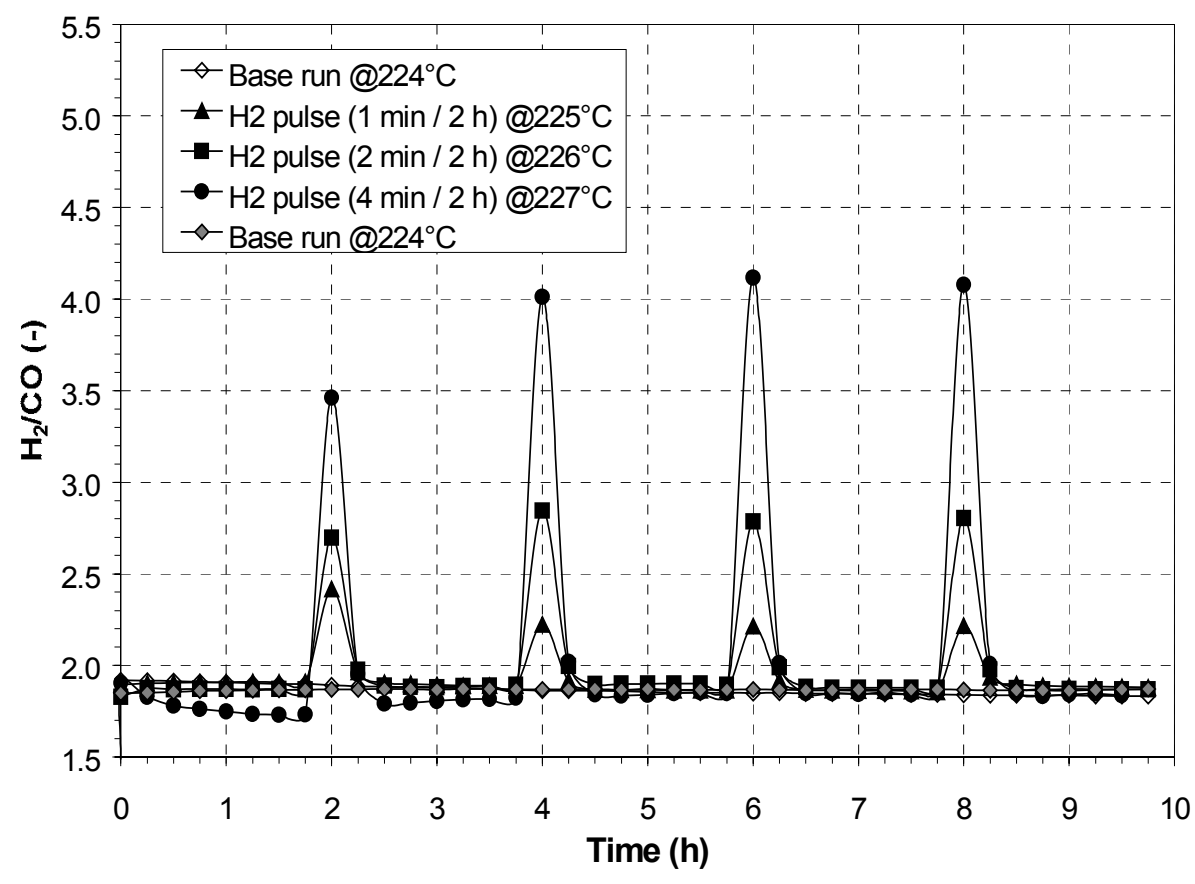

Figure 3.2.4. Effect of $\mathrm{H}_{2}$ pulse duration on outlet $\mathrm{H}_{2}$ : $\mathrm{CO}$ ratio of $\mathrm{Co}-\mathrm{ZrO}_{2} / \mathrm{SiO}_{2} @ 300$ psig and $6000 \mathrm{~h}^{-1}$.

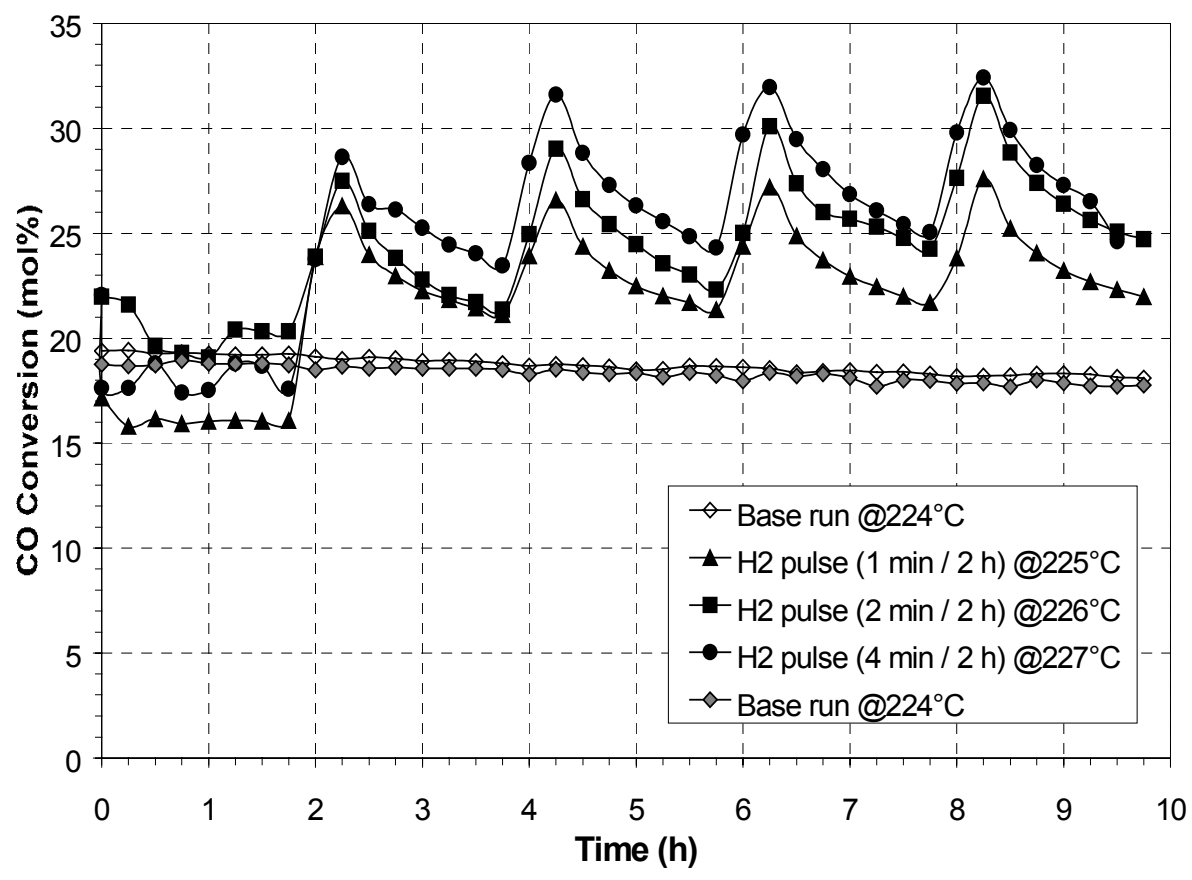

Figure 3.2.5. Effect of $\mathrm{H}_{2}$ pulse duration on $\mathrm{CO}$ conversion of $\mathrm{Co}-\mathrm{ZrO}_{2} / \mathrm{SiO}_{2} @ 300$ psig and $6000 \mathrm{~h}^{-1}$. 


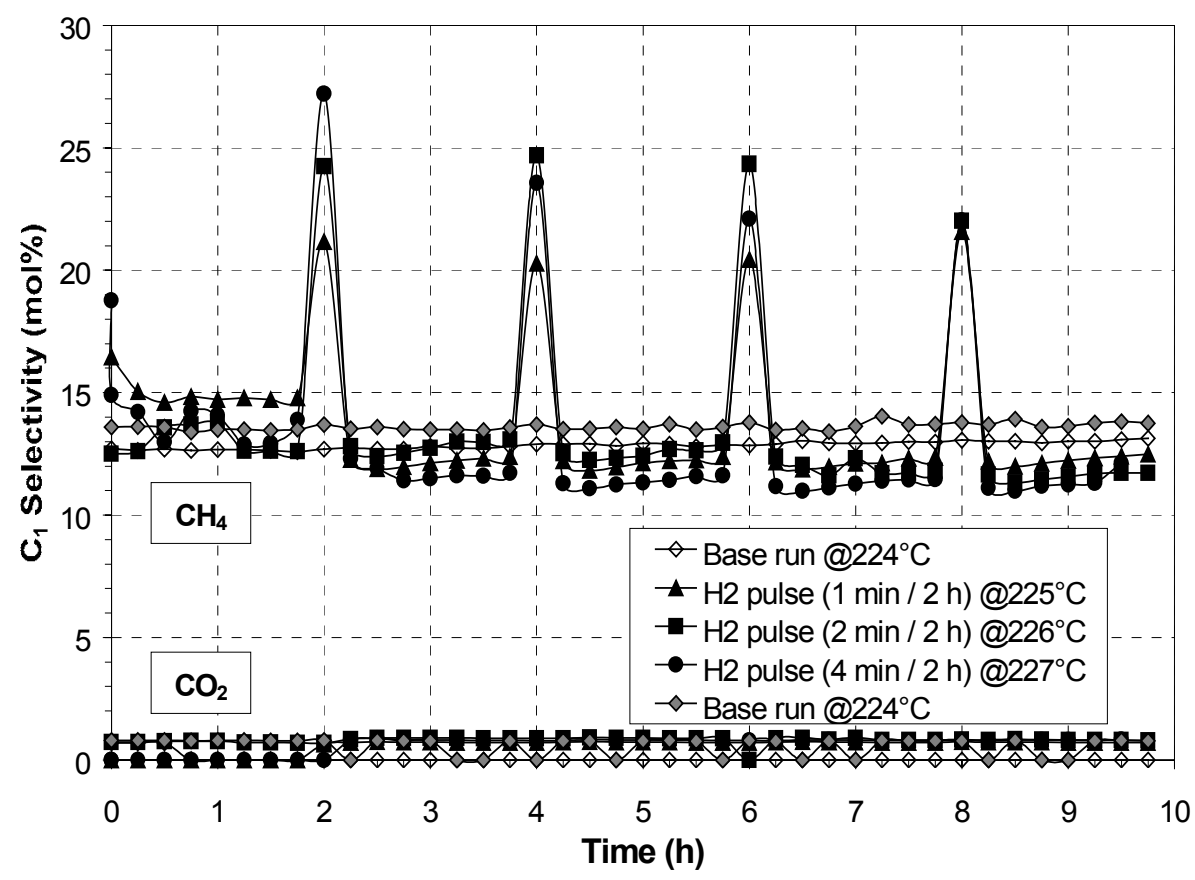

Figure 3.2.6. Effect of $\mathrm{H}_{2}$ pulse duration on $\mathrm{C}_{1}$ selectivity of $\mathrm{Co}-\mathrm{ZrO}_{2} / \mathrm{SiO}_{2} @ 300$ psig and $6000 \mathrm{~h}^{-1}$.

As seen in Fig. 3.2.4, an increase in the $\mathrm{H}_{2}$ pulse duration (1 min, $2 \mathrm{~min}, 4 \mathrm{~min}$ ) increases the outlet $\mathrm{H}_{2}$ : $\mathrm{CO}$ ratio (from a base value of 1.9 to $2.2,2.8$, and 4.1, respectively). However, this ratio is very quickly (within $20 \mathrm{~min}$, as indicated by the $2^{\text {nd }}$ data point after each pulse) restored to its base value of 1.9. Thus there appears to be no impact of the system "dead" volume (from the catalyst bed to the GC sample loop) on the measured parameters within the examined pulse duration (4 min or less).

As expected, application of a $\mathrm{H}_{2}$ pulse causes an increase in the measured $\mathrm{CO}$ conversion (Fig. 3.2.5). An increase in the $\mathrm{H}_{2}$ pulse duration ( $1 \mathrm{~min}, 2 \mathrm{~min}, 4 \mathrm{~min}$ ) increases the maximum obtained CO conversion (from a base value of $18.5 \%$ to $27 \%, 31 \%$, and $32 \%$, respectively). The measured temperature of the catalyst bed also increases (from $224^{\circ} \mathrm{C}$ to $227^{\circ} \mathrm{C}$ ) indicating a strong reaction exotherm. The conversion of $\mathrm{CO}$ decreased gradually until the next $\mathrm{H}_{2}$ pulse (in clear contrast to the observed rapid decrease in the outlet $\mathrm{H}_{2}: \mathrm{CO}$ ratio, Fig. 3.2.4). The observed decrease in $\mathrm{CO}$ conversion after the pulse indicates that the activity tends to return to its steady state (comparing also the base runs before and after the 3 pulse runs).

The selectivity to $\mathrm{CH}_{4}$ is observed to increase instantaneously after each $\mathrm{H}_{2}$ pulse and to eventually stabilize to a common maximum value (from $12-14 \%$ to ca. $22 \%$ for all 3 examined pulse runs). It is then quickly restored to its base value (Fig. 3.2.6). On the other hand, the $\mathrm{CO}_{2}$ formation remains very low (selectivity below 1\%) for both base and pulse runs. The similar time-dependence of the measured outlet $\mathrm{H}_{2}$ : $\mathrm{CO}$ ratio and selectivity to $\mathrm{CH}_{4}$ (Figs. 3.2 .4 and 3.2.6) imply a correlation between the increase in $\mathrm{H}_{2}$ concentration (caused by pulsing) and the extent of the methane formation reaction. The FT reaction, however, appears to have a different dependence on the inlet $\mathrm{H}_{2}$ concentration compared to the undesirable $\mathrm{CH}_{4}$ formation, since it progresses within a different time-frame (Fig. 3.2.5). 
The effect of the $\mathrm{H}_{2}$ pulse duration on the product distribution of the $\mathrm{Co}-\mathrm{ZrO}_{2} / \mathrm{SiO}_{2}$ catalyst is shown in the form of the logarithm of the molar fraction of the hydrocarbon products $\left(\mathrm{C}_{1}-\mathrm{C}_{65}\right)$ vs. the corresponding carbon number ( $\boldsymbol{\alpha}$-plot) in Figure 3.2.7. Only the $\boldsymbol{\alpha}$-plots produced by the initial base run and two $\mathrm{H}_{2}$ pulse runs are shown for purposes of clarity. A straight line with a slope that corresponds to $\alpha=0.9$ is also shown for comparison.

The produced curves of Fig. 3.2.7 appear to be almost overlapping, indicating only minor variations in the product distribution between base and pulse runs, as well as between two pulse runs of different $\mathrm{H}_{2}$ pulse duration ( $1 \mathrm{~min}$ vs. $2 \mathrm{~min}$ ). The slopes of these curves (based on the molar fractions of the $\mathrm{C}_{10}-\mathrm{C}_{65}$ range) are very similar to each other and to that of the $\boldsymbol{\alpha}=0.9$ curve. Indeed, the $\boldsymbol{\alpha}$ values of these runs (as well as those of the other base and pulse runs not included in the graph of Fig. 3.2.7) are equal to $0.890 \pm 0.005$. Therefore, the applied variableduration $\mathrm{H}_{2}$ pulsing apparently does not alter the SFA distribution, similar to the applied variable-frequency $\mathrm{H}_{2}$ pulsing.

The effect of varying $\mathrm{H}_{2}$ pulse duration on the desired $\mathrm{C}_{10}-\mathrm{C}_{20}$ yield vs. the undesired $\mathrm{CH}_{4}$ yield is shown in Figure 3.2.8. The zero pulse duration corresponds to the average of the two nopulse (base) runs before and after the 3 pulse runs. Both $\mathrm{C}_{10}-\mathrm{C}_{20}$ and $\mathrm{CH}_{4}$ yields increase with $\mathrm{H}_{2}$-pulse duration (and so does the yield of $\mathrm{C}_{21+}$ ), obviously due to the enhancement in catalytic activity caused by the pulsing (Fig. 3.2.5). As seen in Fig. 3.2.8, the effect of the 4-min $\mathrm{H}_{2}$ pulse per 2 hours compared to the (average) base run is to increase the $\mathrm{C}_{10}-\mathrm{C}_{20}$ yield by ca. $45 \%$, while the $\mathrm{CH}_{4}$ yield only increased by ca. $28 \%$. This comparison entails a temperature change (from $224^{\circ} \mathrm{C}$ to $227^{\circ} \mathrm{C}$ ); however, the increase in the $\mathrm{C}_{10}-\mathrm{C}_{20}$ yield is more than what could be accounted for solely by a $3^{\circ} \mathrm{C}$ increase in reaction temperature.

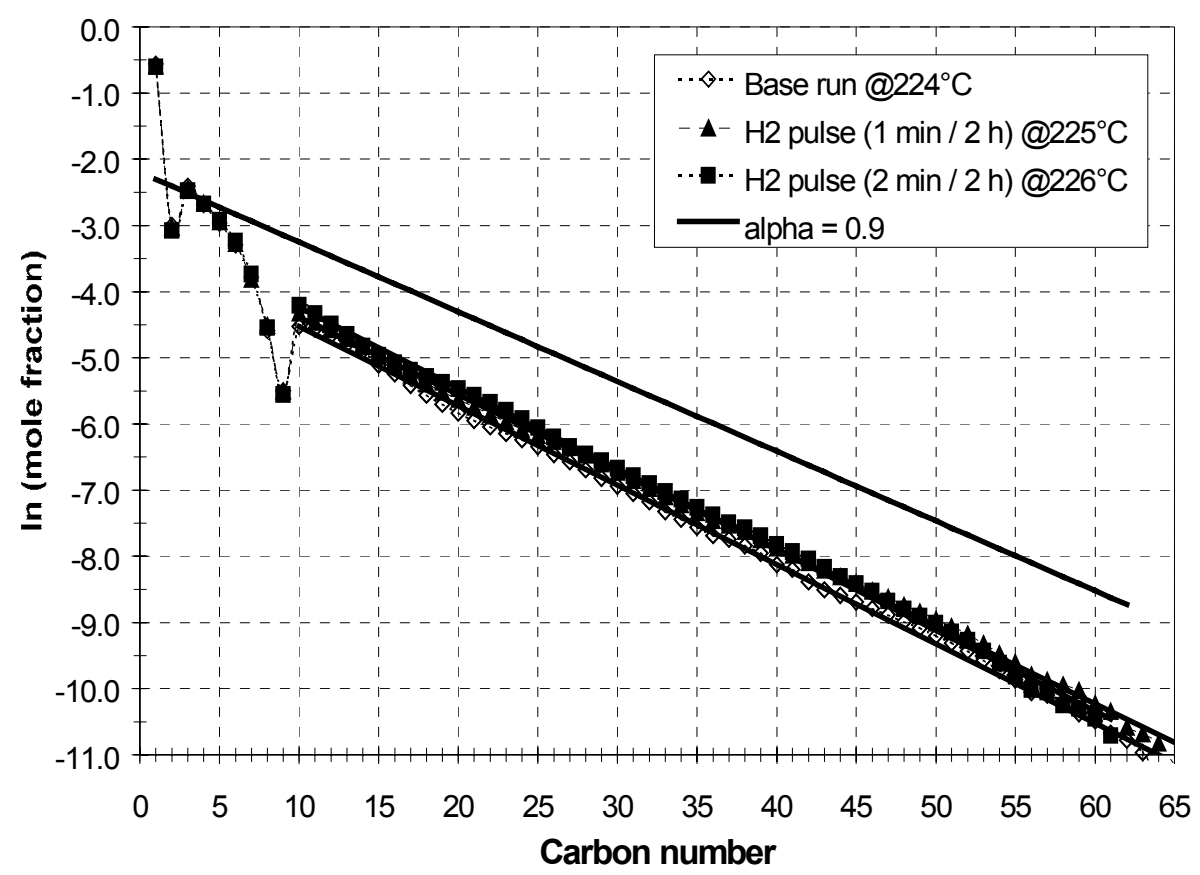

Figure 3.2.7. Effect of $\mathrm{H}_{2}$ pulse duration on product distribution $\left(\alpha\right.$-plot) of $\mathrm{Co}-\mathrm{ZrO}_{2} / \mathrm{SiO}_{2} @ 300$ psig and $6000 \mathrm{~h}^{-1}$. 


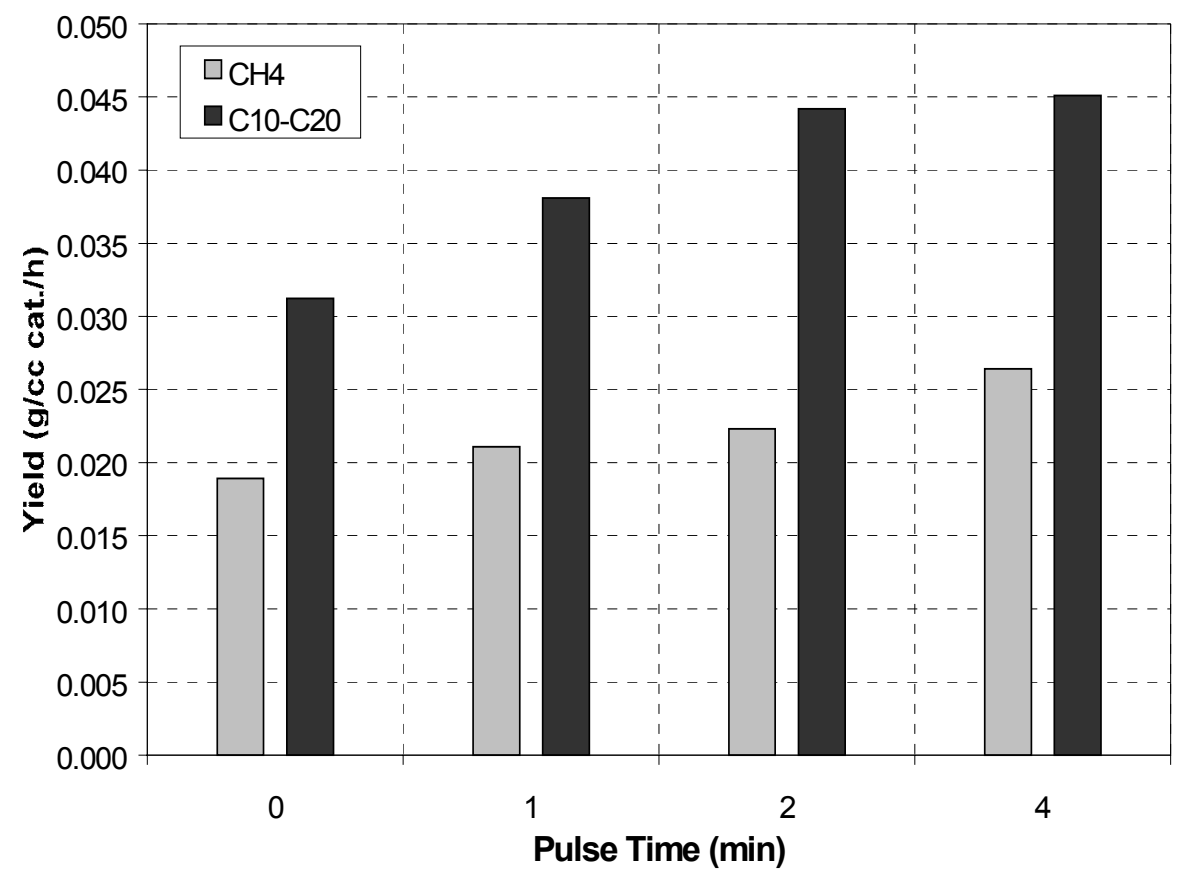

Figure 3.2.3. Effect of $\mathrm{H}_{2}$ pulse duration on product yield of $\mathrm{Co}-\mathrm{ZrO}_{2} / \mathrm{SiO}_{2} @ 300$ psig and $6000 \mathrm{~h}^{-1}$.

Within the examined pulse duration range, the greater difference between the yields of the desirable $\mathrm{C}_{10}-\mathrm{C}_{20}$ and the undesirable $\mathrm{CH}_{4}$ is obtained at the intermediate pulse duration of 2-min $\mathrm{H}_{2}$ per 2 hours. In addition, upon extrapolating to higher $\mathrm{H}_{2}$-pulse duration, we could expect a stronger reaction exotherm and thus an increase in reaction temperature, which is known to cause a shift in FTS product distribution to lower molecular weight compounds and to enhance the methanation reaction [4]. Higher pulse duration would thus tend to increase the $\mathrm{CH}_{4}$ yield much more than the $\mathrm{C}_{10}-\mathrm{C}_{20}$ yield, in a similar manner to the effect of increasing pulse frequency. Therefore, an optimum set of both $\mathrm{H}_{2}$-pulse parameters (pulse frequency and pulse duration) would be required for maximizing the formation of diesel-range FT products.

Additional experiments included studying the effect of pulsing (at 1 min per 1 hour) with a pulse gas other than $\mathrm{H}_{2}$ (namely, $50 \% \mathrm{H}_{2} / \mathrm{N}_{2}$ and $24 \% \mathrm{CO}_{2} / \mathrm{N}_{2}$ ). The dilute $-\mathrm{H}_{2}$ pulse had minimal impact on $\mathrm{CO}$ conversion and $\mathrm{C}_{10}-\mathrm{C}_{20}$ yield compared to the full $\mathrm{H}_{2}$ pulse. The $\mathrm{CO}_{2}$ pulse had a minimal effect on $\mathrm{CO}$ conversion and a positive effect on the selectivity to $\mathrm{CH}_{4}$ (from $18 \%$ to $24 \%$ ), resulting in low $\mathrm{C}_{10}-\mathrm{C}_{20}$ yield. Despite some increased uncertainty on the obtained data, the effect of $\mathrm{CO}_{2}$ pulsing appears to be not promising (or minimal at best).

A final set of experiments involved changing reaction conditions by lowering the $\mathrm{H}_{2}+\mathrm{CO}$ molar flow (or partial pressure) to $16.7 \%$ instead of the standard $50 \%$, and adding $10 \%$ steam. A 1 -min $\mathrm{H}_{2}$ pulse per 1 hour run was performed under these new reaction conditions. The addition of steam caused a decrease in both $\mathrm{CO}$ conversion (from 32.55 to $23.5 \%$ ) and selectivity to $\mathrm{CH}_{4}$ (from $14 \%$ to $9 \%$ ). The applied $\mathrm{H}_{2}$ pulse restored partially both $\mathrm{CO}$ conversion $(29 \%)$ and $\mathrm{CH}_{4}$ selectivity (13\%). Due to increased difficulty in collecting and analyzing the wax product, these experiments (i.e., pulsing in the presence of steam) should be repeated. 


\subsection{FT Reaction on $\mathrm{Fe} / \mathrm{K} / \mathrm{Cu} / \mathrm{SiO}_{2}$ catalyst (HPR-43)}

The effect of pulsing on the FT synthesis activity and product distribution of a very-high-a $(\sim 0.95) \mathrm{Fe} / \mathrm{K} / \mathrm{Cu} / \mathrm{SiO}_{2}$ catalyst, synthesized by the Hampton University, RTI, University of Pittsburgh team under another DOE contract (DE-FG22-96PC96217), was examined. A series of runs were performed after establishing a "pseudo-steady state" at appropriate reaction conditions, including $\mathrm{H}_{2}, 24 \% \mathrm{CO}_{2} / \mathrm{N}_{2}$, and $\mathrm{CO}$ pulses. The objective of this series of runs was to examine the effect of various pulsing types on the FT reaction activity and the $\mathrm{C}_{10}-\mathrm{C}_{20}$ yield of the $\mathrm{Fe} / \mathrm{K} / \mathrm{Cu} / \mathrm{SiO}_{2}$ catalyst (denoted as HPR-43).

A physical mixture of $3 \mathrm{cc}(3.04 \mathrm{~g})$ of catalyst HPR-43 and $9 \mathrm{cc}(14.41 \mathrm{~g})$ of a low-surfacearea $\left(0.2 \mathrm{~m}^{2} / \mathrm{g}\right) \alpha$-alumina (SA5397, Norton) was loaded into the $3 / 8$ in o.d. stainless steel reactor, between two beds of the $\alpha$-alumina.

The catalyst was reduced in-situ under a reactant $\left(\mathrm{H}_{2}+\mathrm{CO} / \mathrm{Ar}\right)$ gas mixture $\left(\mathrm{H}_{2}: \mathrm{CO}=0.67\right.$, $\mathrm{CO}: \mathrm{Ar}=9$ ) at $280^{\circ} \mathrm{C}$ for 8 hours, it was cooled to $112^{\circ} \mathrm{C}$ and was then gradually pressurized to ca. $300 \mathrm{psig}$ (19.4 atm), establishing the following base reaction conditions:

$$
\begin{aligned}
& \text { Reactants: } \mathrm{CO}=24.75 \%, \mathrm{H}_{2}=16.5 \%\left(\mathrm{H}_{2}: \mathrm{CO}=0.67, \mathrm{H}_{2}+\mathrm{CO}=41.25 \%\right) \\
& \text { Inerts: } \mathrm{Ar}=2.75 \%(\mathrm{CO}: \mathrm{Ar}=9), \mathrm{N}_{2}=56 \% \\
& \mathrm{P}=300 \text { psig, } \mathrm{F}=300 \mathrm{scc} / \mathrm{min}, \mathrm{SV}=6000 \mathrm{~h}^{-1} .
\end{aligned}
$$

The reaction temperature was increased so as to start the FT reaction, and was stabilized at $231{ }^{\circ} \mathrm{C}$, allowing the reaction to reach a "pseudo-steady state". Pulse runs involved substituting the reactant $\left(\mathrm{H}_{2}+\mathrm{CO} / \mathrm{Ar}\right)$ feed flow (44\% of total molar flow) with an equal molar flow of a pulse gas, namely $\mathrm{H}_{2}, 24 \% \mathrm{CO}_{2} / \mathrm{N}_{2}$, or $\mathrm{CO}$. The total molar flow and reaction pressure was maintained constant between base and pulse runs. A single pulse sequence of 1 min per 1 hour was applied in all cases.

\section{Effect of $\mathrm{H}_{2}$ pulse at $231^{\circ} \mathrm{C}$}

After establishing a "pseudo-steady state" at $231^{\circ} \mathrm{C}$ and $298 \pm 2$ psig, a 1-min $\mathrm{H}_{2}$ pulse per 1 hour was applied. One 8-hour run was performed under these conditions. The reactant feed was then returned to its standard composition (base run) and the catalyst attained a new "pseudosteady state" at $230^{\circ} \mathrm{C}$.

The effect of the $\mathrm{H}_{2}$ pulse on the outlet $\mathrm{H}_{2}$ : $\mathrm{CO}$ ratio, $\mathrm{CO}$ conversion, and $\mathrm{C}_{1}\left(\mathrm{CH}_{4} / \mathrm{CO}_{2}\right)$ selectivity vs. time-on-stream is shown in Figures 3.3.1, 3.3.2, and 3.3.3, respectively. The last 8 hours of the initial base run are shown as the first 8 hours $(0-8 \mathrm{~h})$ in these figures. The 8 -hour $\mathrm{H}_{2}$-pulse run is shown next (8-16 h), followed by the first 8 hours of the new base run (16-24 h). The data points correspond to measurements of the reactor effluent gas every 15 minutes.

Due to the 15-min analysis time of the permanent gases $\left(\mathrm{H}_{2}, \mathrm{CO}_{2}, \mathrm{Ar}, \mathrm{N}_{2}, \mathrm{CH}_{4}, \mathrm{CO}\right)$, only 4 data points can be obtained for every 1-hour pulse cycle. In order to better observe the effect of a given pulse, a "delay time" is defined as the time difference between the end of a pulse and the following GC data point. The need for applying a delay time arises from the fact that a step change in reactant feed cannot be instantaneously detected due to the dead volume of the reaction/analysis system. A delay time of 5 min was used, i.e., the first 1-min $\mathrm{H}_{2}$ pulse was applied at 8 hours and $55 \mathrm{~min}$ ( $55 \mathrm{~min}$ after starting the pulse run), and the next data point was obtained at 9 hours on stream (Figs 3.3.1, 3.3.2, and 3.3.3). 


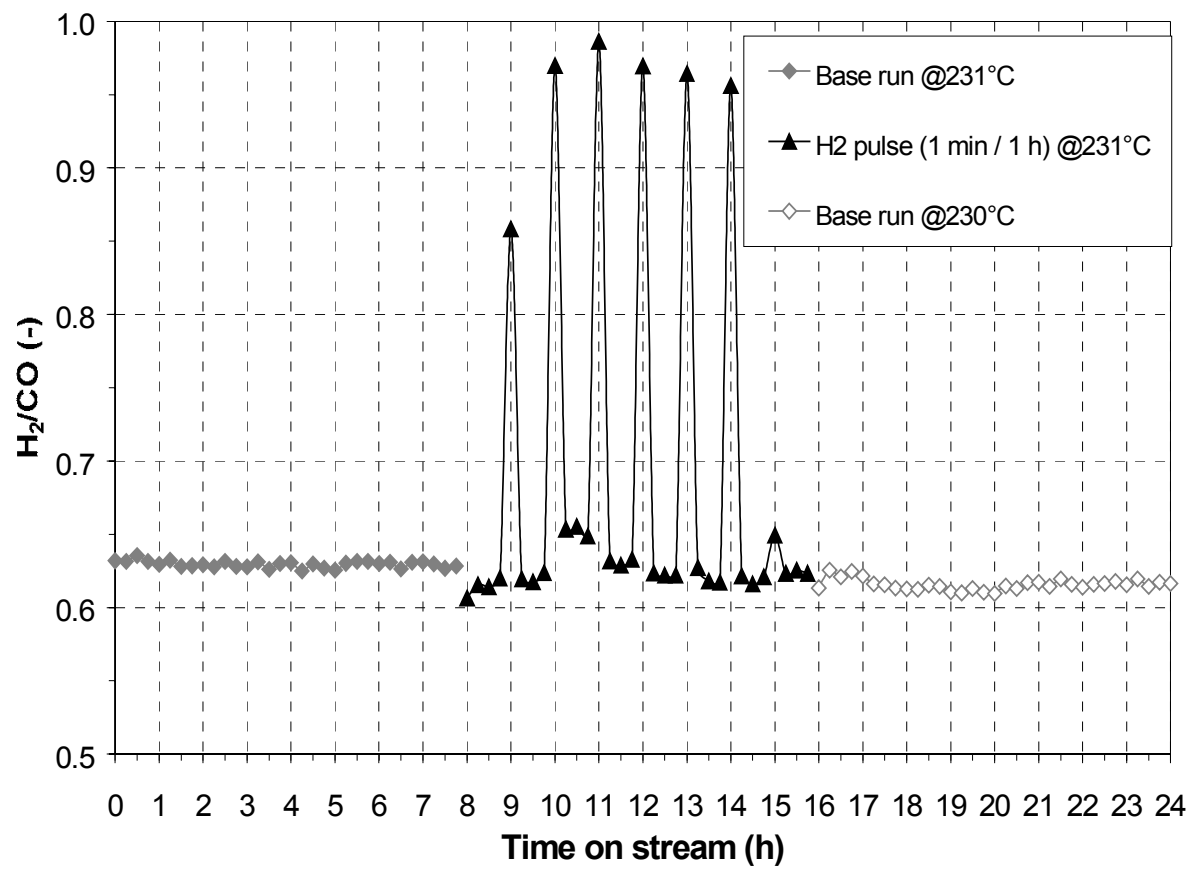

Figure 3.3.1. Effect of $\mathrm{H}_{2}$ pulse on outlet $\mathrm{H}_{2}$ :CO ratio of HPR-43@300 psig and $6000 \mathrm{~h}^{-1}$.

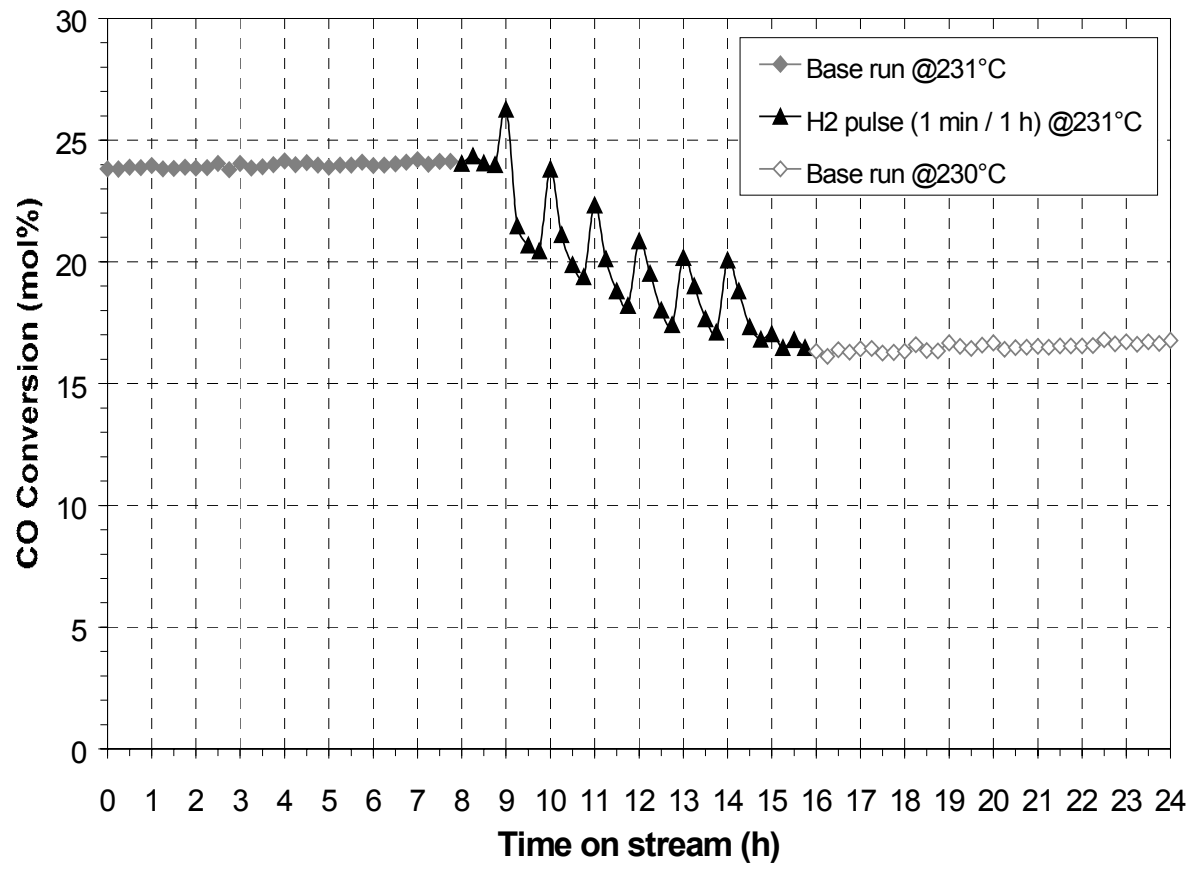

Figure 3.3.2. Effect of $\mathrm{H}_{2}$ pulse on $\mathrm{CO}$ conversion of HPR-43@300 psig and $6000 \mathrm{~h}^{-1}$. 


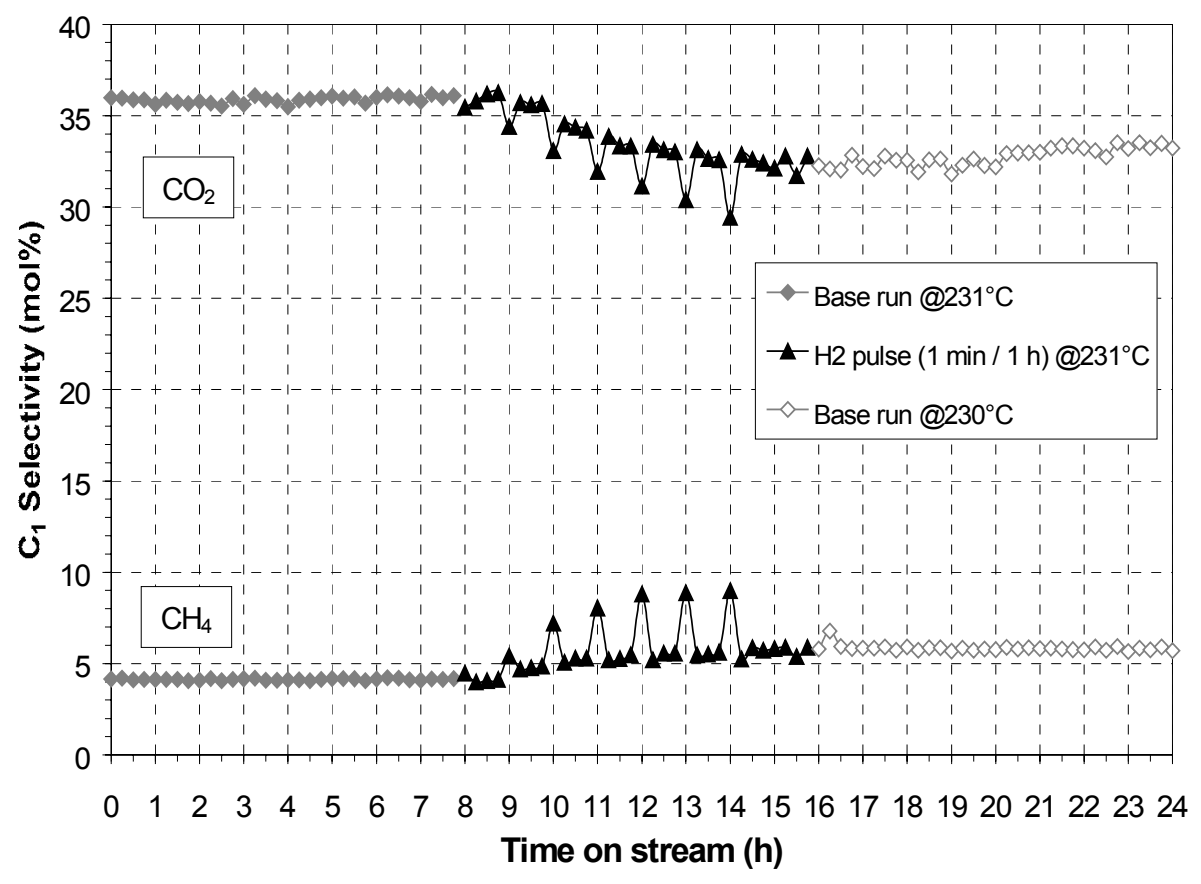

Figure 3.3.3. Effect of $\mathrm{H}_{2}$ pulse on $\mathrm{C}_{1}$ selectivity of HPR-43@300 psig and $6000 \mathrm{~h}^{-1}$.

The 1-min $\mathrm{H}_{2}$ pulse per 1 hour increases the outlet $\mathrm{H}_{2}: \mathrm{CO}$ ratio from 0.63 (base run) to ca. $0.95 \pm 0.05$ (at $5 \mathrm{~min}$ after the pulse), but this ratio is quickly restored (after $20 \mathrm{~min}$ ) to its original value (Fig. 3.3.1). As seen in Fig. 3.3.2, the $\mathrm{H}_{2}$ pulse causes a significant decrease in $\mathrm{CO}$ conversion, from ca. $24 \%$ (initial base run) to ca. $17 \%$ (final base run). The corresponding decrease in $\mathrm{CO}$ productivity is from ca. $350 \mathrm{cc} / \mathrm{cc}$ cat./h to ca. $250 \mathrm{cc} / \mathrm{cc}$ cat./h. The $\mathrm{H}_{2}$ pulse also decreases the selectivity towards $\mathrm{CO}_{2}$ (from ca. 36\% down to ca. 33\%) and increases the selectivity towards $\mathrm{CH}_{4}$ (from ca. $4 \%$ to ca. $6 \%$ ) (Fig. 3.3.3).

The effect of $\mathrm{H}_{2}$ pulse on the product distribution of HPR- 43 at $231{ }^{\circ} \mathrm{C}$ is presented in the form of the logarithm of the molar fraction of the products vs. the corresponding carbon number ( $\boldsymbol{\alpha}$-plot) in Figure 3.3.4. The product distribution curves for the base run before and after the $\mathrm{H}_{2}$ pulse run are also shown for comparison. The $\mathrm{H}_{2}$ pulse is found to slightly decrease the $\boldsymbol{\alpha}$-value (from 0.95 to 0.94 ) while increasing the $\mathrm{C}_{10}-\mathrm{C}_{20}$ weight fraction (from 13.6/15.2\% up to $19.8 \%$ ) and the corresponding yield of this product fraction (from $0.016 \mathrm{~g} / \mathrm{cc}$ cat./h up to $0.022 \mathrm{~g} / \mathrm{cc}$ cat./h). Therefore, the $\mathrm{H}_{2}$ pulse has a positive effect on the $\mathrm{C}_{10}-\mathrm{C}_{20}$ yield but also causes a decrease in catalyst activity and an undesirable increase in the selectivity towards $\mathrm{CH}_{4}$.

Effect of $24 \% \mathrm{CO}_{2} / \mathrm{N}_{2}$ pulse at $230^{\circ} \mathrm{C}$

After the base run at $230^{\circ} \mathrm{C}$ (the results of which are shown in Figs. 3.3.1 to 3.3.4) a 1-min $24 \% \mathrm{CO}_{2} / \mathrm{N}_{2}$ pulse was applied. With respect to the base runs before and after this pulse, there was essentially no effect on $\mathrm{CO}$ conversion (18\%) and selectivity to $\mathrm{CH}_{4}(5 \%)$ or $\mathrm{CO}_{2}(35 \%)$. The effect of the $\mathrm{CO}_{2}$ pulse on product distribution (compared to that of the base runs before and after the pulse) is shown in Figure 3.3.5. There is no measurable effect of the $\mathrm{CO}_{2}$ pulse on the product distribution as well $(\boldsymbol{\alpha}=0.94)$ or the $\mathrm{C}_{10}-\mathrm{C}_{20}$ yield. 


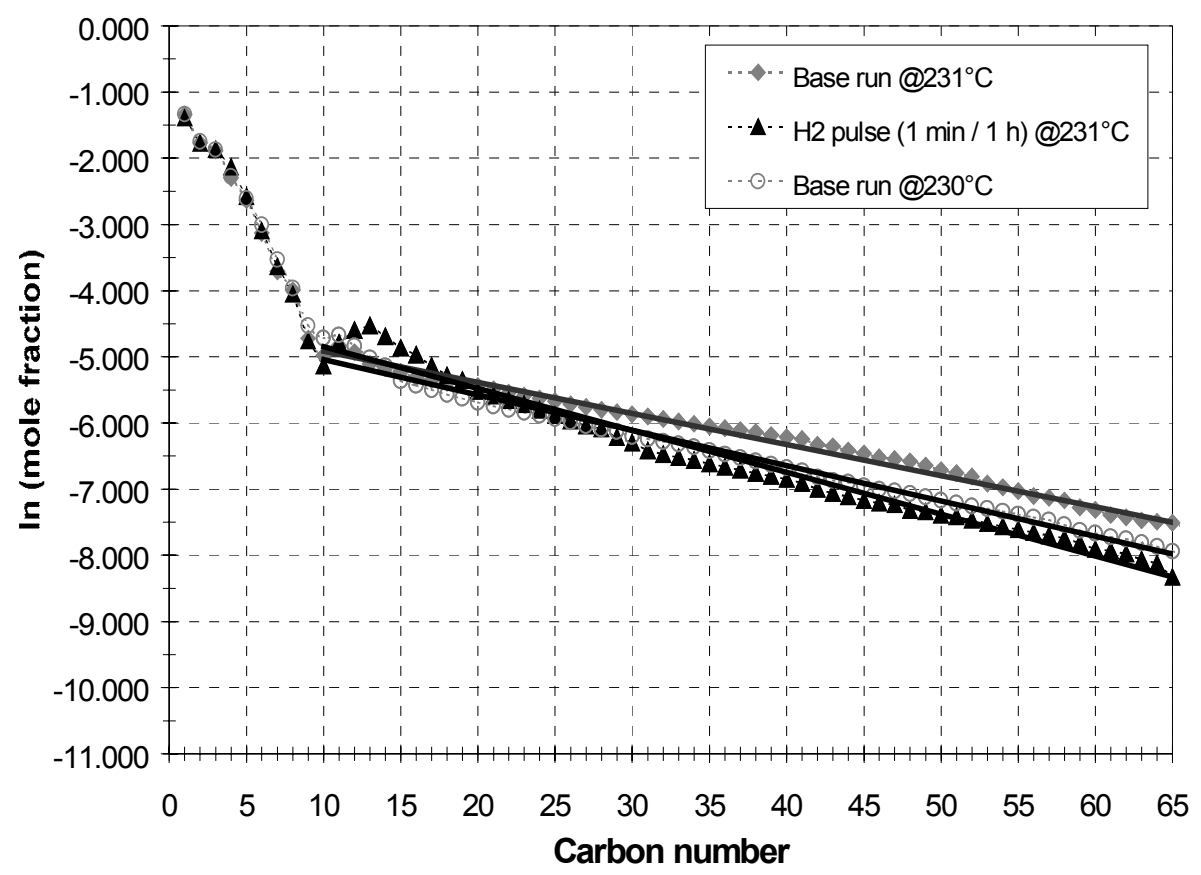

Figure 3.3.4. Effect of $\mathrm{H}_{2}$ pulse on product distribution of HPR-43@300 psig and $6000 \mathrm{~h}^{-1}$.

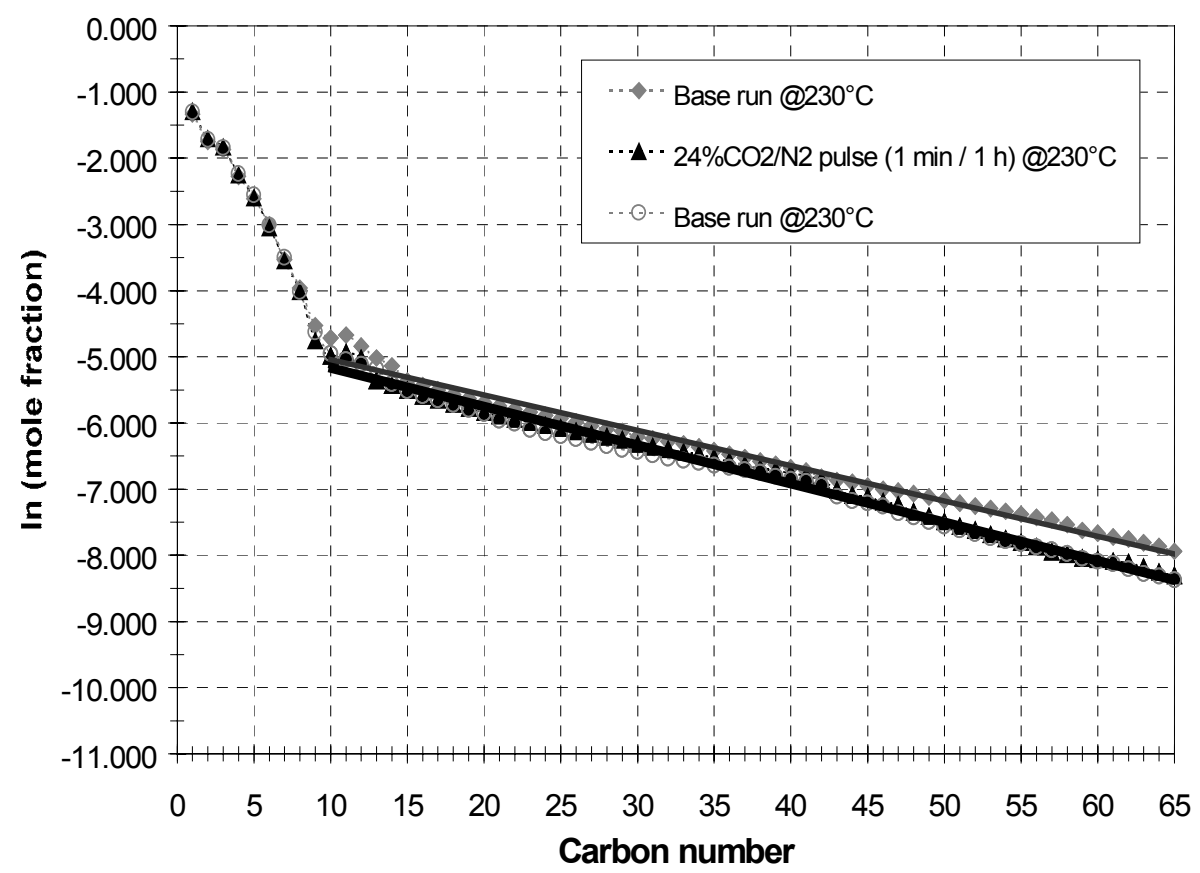

Figure 3.3.5. Effect of $24 \% \mathrm{CO}_{2} / \mathrm{N}_{2}$ pulse on product distribution of HPR-43@300 psig and $6000 \mathrm{~h}^{-1}$. 
Effect of CO pulse at $246 / 253^{\circ} \mathrm{C}$

At the reaction temperature of $230^{\circ} \mathrm{C}$ the temperature distribution within the catalyst bed appears to be essentially uniform (difference of ca. $1^{\circ} \mathrm{C}$ or less between the top and bottom of catalyst bed). However, upon heating up the bed to higher temperatures, an increase in this deviation between top and bottom bed $\mathrm{T}$ was observed. After a slow heating process, a new "pseudo-steady state" was established at $246^{\circ} \mathrm{C}$ (bottom bed T) $/ 253^{\circ} \mathrm{C}$ (top bed T).

At these reaction conditions, the effect of a 1-min CO pulse per 1 hour on the outlet $\mathrm{H}_{2}$ : $\mathrm{CO}$ ratio, the $\mathrm{CO}$ conversion, and the $\mathrm{CH}_{4} / \mathrm{CO}_{2}$ selectivity vs. time-on-stream is shown in Figures 3.3.6, 3.3.7, and 3.3.8, respectively. The last 12 hours of the base run before the CO pulse are shown as the first 12 hours $(0-12 \mathrm{~h})$ in these figures. The 24-hour CO-pulse run is shown next (12-36 h), followed by the first 12 hours of the new base run (36-44 h).

The outlet $\mathrm{H}_{2}$ : $\mathrm{CO}$ ratio decreases from ca. 0.7 to ca. 0.5 as a result of the $\mathrm{CO}$ pulse (Fig. 3.3.6). As seen in Fig. 3.3.7, the applied CO pulse causes a decrease in $\mathrm{CO}$ conversion (from ca. $45 \%$ prior to the pulse run down to ca. $41 \%$ after the pulse run) as well as in CO productivity (from ca. $670 \mathrm{scc} / \mathrm{cc}$ cat./h to ca. $610 \mathrm{scc} / \mathrm{cc}$ cat./h). On the other hand, no measurable effect of the $\mathrm{CO}$ pulse run on $\mathrm{CH}_{4}$ and $\mathrm{CO}_{2}$ selectivity prior to and after the pulse run was observed (Fig. 3.3.8).

The effect of CO pulse on the product distribution of HPR- 43 at $246 / 253^{\circ} \mathrm{C}$ is shown in the $\boldsymbol{\alpha}$-plot of Figure 3.3.9. The CO pulse has only minimal effect on the measured $\boldsymbol{\alpha}$-value (from 0.94 to 0.93 ), while increasing the $\mathrm{C}_{10}-\mathrm{C}_{20}$ weight fraction (from $17.1 / 16.7 \%$ up to $21.7 \%$ ) and the corresponding yield of this fraction (from $0.045 / 0.041 \mathrm{~g} / \mathrm{cc}$ cat./h up to $0.053 \mathrm{~g} / \mathrm{cc}$ cat./h). Therefore, the $\mathrm{CO}$ pulse benefits the $\mathrm{C}_{10}-\mathrm{C}_{20}$ yield without increasing the $\mathrm{CH}_{4}$ or $\mathrm{CO}_{2}$ selectivity.

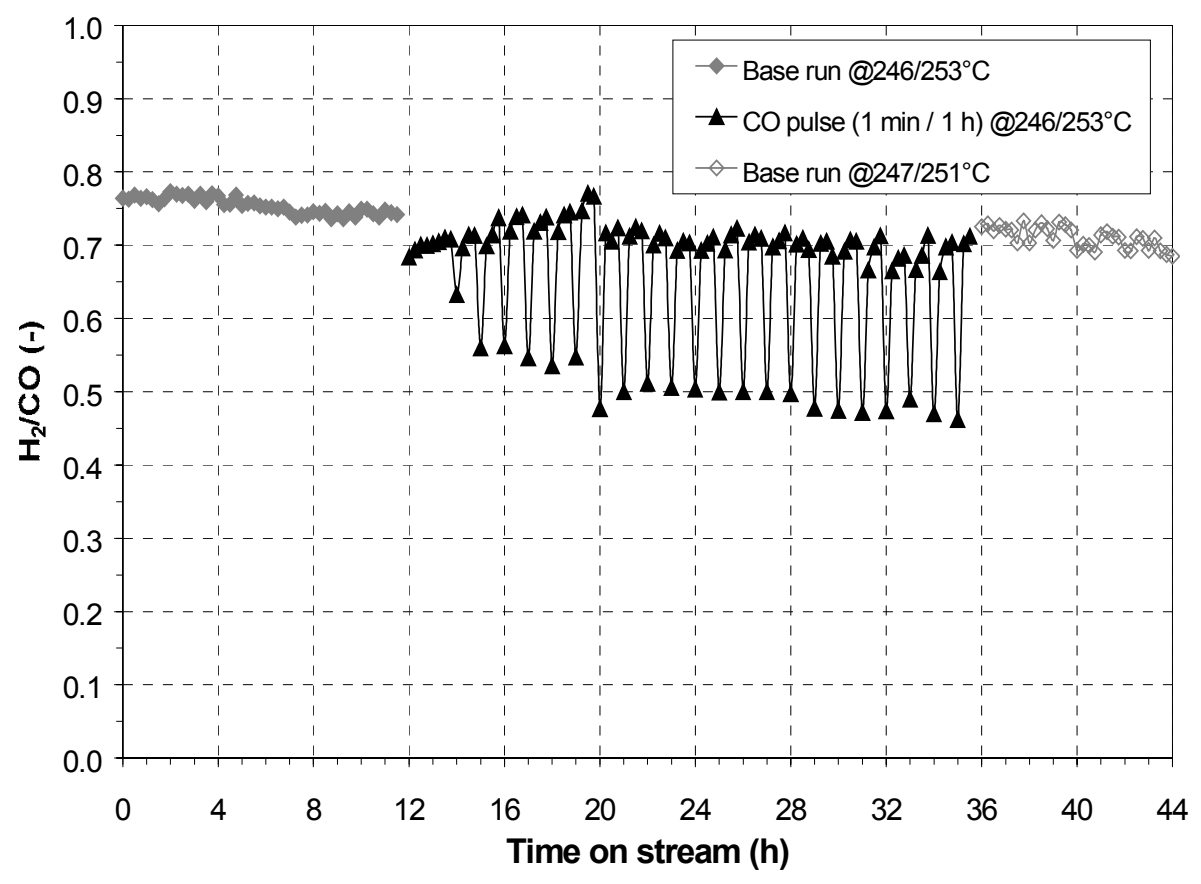

Figure 3.3.6. Effect of $\mathrm{CO}$ pulse on outlet $\mathrm{H}_{2}$ : $\mathrm{CO}$ ratio of HPR-43@300 psig and $6000 \mathrm{~h}^{-1}$. 


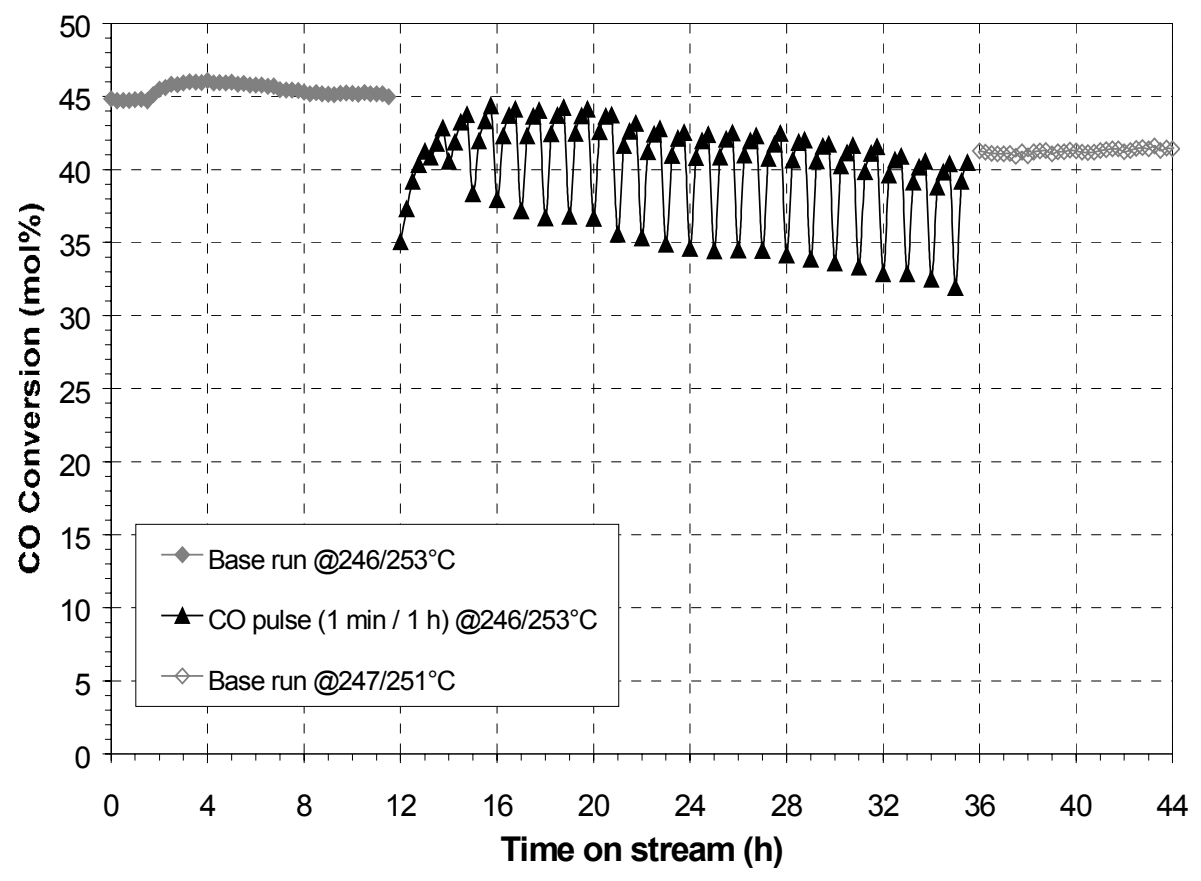

Figure 3.3.7. Effect of $\mathrm{CO}$ pulse on $\mathrm{CO}$ conversion of HPR-43@300 psig and $6000 \mathrm{~h}^{-1}$.

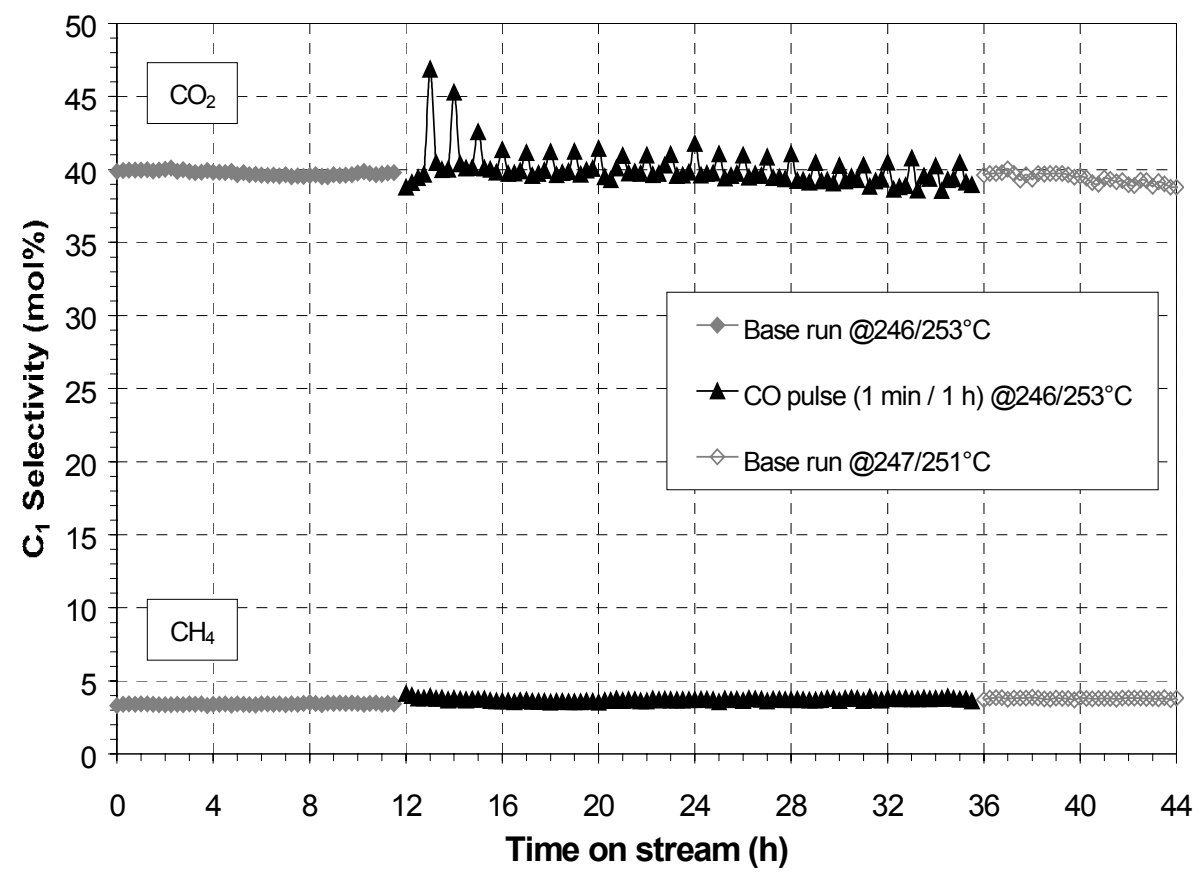

Figure 3.3.8. Effect of $\mathrm{CO}$ pulse on $\mathrm{C}_{1}$ selectivity of HPR-43@300 psig and $6000 \mathrm{~h}^{-1}$. 


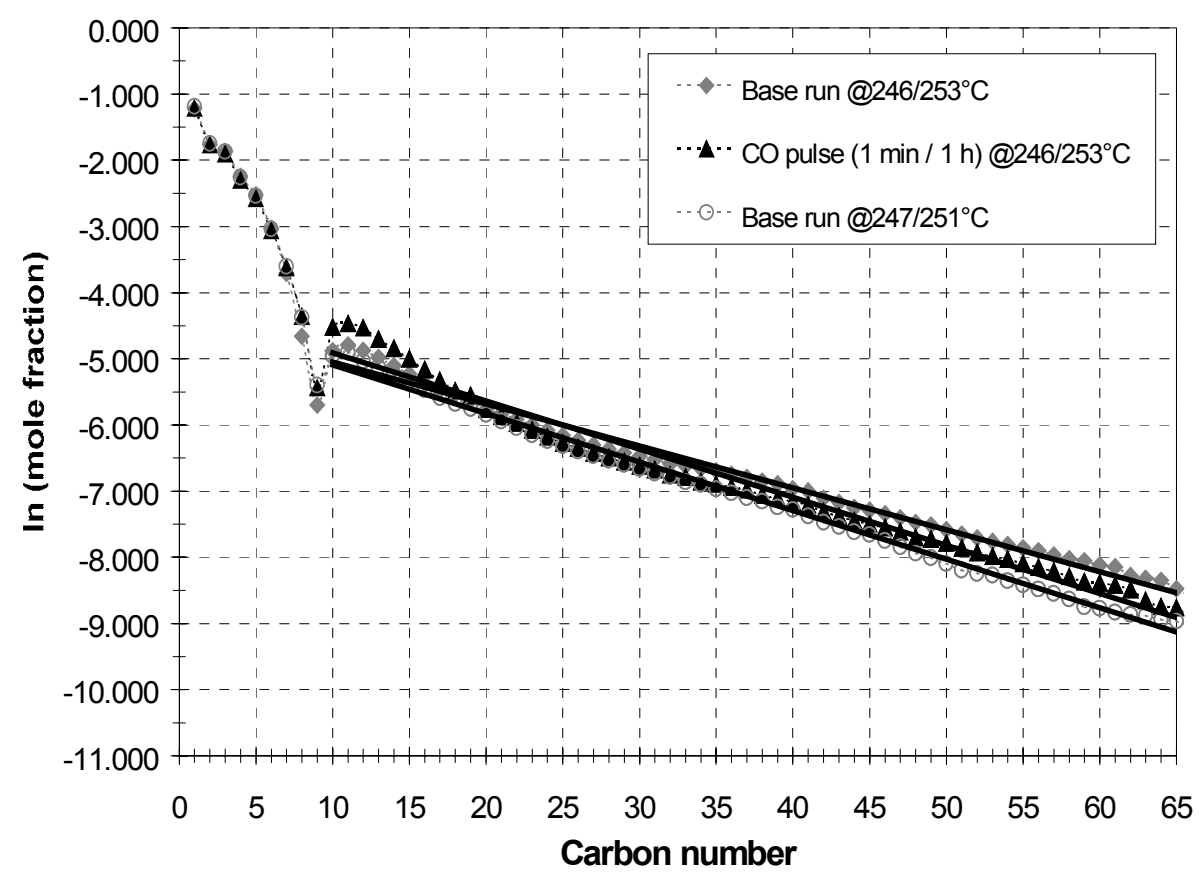

Figure 3.3.9. Effect of $\mathrm{CO}$ pulse on product distribution of HPR-43@300 psig and $6000 \mathrm{~h}^{-1}$.

\section{Effect of $\mathrm{H}_{2}$ and $\mathrm{CO}$ pulse at elevated temperatures}

A 1-min $\mathrm{H}_{2}$ pulse per 1 hour was applied for a period of 24 hours after the reaction system had reached a new "pseudo-steady state" at $262 / 272^{\circ} \mathrm{C}$. The measured CO conversion decreased from ca. $51 \%$ prior to the pulse run to ca. $40 \%$ after the pulse run (the corresponding $\mathrm{CO}$ productivity was ca. 750 and ca. $600 \mathrm{scc} / \mathrm{cc}$ cat./h, respectively). Also, an increase in the selectivity to $\mathrm{CH}_{4}$ was observed (from ca. $4.5 \%$ to ca. $5.5 \%$ ), whereas there was no measurable variation in the $\mathrm{CO}_{2}$ selectivity.

A 1-min CO pulse per 1 hour was then applied for 24 hours after reaching a new "pseudosteady state" at $261 / 271^{\circ} \mathrm{C}$. In good qualitative agreement with previous observations, the $\mathrm{CO}$ conversion decreased moderately (from ca. $42 \%$ to ca $38.5 \%$ ) as a result of the $\mathrm{CO}$ pulse, whereas the $\mathrm{CH}_{4}$ and $\mathrm{CO}_{2}$ selectivity remained constant (ca. 5\% and 42\%, respectively). Consequently, the observed effect of the $\mathrm{H}_{2}$ and the $\mathrm{CO}$ pulse appears to be applicable throughout the examined reaction temperature range (i.e., from ca. $230^{\circ} \mathrm{C}$ to ca. $270^{\circ} \mathrm{C}$ ).

\subsection{Fixed bed (RTI) and CSTR data (Syntroleum Corp.) of catalyst HPR-43}

Syntroleum Corp. performed a CSTR run of FT reaction on catalyst HPR-43. All tests were run at $\mathrm{GHSV}=2300 \mathrm{~h}^{-1}, 300 \mathrm{psig}$, and $\mathrm{H}_{2}: \mathrm{CO}$ feed ratio of 0.67 , using $10 \mathrm{cc}$ of catalyst in paraffin wax. Because of equipment limitations, the tests were run at $232^{\circ} \mathrm{C}$ for the first 310 hours; then the temperature was increased to $260^{\circ} \mathrm{C}$ for an additional 218 hours. Figure 3.4.1. shows the results. The $\mathrm{CO}$ productivity at $232^{\circ} \mathrm{C}$ is $\mathrm{ca} .350 \mathrm{cc} \mathrm{CO} / \mathrm{cc}$ cat $/ \mathrm{h}$ (corresponding to $25 \% \mathrm{CO}$ conversion) and remains steady after the first 24 hours. When the temperature was increased to $260^{\circ} \mathrm{C}$ the conversion initially increases and then decreases to the previous level. This may be due to loss of catalyst from the reactor - possibly due to buildup of wax. 


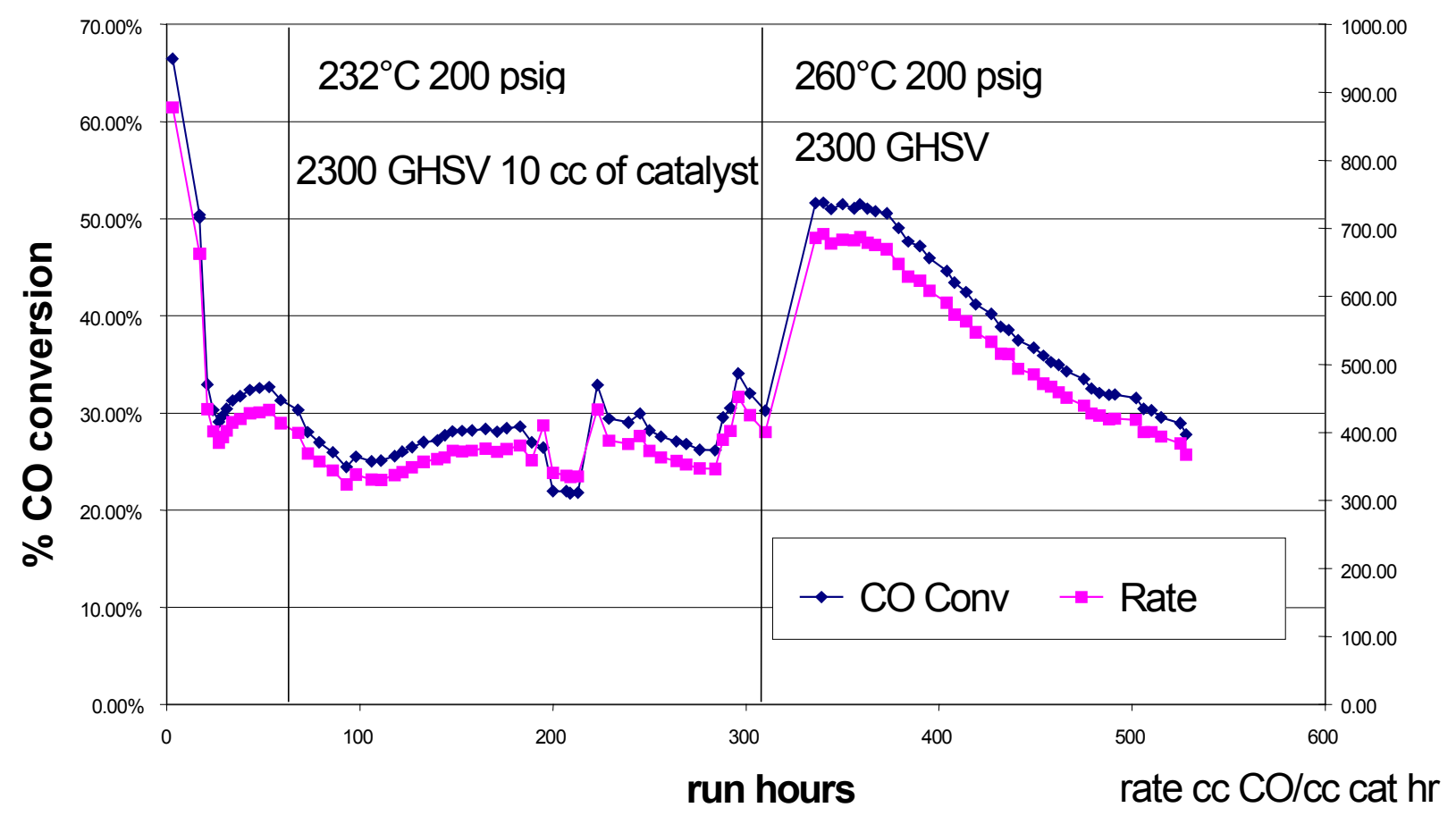

Figure 3.4.1. \% CO conversion and rate (cc CO / ce cat/h) from CSTR run of RTI catalyst HPR-43.

A comparison between the fixed bed data (obtained by RTI) and the CSTR data (obtained by Syntroleum) on catalyst HPR-43 is presented in Table 3.4.1.

Table 3.4.1. Fixed bed and CSTR data of catalyst HPR-43.

\begin{tabular}{|c|c|c|c|c|}
\hline & \multicolumn{2}{|c|}{ Fixed bed } & \multicolumn{2}{|c|}{ CSTR } \\
\hline $\mathrm{CO}(\%)$ & \multicolumn{2}{|c|}{24.8} & \multicolumn{2}{|c|}{56.7} \\
\hline $\mathrm{H}_{2}(\%)$ & \multicolumn{2}{|c|}{16.5} & \multicolumn{2}{|c|}{38.4} \\
\hline $\mathrm{N}_{2}+\operatorname{Ar}(\%)$ & \multicolumn{2}{|c|}{58.7} & \multicolumn{2}{|c|}{4.9} \\
\hline $\mathrm{SV}\left(\mathrm{h}^{-1}\right)$ & \multicolumn{2}{|c|}{6000} & \multicolumn{2}{|c|}{2300} \\
\hline $\mathrm{T}\left({ }^{\circ} \mathrm{C}\right)$ & 231 & 258 & 230 & 260 \\
\hline$P(p s i g)$ & 300 & 300 & 200 & 300 \\
\hline CO productivity $(\mathrm{cc} / \mathrm{cc} / \mathrm{h})$ & 350 & 650 & 350 & 800 \\
\hline Alpha (-) & 0.95 & 0.92 & 0.94 & - \\
\hline Water $(\mathrm{g} / \mathrm{cc} / \mathrm{h})$ & 0.05 & 0.036 & 0.022 & 0.008 \\
\hline Oil + Wax (g/cc/h) & 0.07 & 0.1 & 0.1 & 0.13 \\
\hline $\mathrm{CH}_{4}$ selectivity $(\mathrm{mol} \%)$ & 4.0 & 4.0 & 2.2 & 2.1 \\
\hline $\mathrm{C}_{10}-\mathrm{C}_{20}$ yield $(\mathrm{g} / \mathrm{cc} / \mathrm{h})$ & 0.016 & 0.051 & - & - \\
\hline
\end{tabular}




\subsection{FT Reaction on $0.5 \% \mathrm{Ru} / \mathrm{Al}_{2} \mathrm{O}_{3}$}

A $0.5 \mathrm{wt} \% \mathrm{Ru} / \mathrm{Al}_{2} \mathrm{O}_{3}$ catalyst was synthesized (by Henry lamb at North Carolina State University, in sub-contract to RTI) using the incipient wetness impregnation method on a highpurity CATAPAL alumina. After drying, the catalyst was reduced (without prior calcination) in $7 \% \mathrm{H}_{2} / \mathrm{Ar}$ at $300^{\circ} \mathrm{C}$ and was then passivated in air at room temperature. The actual $\mathrm{Ru}$ loading (determined by elemental analysis) was $0.5 \mathrm{wt} \%$.

A physical mixture of $2 \mathrm{cc}(1.77 \mathrm{~g})$ of the reduced $\mathrm{Ru} / \mathrm{Al}_{2} \mathrm{O}_{3}$ catalyst and $10 \mathrm{cc}(16.02 \mathrm{~g})$ of a low-surface-area $\left(0.2 \mathrm{~m}^{2} / \mathrm{g}\right) \alpha$-alumina (SA5397, Norton) was loaded into the reactor. The catalyst was reduced in-situ under $\mathrm{H}_{2}$ at $300^{\circ} \mathrm{C}$ for $8 \mathrm{~h}$, and was cooled and pressurized to ca. 400 psig $(26.2 \mathrm{~atm})$. The FT reaction was started by feeding a $3.3 \% \mathrm{Ar} / 33.3 \% \mathrm{CO} / 63.4 \% \mathrm{H}_{2}$ reactant mixture, thus establishing the following base reaction conditions:

$$
\begin{aligned}
& \mathrm{H}_{2}=63.4 \%, \mathrm{CO}=33.3 \%\left(\mathrm{H}_{2}: \mathrm{CO}=1.9\right) \\
& \text { Inert }(\mathrm{Ar})=3.3 \%(\mathrm{Ar}: \mathrm{CO}=0.1) \\
& \left.\mathrm{F}=100 \mathrm{scc} / \mathrm{min}, \mathrm{SV}=3000 \mathrm{~h}^{-1}, \mathrm{P}=26 \mathrm{~atm} \text { (typical operating pressure: } 100-1000 \mathrm{~atm}\right) .
\end{aligned}
$$

The reaction temperature was increased slowly to $245^{\circ} \mathrm{C}$ (typical operating $\mathrm{T}$ : $160^{\circ} \mathrm{C}$ ). However, the reaction did not actually reach a "pseudo-steady state"; the CO conversion was found to increase at a very slow rate (from ca. $12 \%$ to ca. $18 \%$ in a period of 66 hours) and the measured bed temperature was $243^{\circ} \mathrm{C}$ (bottom) and $252^{\circ} \mathrm{C}$ (top). Despite not attaining steady state, this isothermal run was followed by a pulse run, involving substitution of the reactant feed flow $\left(\mathrm{H}_{2} / \mathrm{CO} / \mathrm{Ar}\right)$ with an equal molar flow of a pulse gas $\left(\mathrm{H}_{2}\right)$. The total molar flow and the reaction pressure were kept constant between base and pulse runs. A pulse sequence of $1 \mathrm{~min}$ per 1 hour was applied. The time-on-stream data on the outlet $\mathrm{H}_{2}: \mathrm{CO}$ ratio, the $\mathrm{CO}$ conversion, and selectivity to $\mathrm{CH}_{4} / \mathrm{CO}_{2}$ are shown in Figures 3.5.1, 3.5.2, and 3.5.3, respectively.

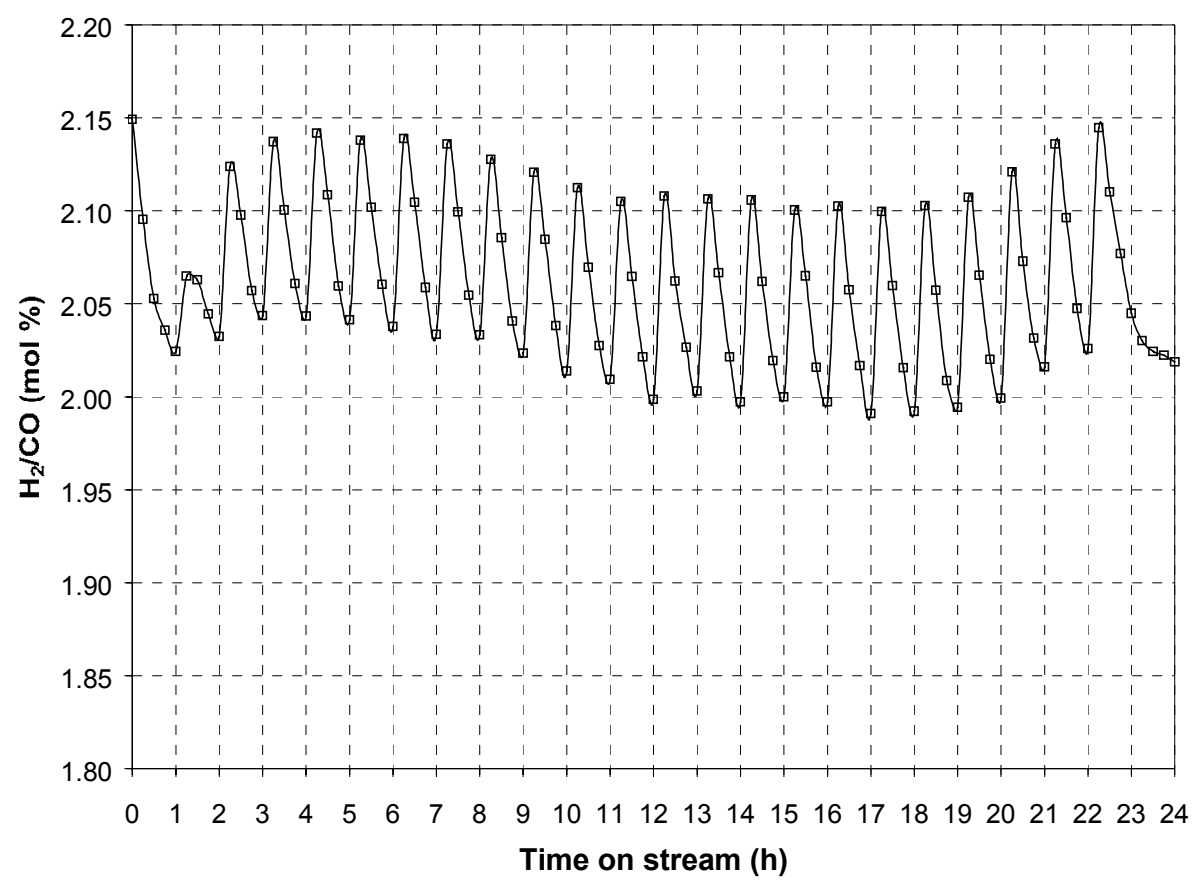

Figure 3.5.1. Effect of $\mathrm{H}_{2}$ pulse on outlet $\mathrm{H}_{2}$ :CO ratio of $\mathrm{Ru} / \mathrm{Al}_{2} \mathrm{O}_{3} @ 400$ psig and $3000 \mathrm{~h}^{-1}$. 


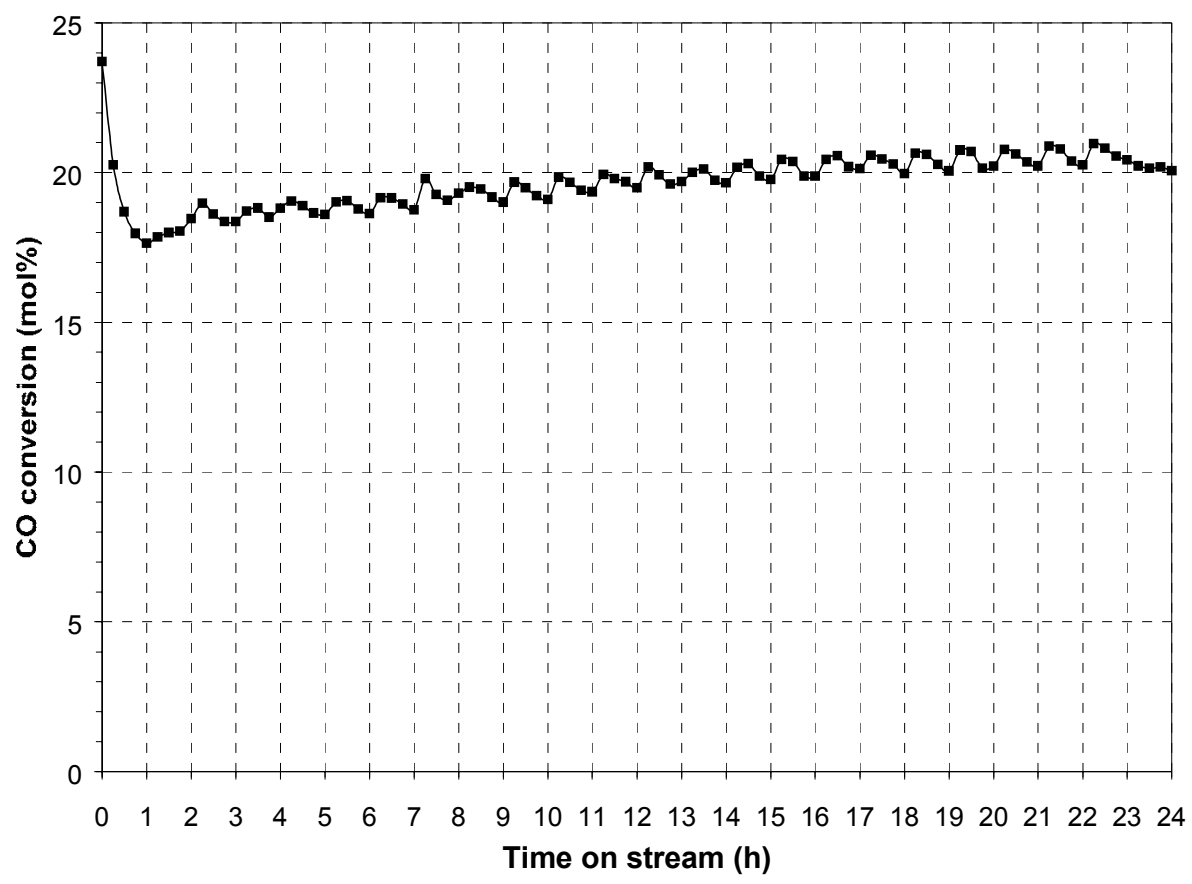

Figure 3.5.2. Effect of $\mathrm{H}_{2}$ pulse on $\mathrm{CO}$ conversion of $\mathrm{Ru} / \mathrm{Al}_{2} \mathrm{O}_{3} @ 400$ psig and $3000 \mathrm{~h}^{-1}$.

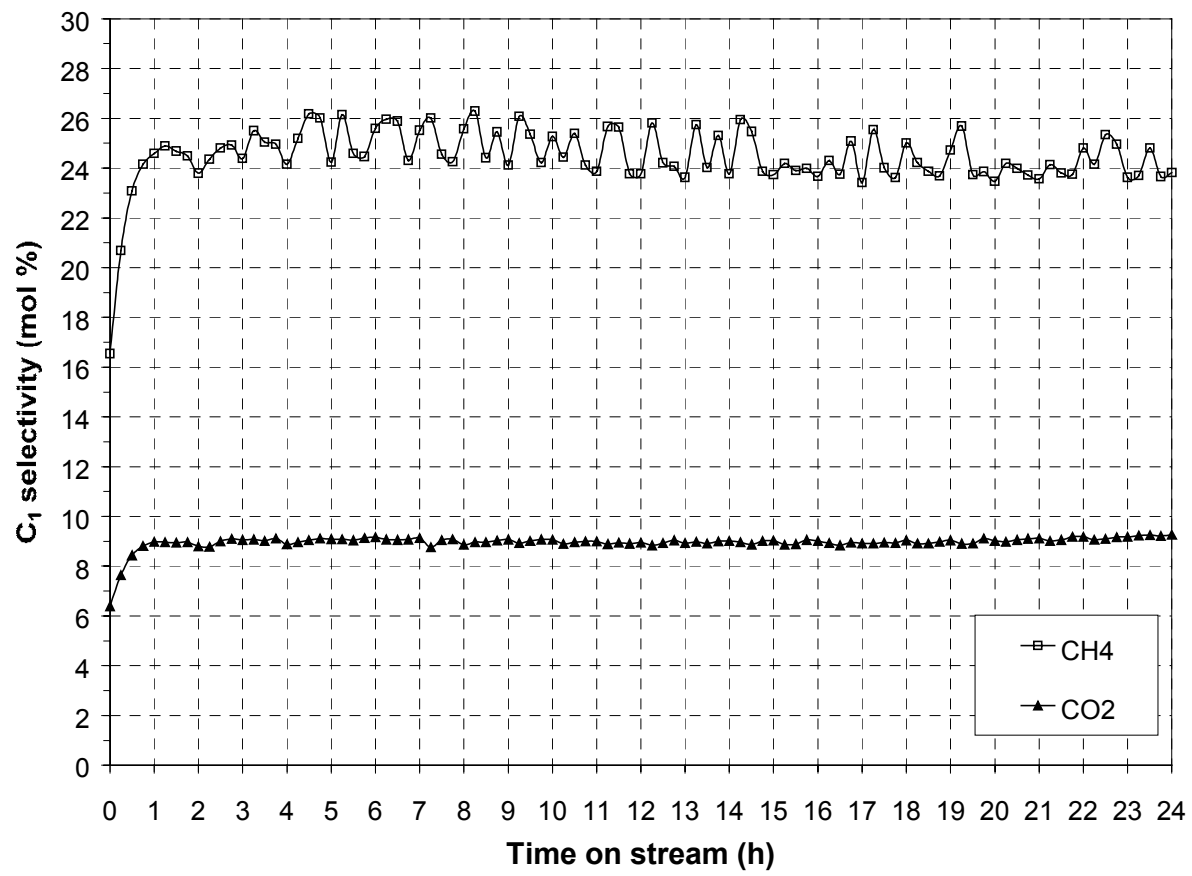

Figure 3.5.3. Effect of $\mathrm{H}_{2}$ pulse on $\mathrm{C}_{1}$ selectivity of $\mathrm{Ru} / \mathrm{Al}_{2} \mathrm{O}_{3} @ 400 \mathrm{psig}$ and $3000 \mathrm{~h}^{-1}$. 
The applied $\mathrm{H}_{2}$ pulse increases the outlet $\mathrm{H}_{2}$ : $\mathrm{CO}$ ratio only moderately (from ca. 2.0 to ca. 2.1), in a time-pattern similar to that observed for the other examined FT catalysts (Fig. 3.5.1). The CO conversion increases from ca. $18 \%$ to ca. $20 \%$ during the 24 -hour run; however, this increase in activity is apparently not associated with the application of the $\mathrm{H}_{2}$ pulse, since it matches with that observed for the isothermal run (increase by ca. $6 \%$ in almost 3 days). Indeed, each applied $\mathrm{H}_{2}$ pulse has only minimal positive effect on $\mathrm{CO}$ conversion (increase of only $1 \%$, Fig. 3.5.2). The selectivity to $\mathrm{CH}_{4}$ and $\mathrm{CO}_{2}$ is very high (ca. $24 \%$ and ca. $9 \%$, respectively), with small fluctuations (mainly for $\mathrm{CH}_{4}$ ) due to the applied pulse sequence. Therefore, the $\mathrm{H}_{2}$ pulse has only a minimal effect on the activity and $\mathrm{C}_{1}$ selectivity of the Ru/alumina catalyst, which appears to show high methanation (product $\mathrm{CH}_{4}$ ) and water-gas-shift (product $\mathrm{CO}_{2}$ ) activity.

The poor FT synthesis performance of the Ru/alumina catalyst could be due to insufficient reduction of $\mathrm{Ru}$ at $300^{\circ} \mathrm{C}$. In order to examine this hypothesis, after the pulse run the reactor was depressurized gradually, the catalyst was reduced again in-situ under $\mathrm{H}_{2}$ at $350^{\circ} \mathrm{C}$ for 8 hours, it was cooled to $115^{\circ} \mathrm{C}$ and pressurized back to 400 psig under the $\mathrm{H}_{2} / \mathrm{CO} / \mathrm{Ar}$ reactant mixture. The catalyst was then heated from $115^{\circ} \mathrm{C}$ to $215^{\circ} \mathrm{C}$ by $15^{\circ} \mathrm{C} / \mathrm{h}$. Due to an error in the controller program, after reaching the target temperature of $215^{\circ} \mathrm{C}$ the bed was cooled back to the initial temperature of $115^{\circ} \mathrm{C}$. The heating process was repeated and the bed temperature was stabilized at $214^{\circ} \mathrm{C}$ (bottom) and $219^{\circ} \mathrm{C}$ (top), establishing a new "base" reaction condition. The variation in $\mathrm{CO}$ conversion with time-on-stream is shown in the composite plot of Figure 3.5.4, composed of two 14-hour segments of the two heat-up processes.

The CO conversion curves for the two activation runs are essentially identical (Fig. 3.5.4), suggesting that there is no effect of applying these procedures on catalyst activity. The effect of temperature on the rate of $\mathrm{CO}$ disappearance (calculated from the measured $\mathrm{CO}$ conversion assuming differential plug-flow reactor conditions) is shown in Figure 3.5.5.

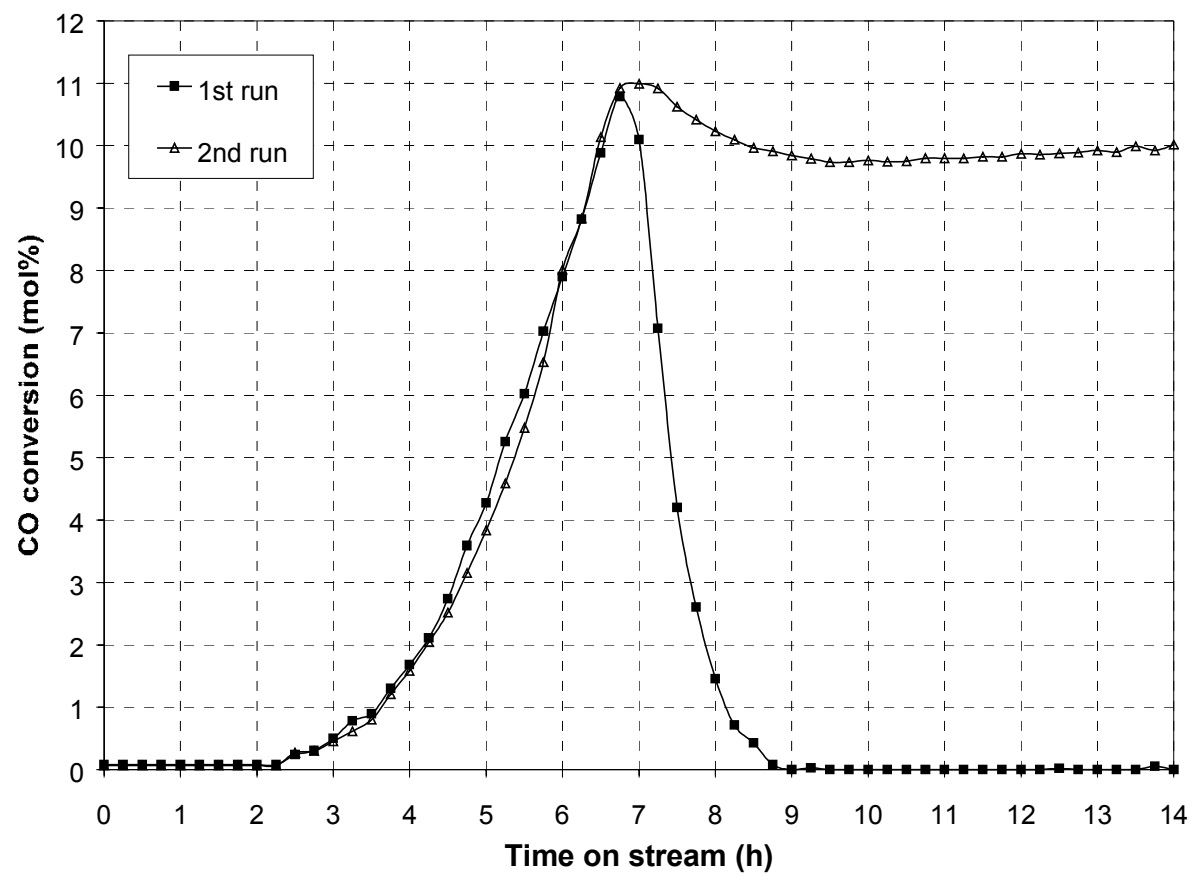

Figure 3.5.4. Effect of activation process on $\mathrm{CO}$ conversion of $\mathrm{Ru} / \mathrm{Al}_{2} \mathrm{O}_{3} @ 400$ psig and $3000 \mathrm{~h}^{-1}$. 


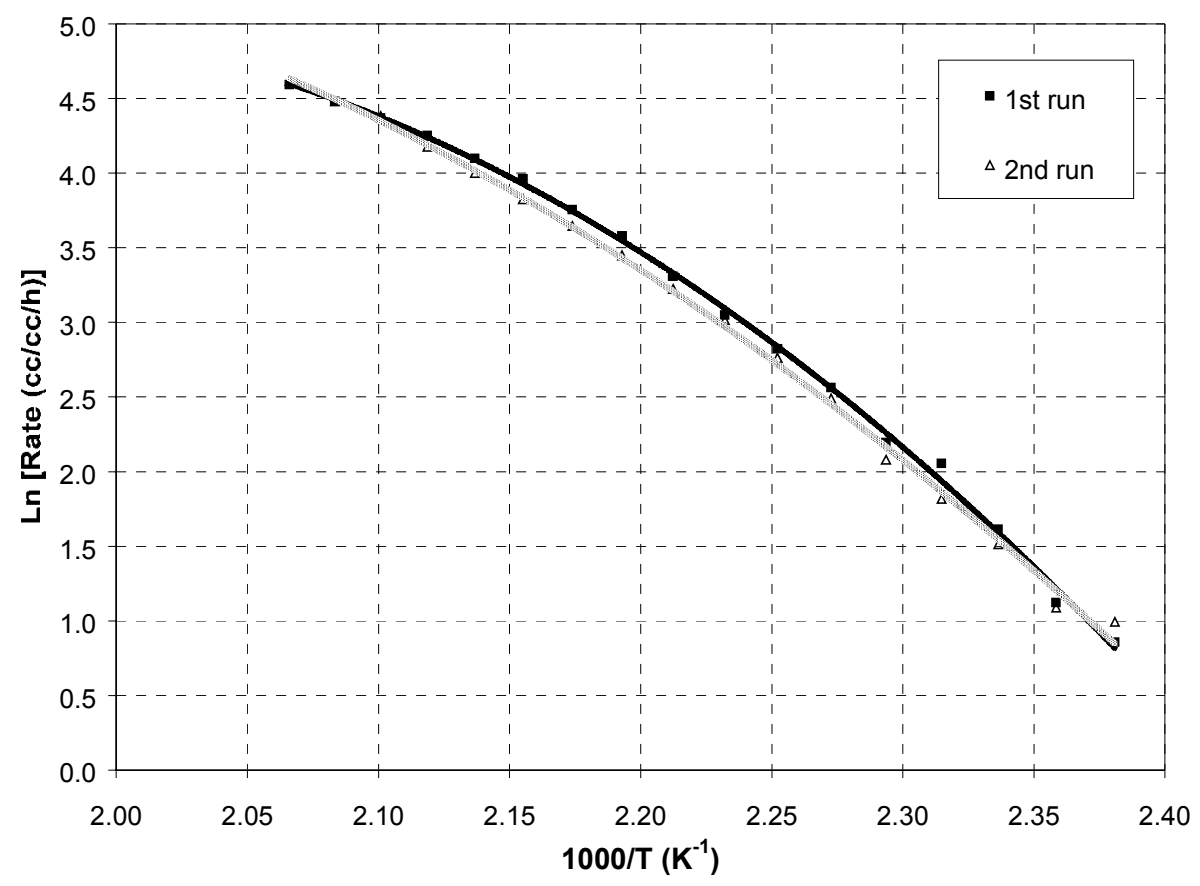

Figure 3.5.5. Effect of temperature on rate of $\mathrm{CO}$ consumption of $\mathrm{Ru} / \mathrm{Al}_{2} \mathrm{O}_{3} @ 400$ psig and $3000 \mathrm{~h}^{-1}$.

The Arrhenius-type plots of Fig. 3.5.5 present the dependence of the experimentally determined rate of reaction (rate of $\mathrm{CO}$ consumption) on the reciprocal temperature of reaction (the "bottom" bed temperature was used). The slope of these curves provides a measurement for the apparent energy of activation for the overall reaction on the Ru/alumina catalyst, under the examined reaction conditions. The curvature of the plots in Fig. 3.5.5 implies a shift between two regimes with a different reaction-controlling (rate-determining) step. Based on the low-T data (7 last points) of these curves the obtained apparent energy of activation is:

$$
E_{a(l o w-T)}=125 \pm 5 \mathrm{~kJ} / \mathrm{mol} \text {. }
$$

On the other hand, the high-T data (first 5 points) give the apparent activation energy of:

$$
E_{a(h i g h-T)}=65 \pm 7 \mathrm{~kJ} / \mathrm{mol} \text {. }
$$

The decrease in the apparent activation energy with increasing reaction temperature is a clear indication of a transition from a kinetics-controlled reaction (at low-T) to a diffusion-controlled reaction (at high-T) under the examined conditions. More specifically, for a $1^{\text {st }}$ order reaction $\left(1^{\text {st }}\right.$ order dependence of the reaction rate on the concentration of $\mathrm{CO}$ ) the apparent activation energy under diffusion-control is close to one half of that under kinetics-control. The numerical values of the two apparent activation energies in this experiment appear to be in good agreement with this prediction. Therefore, the obtained data imply a pseudo- $1^{\text {st }}$ order dependence of the overall FT reaction on the concentration of $\mathrm{CO}$. 
After the second activation procedure, the bed temperature was stabilized at $214 / 219^{\circ} \mathrm{C}$, thus allowing the reaction to reach a new "pseudo-steady state". The measured conversion was ca. $11 \%$ (in comparison to $12 \%-18 \%$ at $243 / 252^{\circ} \mathrm{C}$ ), indicating a clear activation of the catalyst, with still a tendency for minor increase in activity with time on stream. The outlet $\mathrm{H}_{2}: \mathrm{CO}$ ratio dropped to ca. 1.9 (compared to ca. 2.0 prior to the activation). The most important difference, however, in the measured parameters before and after the activation, was the strong suppression of the selectivity to $\mathrm{CH}_{4}$ (ca. $14 \%$ instead of ca. $24 \%$ ) and $\mathrm{CO}_{2}$ (ca. $4 \%$ instead of ca. $9 \%$ ). This shift in selectivity from the undesired $\mathrm{C}_{1}$ compounds to the desired FT reaction hydrocarbon products is apparently related to the lower reaction temperature while maintaining a reasonable conversion of $\mathrm{CO}$ (which in turn suggests a better activation of the catalyst).

Following this "base" run a 1-min $\mathrm{H}_{2}$ pulse per 1 hour was applied, so as to compare the effect of $\mathrm{H}_{2}$ pulsing between the runs prior to and after the activation. The time-on-stream response of the $\mathrm{CO}$ conversion and the $\mathrm{CH}_{4} / \mathrm{CO}_{2}$ selectivity are given in Figures 3.5.6 and 3.5.7, respectively. The CO conversion increases by $1 \%$ (from $11 \%$ to $12 \%$ ) in the 24 -hour duration of the run. Again, this minor increase in activity is due to the continuous activation of the catalyst by the strong reaction exotherm, rather than the applied $\mathrm{H}_{2}$ pulse sequence. Each $\mathrm{H}_{2}$ pulse has only minimal positive effect on the measured $\mathrm{CO}$ conversion (Fig. 3.5.6). The selectivity to $\mathrm{CH}_{4}$ shows a minor increase with each $\mathrm{H}_{2}$ pulse (ranging between $12 \%$ and $14 \%$ ), and the selectivity to $\mathrm{CO}_{2}$ remains essentially constant at $4 \%$ (Fig. 3.5.7).

Therefore, the $\mathrm{H}_{2}$ pulsing appears to have only minimal impact on the activity and selectivity of the $\mathrm{Ru} /$ alumina catalyst even after the second reduction. The catalyst is significantly better activated after applying the second reduction procedure, resulting in exhibiting the same activity at lower reaction temperatures, which in turn suppresses the selectivity to undesired compounds $\mathrm{CH}_{4}$ and $\mathrm{CO}_{2}$.

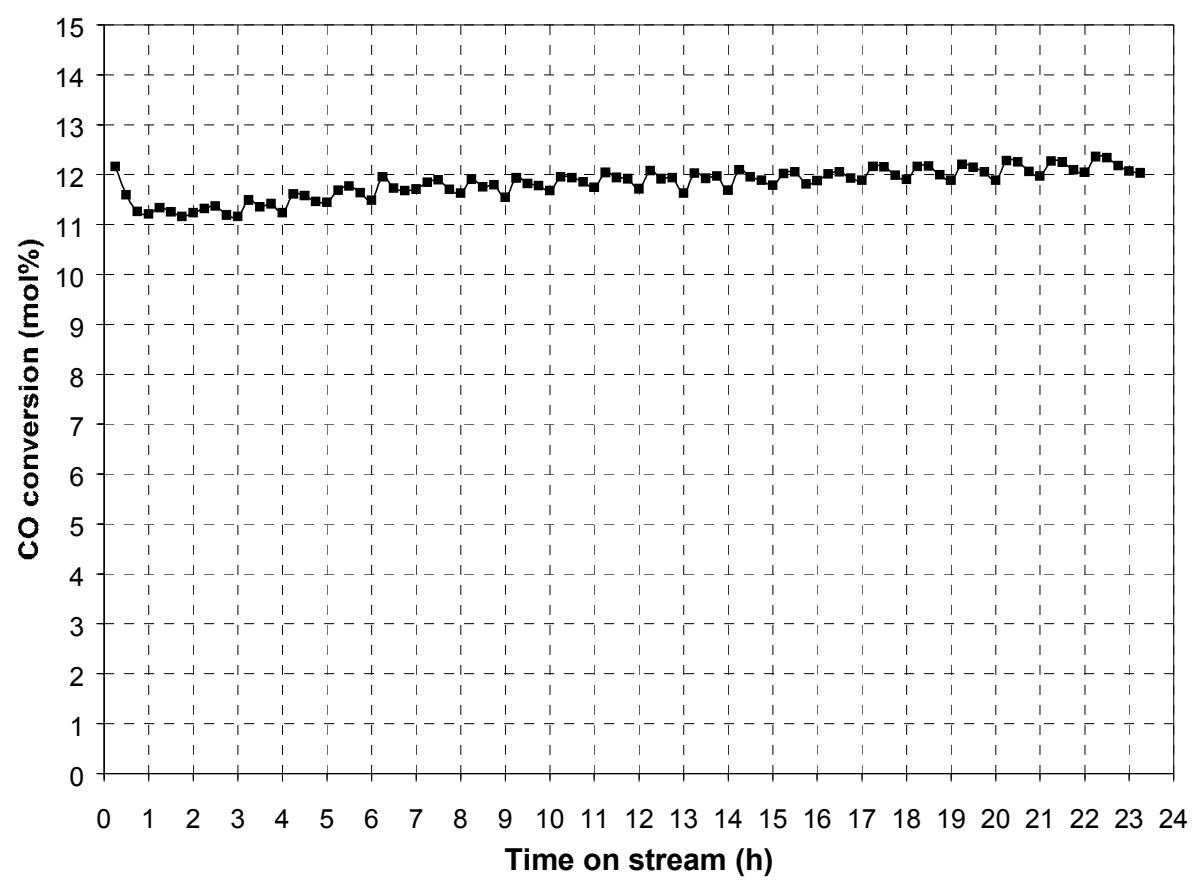

Figure 3.5.6. Effect of $\mathrm{H}_{2}$ pulse on $\mathrm{CO}$ conversion of $\mathrm{Ru} / \mathrm{Al}_{2} \mathrm{O}_{3} @ 400$ psig and $3000 \mathrm{~h}^{-1}$. 


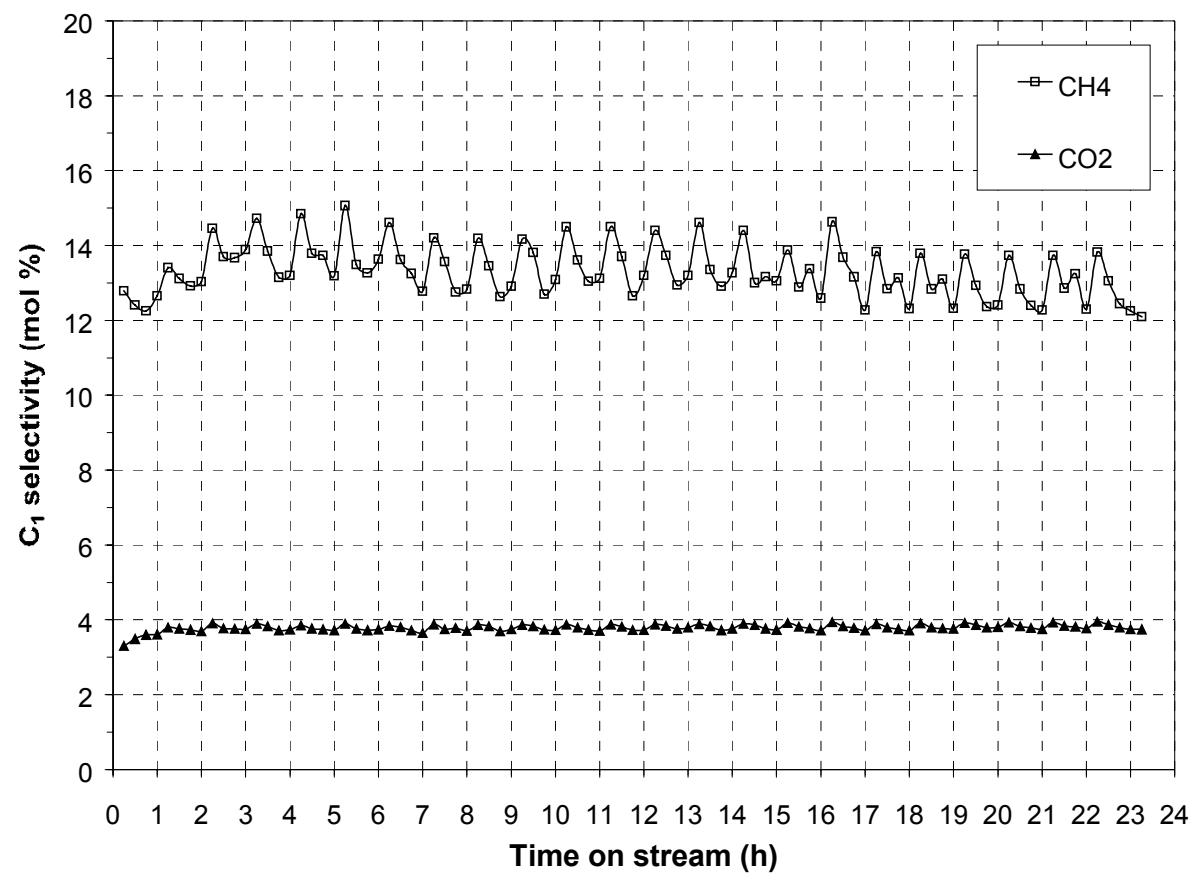

Figure 3.5.7. Effect of $\mathrm{H}_{2}$ pulse on $\mathrm{C}_{1}$ selectivity of $\mathrm{Ru} / \mathrm{Al}_{2} \mathrm{O}_{3} @ 400 \mathrm{psig}$ and $3000 \mathrm{~h}^{-1}$.

The analysis of the wax for the base run at $214 / 219^{\circ} \mathrm{C}$ resulted in obtaining a hydrocarbon product distribution with a chain growth factor $\boldsymbol{\alpha}$ of ca. 0.74 , which is clearly a very low value for the given type of catalyst. The molar selectivity to the $\mathrm{C}_{10}-\mathrm{C}_{20}$ compound range was ca. $24 \%$. Due to difficulties in the collection of the wax sample for the $\mathrm{H}_{2}$ pulse run the corresponding product analysis involved a large degree of uncertainty. Based on the $\mathrm{C}_{10}-\mathrm{C}_{30}$ product fraction the obtained $\boldsymbol{\alpha}$ value was ca. 0.80 , while the selectivity to $\mathrm{C}_{10}-\mathrm{C}_{20}$ was ca. $19 \%$. The observed increase in the $\boldsymbol{\alpha}$ value for the $\mathrm{H}_{2}$ pulse run could not be positively attributed to the pulsing itself, since a follow-up base run at the same temperature $\left(214 / 219^{\circ} \mathrm{C}\right)$ also gave a higher $\boldsymbol{\alpha}$ value (ca. 0.79). Despite the significant uncertainty associated with these values, the observed chain growth is overall much lower than that expected for the $\mathrm{Ru} /$ alumina catalyst based on literature references. It is quite possible that the reaction pressure for this experiment (400 psig) is not high enough for this catalyst to show significant FT reaction activity. 


\section{CONCLUSIONS}

Based on the presented results the following conclusions can be drawn:

The $\alpha$-alumina used for diluting the examined catalysts shows no measurable activity for FT synthesis at temperatures up to $270^{\circ} \mathrm{C}$, thus its presence does not affect the activity of the examined catalysts.

"Blank" pulse runs (i.e., runs involving no variations in feed composition) have no effect on measurements of the progress of the FT reaction (conversion, selectivity). "Inert" $\left(\mathrm{N}_{2}\right)$ pulsing shows only minimal variations in activity (CO conversion) or in product selectivity ( $\boldsymbol{\alpha}$-value, $\mathrm{CH}_{4}$ yield, and $\mathrm{C}_{10}-\mathrm{C}_{20}$ yield) for FT synthesis.

Hydrogen pulsing causes significant increase in $\mathrm{CO}$ conversion on a $\mathrm{Co}-\mathrm{ZrO}_{2} / \mathrm{SiO}_{2} \mathrm{FT}$ synthesis catalyst, along with an observed enhanced reaction exotherm. Then, the $\mathrm{CO}$ conversion decreases gradually until the next $\mathrm{H}_{2}$ pulse, indicating that the catalyst activity tends to return slowly to its steady-state value. The selectivity to undesirable $\mathrm{CH}_{4}$ increases instantaneously after each $\mathrm{H}_{2}$ pulse on the $\mathrm{Co}-\mathrm{ZrO}_{2} / \mathrm{SiO}_{2}$ catalyst, but it is quickly restored to its steady-state value. Thus, $\mathrm{H}_{2}$ pulsing increases catalytic activity while only briefly increasing the formation of $\mathrm{CH}_{4}$.

An increase in the $\mathrm{H}_{2}$ pulse frequency has a positive effect on the selectivity to $\mathrm{C}_{10}-\mathrm{C}_{20}$ and $\mathrm{C}_{21+}$ compounds (while maintaining or slightly decreasing the selectivity to $\mathrm{CH}_{4}$ ) but the chaingrowth probability $\boldsymbol{\alpha}$ remains essentially unaffected. An increase in the $\mathrm{H}_{2}$ pulse duration increases the maximum obtained $\mathrm{CO}$ conversion and the instantaneous selectivity to $\mathrm{CH}_{4}$.

The extent of the $\mathrm{CH}_{4}$ formation reaction appears to be correlated to the increase in $\mathrm{H}_{2}$ concentration as caused by pulsing. The FT reaction, however, appears to have a different dependence on $\mathrm{H}_{2}$ concentration, since it progresses within a different time frame. An optimum set of both $\mathrm{H}_{2}$ pulsing parameters (pulse frequency and pulse duration) is required for maximizing the yield of (diesel-range) $\mathrm{C}_{10}-\mathrm{C}_{20}$ FT products.

Hydrogen pulsing has a positive effect on the $\mathrm{C}_{10}-\mathrm{C}_{20}$ yield of a high- $\boldsymbol{\alpha} \mathrm{Fe} / \mathrm{K} / \mathrm{Cu} / \mathrm{SiO}_{2} \mathrm{FT}$ catalyst. However, it also causes a significant decrease in catalyst activity (CO conversion) and an undesirable increase in the selectivity to $\mathrm{CH}_{4}$. Pulsing with $\mathrm{CO}$ also has a positive effect on the $\mathrm{C}_{10}-\mathrm{C}_{20}$ yield and no measurable effect on the selectivity to $\mathrm{CH}_{4}$ and $\mathrm{CO}_{2}$, and causes only a moderate decrease in $\mathrm{CO}$ conversion. Pulsing with a $24 \% \mathrm{CO}_{2} / \mathrm{N}_{2}$ gas mixture has essentially no effect on catalytic activity or product distribution ( $\boldsymbol{\alpha}$-value, $\mathrm{C}_{10}-\mathrm{C}_{20}$ yield).

Hydrogen pulsing has only minimal effect on the activity and $\mathrm{C}_{1}$ selectivity of a Ru/alumina FT synthesis catalyst, which appears to show enhanced methanation and water-gas-shift activity. A second reduction procedure produces a better-activated catalyst, showing the same activity at lower temperatures, along with lower selectivity to undesirable compounds $\mathrm{CH}_{4}$ and $\mathrm{CO}_{2}$. Still there is only minimal impact of $\mathrm{H}_{2}$ pulsing on the catalyst performance even after the second reduction. 


\section{BIBLIOGRAPHY}

1. R.B. Anderson, The Fischer-Tropsch Synthesis, Acad. Press, New York, 1984.

2. M.E. Dry, Appl. Catal. A, 138 (1996) 319.

3. A.A. Adesina, Appl. Catal. A, 138 (1996) 345.

4. M.E. Dry, The Fischer-Tropsch Synthesis, in Catalysis - Science and Technology 1 (J.R. Ander and M. Boudart, eds.), Springer-Verlag, New York, 1981.

5. G. Parkinson, Chem. Eng., 4 (1997) 39.

6. C.D. Chang, W.H. Lang, and A.J. Silvestri, J. Catal., 56 (1979) 268.

7. R.J. Gormley, V.U.S. Rao, R.R. Anderson, R.R. Schehl, and R.D.H. Chi, J. Catal., 113 (1988) 195.

8. S. Bessell, Appl. Catal. A, 126 (1995) 235.

9. K. Jothimurugesan and S.K. Gangwal, Ind. Eng. Chem. Res., 37(4) (1998) 1181.

10. D.L. King, J.A. Cusamano, and R.L. Garten, Catal. Rev. Sci. Eng., 23(1-2) (1981) 233.

11. A.A. Adesina, R.R. Hudgins, and P.L. Silveston, Can. J. Chem. Eng., 25 (1995) 127.

12. J.W. Dun, and E. Gulari, Can. J. Chem. Eng., 64(2) (1986) 260.

13. G. Beer, Gas Conversion Process Using a Chain-Limiting Reactor, WO Patent No. 98/ 19979 (1997).

14. E. Peacock-Lopez and K. Lindenberg, J. Phys. Chem., 88 (1984) 2270.

15. E. Peacock-Lopez and K. Lindenberg, J. Phys. Chem., 90 (1986) 1725.

16. A.A. Khodadadi, R.R. Hudgins, and P.L. Silverston, Canadian J. Chem. Eng., 74 (1996) 695.

17. F.M. Dautzenberg, J.M. Heller, R.A. van Santen, and H. Berbeek, J. Catal., 50 (1977) 8.

18. A. Hoek, M.F.M. Post, J.K. Minderhoud, and P.W. Lednor, Process for the Preparation of a Fischer-Tropsch Catalyst and Preparation of Hydrocarbons from Syngas, US Patent No. 4,499,209 (1985). 


\section{APPENDICES}

\section{Appendix I.}

Two-page abstract entitled "Fischer-Tropsch Synthesis on a $\mathrm{Co}-\mathrm{ZrO}_{2} / \mathrm{SiO}_{2}$ Catalyst: Effect of $\mathrm{H}_{2}$ Pulsing", submitted for presentation in the $17^{\text {th }}$ North American Catalysis Society Meeting, to be held in Toronto, Canada, on June 3-8, 2001.

\section{Appendix II.}

Six-page camera-ready manuscript entitled "Effect of Periodic Pulsed Operation on Product Selectivity in Fischer-Tropsch Synthesis on $\mathrm{Co}-\mathrm{ZrO}_{2} / \mathrm{SiO}_{2}$ ", submitted for oral presentation and publication in the Proceedings of the $6^{\text {th }}$ Natural Gas Conversion Symposium, to be held in Girdwood, Alaska, on June 17-21, 2001. 


\section{APPENDIX I}

\section{Fischer-Tropsch Synthesis on a Co- $\mathrm{ZrO}_{2} / \mathrm{SiO}_{2}$ Catalyst: Effect of $\mathrm{H}_{2}$ Pulsing}

\section{A.A. Nikolopoulos and S.K. Gangwal}

Research Triangle Institute, P.O. Box 12194, RTP, NC 27709-2194, U.S.A.

\section{Introduction}

Currently there is significant commercial interest in producing diesel-fuel-range middle distillates $\left(\mathrm{C}_{10}-\mathrm{C}_{20}\right.$ paraffins $)$ from natural-gas-derived syngas by FischerTropsch (FT) synthesis. Increasing the selectivity of the FT reaction to diesel $\left(\mathrm{C}_{10^{-}}\right.$ $\left.\mathrm{C}_{20}\right)$ or gasoline $\left(\mathrm{C}_{5}-\mathrm{C}_{11}\right)$ products by altering the Shultz-Flory-Anderson (SFA) distribution is economically attractive. Use of bifunctional (FT-active metal on zeolite) catalysts to produce gasoline-range hydrocarbons has been economically unsuccessful [1-2]; the enhanced cracking activity of the zeolite lowers the chaingrowth probability $\boldsymbol{\alpha}$, thus producing increased amounts of undesirable $\mathrm{C}_{1}-\mathrm{C}_{4}$ gases.

The present emphasis has shifted towards maximizing the yield of zero-sulfur high-cetane $\mathrm{C}_{10}-\mathrm{C}_{20}$ products from $\mathrm{FT}$ synthesis. Among various approaches, periodic pulsing of $\mathrm{H}_{2}$ or other gases has been examined so as to limit chain growth on a high- $\boldsymbol{\alpha}$ FT catalyst by removing the growing chain from the catalyst surface [35], thus maximizing the $\mathrm{C}_{10}-\mathrm{C}_{20}$ yield (Figure 1). Experimental studies have shown the potential to alter the SFA distribution [6,7]; however, they were conducted under conditions of limited industrial interest. The scope of this study is to investigate the effect of $\mathrm{H}_{2}$ pulsing on the activity and product distribution of a high- $\boldsymbol{\alpha}(\sim 0.9)$ $\mathrm{Co} / \mathrm{ZrO}_{2} / \mathrm{SiO}_{2} \mathrm{FT}$ synthesis catalyst, in an attempt to maximize the $\mathrm{C}_{10}-\mathrm{C}_{20}$ product yield.

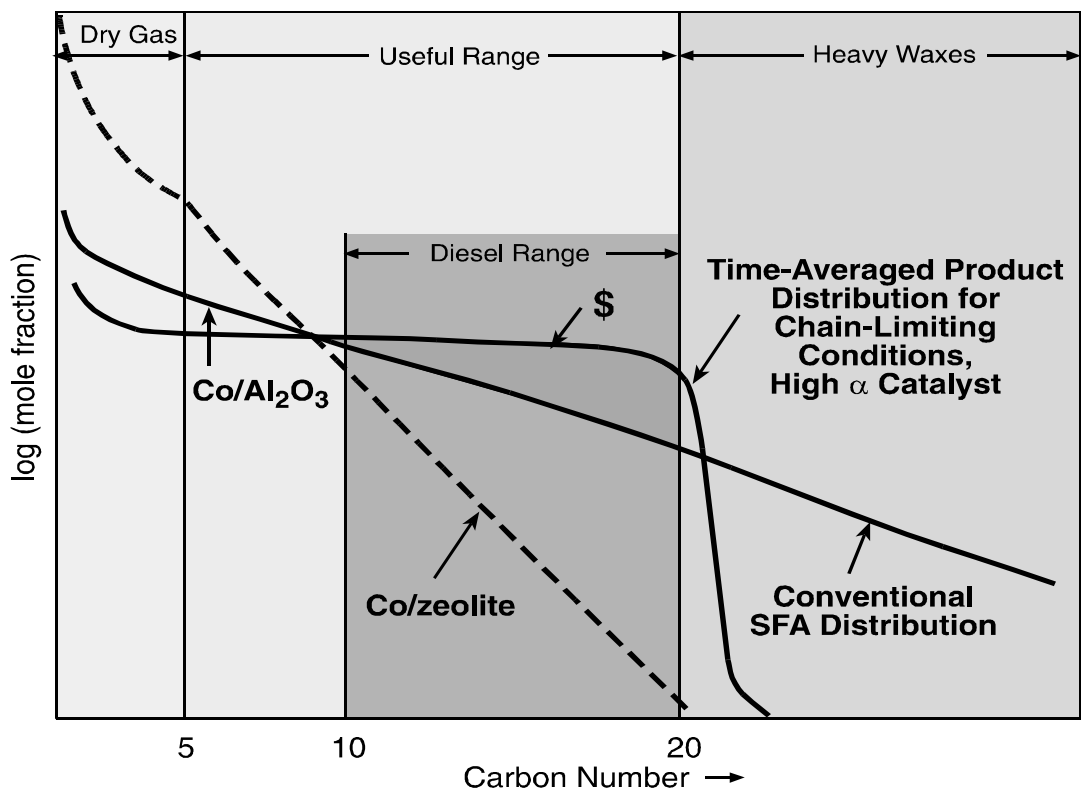

Figure 2. Product distribution ( $\boldsymbol{\alpha}$-plot) for FT synthesis 


\section{Experimental}

A $25 \% \mathrm{Co}-18 \% \mathrm{Zr} / \mathrm{SiO}_{2}$ catalyst was synthesized by sequential incipient wetness impregnation of a high-purity, high-surface-area silica (XS16080, Norton) with $\mathrm{Zr}$ tetrapropoxide and Co nitrate [8]. A mixture of $2 \mathrm{cc}$ of the calcined Co$\mathrm{Zr} / \mathrm{SiO}_{2}$ catalyst and $10 \mathrm{cc}$ of a low-surface-area $\alpha$-alumina (SA5397, Norton) was loaded into a 0.305 -in stainless steel down-flow reactor. The catalyst was reduced in-situ in $\mathrm{H}_{2}$ at $350^{\circ} \mathrm{C}$ and was cooled and pressurized to approximately $300 \mathrm{psig}$. The feed was $33.3 \% \mathrm{H}_{2}, 16.7 \% \mathrm{CO}\left(\mathrm{H}_{2}: \mathrm{CO}=2: 1\right)$, $1.7 \% \mathrm{Ar}$ (internal standard), balance $\mathrm{N}_{2}$, at $6000 \mathrm{~h}^{-1}$ space velocity. Pulse runs involved substituting the reactant feed flow with an equal molar flow of a pulse gas, thus maintaining the total molar flow and pressure between base and pulse runs.

\section{Results}

Runs with a "blank" pulse (i.e., switching between two equal flows of $\mathrm{H}_{2}+\mathrm{CO} / \mathrm{Ar}$ ) indicated no effect on $\mathrm{CO}$ conversion or product distribution ( $\boldsymbol{\alpha}$-value, $\mathrm{C}_{10}-\mathrm{C}_{20}$ yield). A 1-min $\mathrm{N}_{2}$ pulse per 1 hour gave only minimal variation in activity (CO conversion) and product selectivity. On the other hand, a 1-min $\mathrm{H}_{2}$ pulse per 1 hour resulted in a significant increase in $\mathrm{CO}$ conversion at $225^{\circ} \mathrm{C}$. The measured $\mathrm{CO}$ conversion after the pulse was observed to gradually decrease before the next pulse. The $\mathrm{CH}_{4}$ selectivity also increased substantially (due to the excess of $\mathrm{H}_{2}$ ) but was quickly restored to its base value. Thus $\mathrm{H}_{2}$ pulsing increased the desired $\mathrm{CO}$ productivity while only instantaneously increasing the undesired $\mathrm{CH}_{4}$ selectivity.

The effect of varying $\mathrm{H}_{2}$ pulse frequency (1-min $\mathrm{H}_{2}$ per 1,2 , and 4 hours) on the activity and product yield of the $\mathrm{Co}-\mathrm{ZrO}_{2} / \mathrm{SiO}_{2}$ catalyst is given in Table 1 . Both $\mathrm{CH}_{4}$ yield and $\mathrm{C}_{10}-\mathrm{C}_{20}$ yield increase with $\mathrm{H}_{2}$-pulse frequency. An optimum set of pulse parameters (pulse frequency, pulse duration) appears to be required for maximizing the $\mathrm{C}_{10}-\mathrm{C}_{20}$ yield.

Table 1. Effect of $\mathrm{H}_{2}$ pulse frequency on product yield $@ 225^{\circ} \mathrm{C}, \mathrm{P}=300 \mathrm{psig}$

\begin{tabular}{cccccc}
\hline $\begin{array}{c}\text { Frequency } \\
\left(\mathbf{h}^{-\mathbf{1}}\right)\end{array}$ & $\begin{array}{c}\text { Alpha } \\
\mathbf{( - )}\end{array}$ & $\begin{array}{c}\mathbf{C H}_{\mathbf{4}} \\
\mathbf{( w t \% )}\end{array}$ & $\begin{array}{c}\mathbf{C H}_{\mathbf{4}} \text { yield } \\
\mathbf{( g / c c ~ c a t} / \mathbf{h})\end{array}$ & $\begin{array}{c}\mathbf{C}_{\mathbf{1 0}}-\mathbf{C}_{\mathbf{2 0}} \\
\mathbf{( w t \% )}\end{array}$ & $\begin{array}{c}\mathbf{C}_{\mathbf{1 0}} \mathbf{C}_{\mathbf{2 0}} \text { yield } \\
\mathbf{( g / c c} \mathbf{c a t} / \mathbf{h})\end{array}$ \\
\hline 0 (no pulse) & 0.887 & 17.0 & 0.0189 & 28.2 & 0.0312 \\
0.25 & 0.892 & 15.8 & 0.0228 & 26.4 & 0.0380 \\
0.5 & 0.885 & 14.3 & 0.0223 & 31.0 & 0.0484 \\
1 & 0.890 & 15.4 & 0.0253 & 29.7 & 0.0490 \\
\hline
\end{tabular}

\section{References}

C.D. Chang, W.H. Lang, and A.J. Silvestri, J. Catal., 56 (1979) 268.

K. Jothimurugesan and S.K. Gangwal, Ind. Eng. Chem. Res., 37(4) (1998) 1187.

G. Beer, WO Patent No. 98/ 19979 (1997).

E. Peacock-Lopez and K. Lindenberg, J. Phys. Chem., 88 (1984) 2270.

E. Peacock-Lopez and K. Lindenberg, J. Phys. Chem., 90 (1986) 1725.

A.A. Khodadadi, R.R. Hudgins, and P.L. Silverston, Canadian J. Chem. Eng., 74 (1996) 695.

F.M. Dautzenberg, J.M. Heller, R.A. van Santen, and H. Berbeek, J. Catal., 50 (1977) 8.

A. Hoek, M.F.M. Post, J.K. Minderhoud, and P.W. Lednor, US Patent No. 4,499,209 (1985). 


\title{
APPENDIX II
}

\section{Effect of periodic pulsed operation on product selectivity in Fischer-Tropsch synthesis on $\mathrm{Co}-\mathrm{ZrO}_{2} / \mathrm{SiO}_{2}$}

\author{
A.A. Nikolopoulos, S.K. Gangwal, and J.J. Spivey* \\ Research Triangle Institute, P.O. Box 12194, RTP, NC 27709-2194, U.S.A.
}

The effect of $\mathrm{H}_{2}$ pulsing on the activity and product distribution of a high- $\boldsymbol{\alpha}(\sim 0.9)$ $\mathrm{Co} / \mathrm{ZrO}_{2} / \mathrm{SiO}_{2}$ Fischer-Tropsch (FT) synthesis catalyst was investigated in an attempt to maximize the diesel-range product yield. $\mathrm{H}_{2}$ pulsing increases $\mathrm{CO}$ conversion significantly but only temporarily; catalyst activity decreases gradually towards its steady state. Increasing $\mathrm{H}_{2}$-pulse frequency has a positive effect on the yield of both $\mathrm{CH}_{4}$ (undesirable) and $\mathrm{C}_{10}-\mathrm{C}_{20}$ (desirable) products. An optimum $\mathrm{H}_{2}$-pulse frequency is apparently required in order to maximize the yield of diesel-range FT products without substantially increasing the $\mathrm{CH}_{4}$ yield.

\section{INTRODUCTION}

The Fischer-Tropsch synthesis (FTS) can convert solid fuel- or natural gas-derived syngas $\left(\mathrm{CO}+\mathrm{H}_{2}\right)$ to liquid fuels and high-value products. The extensively reviewed FischerTropsch (FT) reaction [1-3] produces a non-selective distribution of hydrocarbons $\left(\mathrm{C}_{1}-\mathrm{C}_{100+}\right)$ from syngas. FT catalysts are typically based on Group-VIII metals ( $\mathrm{Fe}, \mathrm{Co}, \mathrm{Ni}$, and $\mathrm{Ru}$ ), with $\mathrm{Fe}$ and $\mathrm{Co}$ most frequently used. The product distribution over these catalysts is generally governed by the Schultz-Flory-Anderson (SFA) polymerization kinetics [4].

Currently there is significant commercial interest in producing diesel-fuel range middle distillates $\left(\mathrm{C}_{10}-\mathrm{C}_{20}\right.$ paraffins) from natural gas-derived syngas [5]. Increasing the selectivity of FTS to desired products such as diesel $\left(\mathrm{C}_{10}-\mathrm{C}_{20}\right)$ or gasoline $\left(\mathrm{C}_{5}-\mathrm{C}_{11}\right)$ by altering the SFA distribution is economically attractive. Use of bifunctional catalysts (FT-active metals on zeolite, e.g. ZSM-5) to produce high-octane gasoline-range hydrocarbons (explored in the past 2 decades), has been economically unsuccessful [6-9]. The zeolite cracking activity lowers the chain-growth probability $(\boldsymbol{\alpha})$, producing gasoline-range products in excess of 48 $\mathrm{wt} \%$ of the total hydrocarbon product; however, it also produces a significant amount of undesirable $\mathrm{C}_{1}-\mathrm{C}_{4}$ gases (Figure 1).

The present emphasis has shifted towards maximizing the yield of high-cetane $\mathrm{C}_{10}-\mathrm{C}_{20}$ products from FTS. Increased worldwide demand for low-sulfur diesel has further stressed the importance of development of zero-sulfur FT-diesel products. An alternative approach to the use of bifunctional catalysts to alter selectivity is periodic FT reactor operation (pulsing) [3]. It entails alternatively switching between two predetermined input compositions over the FT catalyst to promote time-average rate, selectivity, and catalyst life [10-12]. Periodic pulsing of $\mathrm{H}_{2}$ has been examined so as to limit chain growth by removing the growing

\footnotetext{
*Present address: $\quad$ Chemical Engineering Dept., North Carolina State University, Raleigh, NC 27695
} 


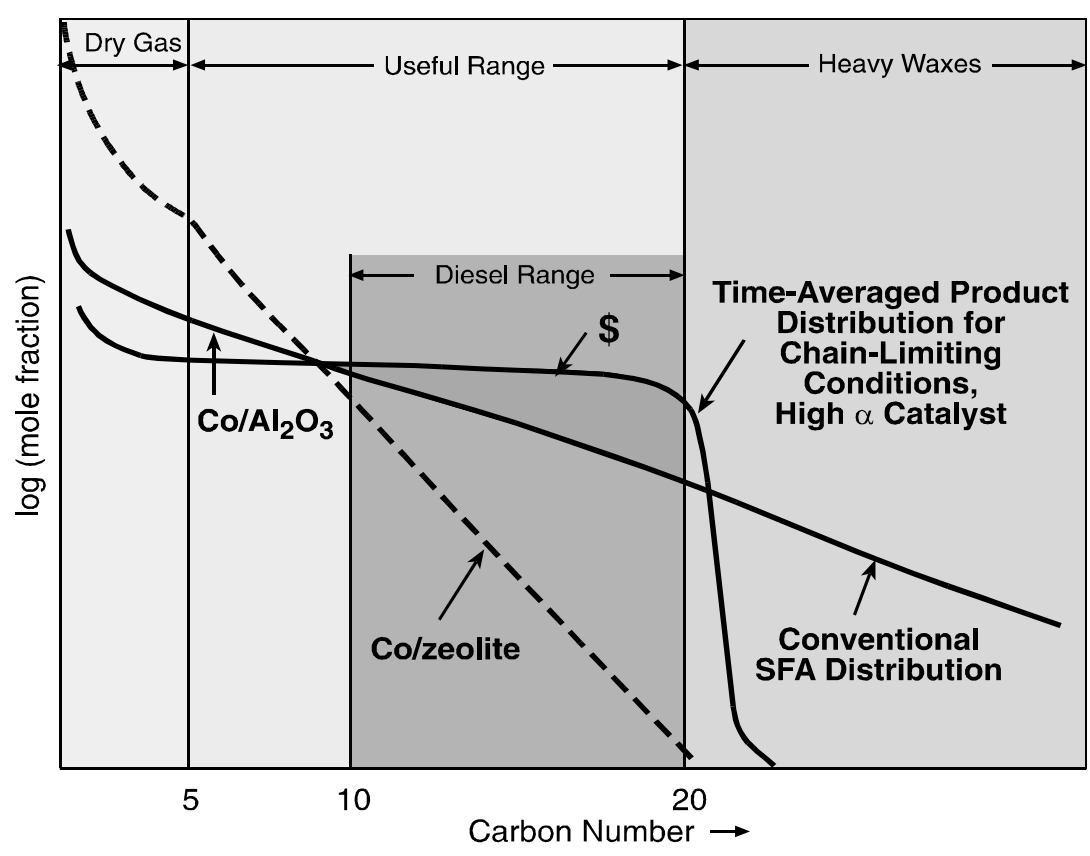

Figure 3. Product distribution ( $\boldsymbol{\alpha}$-plot) for FT synthesis hydrocarbon chain from the catalyst surface [1315]. Experimental studies have shown the potential to alter the SFA distribution $[16,17]$; they were performed, however, at conditions of limited industrial interest.

The chain-limiting concept using pulsing to maximize diesel yield is shown in a plot of carbon number vs. mole fraction (Fig. 1). The slope of the curve is determined by the chain-growth probability, $\boldsymbol{\alpha}$. Periodic operation on a high- $\boldsymbol{\alpha}$ catalyst may result in removal of the growing chain from the surface at

the desired $\mathrm{C}_{10}-\mathrm{C}_{20}$ length, thereby maximizing diesel yield without increasing the dry gas. Thus, the objective of this study is to investigate the effect of $\mathrm{H}_{2}$ pulsing on the activity and product distribution of a high- $\alpha(\sim 0.9) \mathrm{Co} / \mathrm{ZrO}_{2} / \mathrm{SiO}_{2} \mathrm{FT}$ synthesis catalyst, in an attempt to maximize the $\mathrm{C}_{10}-\mathrm{C}_{20}$ product yield.

\section{EXPERIMENTAL}

\subsection{Catalyst synthesis and characterization}

A $25 \% \mathrm{Co}-18 \% \mathrm{Zr} / \mathrm{SiO}_{2}$ catalyst was synthesized by sequential incipient wetness impregnation of a high-purity, high-surface-area $\left(144-\mathrm{m}^{2} / \mathrm{g}\right)$ silica support (XS 16080, Norton) [18]. The support (crushed and sieved to a particle size of 100-150 $\mu \mathrm{m}$ ) was degassed in vacuum and heated to $80^{\circ} \mathrm{C}$. A zirconium tetrapropoxide $\left(\mathrm{Zr}\left(\mathrm{OCH}_{2} \mathrm{CH}_{2} \mathrm{CH}_{3}\right)_{4}\right)$ solution in 1-propanol (Aldrich) was used for the incipient wetness impregnation, performed in two steps. After each impregnation step, the product was dried $\left(120^{\circ} \mathrm{C}, 2 \mathrm{~h}\right)$ and calcined in air $\left(500^{\circ} \mathrm{C}, 1\right.$ hour $)$. The produced material had a nominal loading of $18 \% \mathrm{Zr} /$ silica.

Cobalt was impregnated on the zirconia/silica support using a cobalt nitrate hexahydrate precursor $\left(\mathrm{Co}\left(\mathrm{NO}_{3}\right)_{2} \cdot 6 \mathrm{H}_{2} \mathrm{O}\right.$, Aldrich). The hexahydrate was dissolved in water and the formed solution was added in a controlled manner to the zirconia/silica support, forming the catalyst with a nominal composition of $25 \% \mathrm{Co}-18 \% \mathrm{Zr} / \mathrm{SiO}_{2}$. Finally, the catalyst was calcined in air at $350^{\circ} \mathrm{C}$ for 1 hour.

The surface area of the $\mathrm{Co}-\mathrm{ZrO}_{2} / \mathrm{SiO}_{2}$ catalyst was measured (by BET method) to be $102 \pm 3 \mathrm{~m}^{2} / \mathrm{g}$. Its pore volume was estimated at $0.40 \pm 0.01 \mathrm{cc} / \mathrm{g}$ (by mercury porosimetry). Its crystalline structure was examined by X-ray diffraction (XRD). The predominant phase was $\mathrm{Co}_{3} \mathrm{O}_{4}$, with no other $\mathrm{Co}-\mathrm{O}$ or $\mathrm{Zr}-\mathrm{O}$ crystalline phases or cobalt silicate present in the diffraction pattern. 


\subsection{Reaction set-up}

The reaction system consisted of the gas-feed, a fixed-bed reactor, and a sampling/ analysis system for the liquid and gaseous products. The feed system blended CO/Ar, $\mathrm{H}_{2}$, $\mathrm{N}_{2}$, or other premixed gases in desired concentrations. A time-programmable interface system (Carolina Instrumentation Co.) was used to control a series of actuated valves, so that a (reactant or inert) flow opened / closed automatically and independently of the others. Appropriate periodic switch of these valves offered the capability to perform various pulsingtype experiments with this configuration.

A stainless-steel 3/8-in o.d. (0.305-in i.d.) downflow reactor was enclosed in a three-zone programmable furnace. The liquid products were collected and separated into a wax trap (waxes) maintained at $140^{\circ} \mathrm{C}$ and a water trap (oil + water) maintained at $25^{\circ} \mathrm{C}$. Two sets of these traps, positioned in parallel, enabled continuous operation. A Kammer back-pressurecontrol valve, located downstream of the traps, controlled the reactor and trap pressure.

An on-line GC-Carle (TCD) analyzed the permanent gases $\left(\mathrm{H}_{2}, \mathrm{CO}_{2}, \mathrm{Ar}, \mathrm{N}_{2}, \mathrm{CH}_{4}, \mathrm{CO}\right)$. Argon was used as internal standard. An on-line GC-FID (100-m Petrocol column, ramped from -25 to $\left.300^{\circ} \mathrm{C}\right)$ analyzed the light hydrocarbons $\left(\mathrm{C}_{1}-\mathrm{C}_{15}\right)$. A third off-line GC-FID (15$\mathrm{m}$ SPB-1 capillary column, $0.1-\mu \mathrm{m}$, ramped from 50 to $350^{\circ} \mathrm{C}$ ) analyzed the composite wax and oil collected from the wax and water traps, respectively.

\subsection{Reaction procedure}

A physical mixture of $2 \mathrm{cc}(1.55 \mathrm{~g})$ of the calcined $\mathrm{Co}-\mathrm{ZrO}_{2} / \mathrm{SiO}_{2}$ catalyst and $10 \mathrm{cc}$ (15.91 g) of a low-surface-area $\left(0.2 \mathrm{~m}^{2} / \mathrm{g}\right) \alpha$-alumina (SA5397, Norton) was loaded into the reactor. The catalyst was reduced in-situ under $\mathrm{H}_{2}$ at $350^{\circ} \mathrm{C}$ for $14 \mathrm{~h}$, and was cooled and pressurized to ca. $300 \mathrm{psig}(19.4 \mathrm{~atm})$. The FT reaction was started by feeding a $10 \% \mathrm{Ar} / \mathrm{CO}$ gas mix, thus establishing the following base reaction conditions:

Syngas $\left(\mathrm{H}_{2}+\mathrm{CO}\right)=50 \%, \mathrm{H}_{2}: \mathrm{CO}=2: 1$ (i.e., $33.3 \% \mathrm{H}_{2}$ and $16.7 \% \mathrm{CO}$ )

Inerts $\left(\mathrm{N}_{2}+\mathrm{Ar}\right)=50 \%\left(1.7 \% \mathrm{Ar}, 48.3 \% \mathrm{~N}_{2}\right)$

$\mathrm{P}=300 \mathrm{psig}, \mathrm{F}=200 \mathrm{scc} / \mathrm{min}, \mathrm{SV}=6000 \mathrm{~h}^{-1}$.

The reaction temperature was increased (by $0.5^{\circ} \mathrm{C} / \mathrm{h}$ or less) to $224^{\circ} \mathrm{C}$ and was stabilized at this value, thus allowing the reaction to reach a "pseudo-steady state". Pulse runs involved substituting the reactant feed flow $\left(\mathrm{H}_{2}+\mathrm{CO} / \mathrm{Ar}\right)$ with an equal molar flow of a pulse gas. The total molar flow and the reaction pressure were kept constant between base and pulse runs.

\section{RESULTS AND DISCUSSION}

A "blank" pulse run (i.e., switching between two equal flows of $\mathrm{H}_{2} / \mathrm{CO} / \mathrm{Ar}$ reactant mix) was performed in order to identify the possible effect of the periodic pressure disturbance (directly related to the applied pulse) due to non-ideal switching of the actuated valves. This run produced no measurable variation on $\mathrm{CO}$ conversion, $\mathrm{H}_{2}: \mathrm{CO}$ ratio, or product distribution $\left(\boldsymbol{\alpha}\right.$-value, $\mathrm{C}_{10}-\mathrm{C}_{20}$ yield). Therefore, pulse runs involving no variations in feed composition have no effect on measurements of the progress of the FT reaction.

A 1-min $\mathrm{N}_{2}$ (inert) pulse per 1 hour (i.e., substituting the $\mathrm{H}_{2} / \mathrm{CO} / \mathrm{Ar}$ flow, which is $51.7 \%$ of the total, with an equal flow of $\mathrm{N}_{2}$ for 1 min every hour) was applied so as to examine the effect of inert pulsing on the reaction progress. The $\mathrm{N}_{2}$ pulse gave only minimal variations in activity (CO conversion) or product selectivity ( $\alpha$-value, $\mathrm{CH}_{4}$ yield, $\mathrm{C}_{10}-\mathrm{C}_{20}$ yield), implying that short (1-min) disruptions in reactant flow do not substantially affect the FT reaction. 
In contrast to the inert pulse, a 1-min $\mathrm{H}_{2}$ (reactant) pulse caused significant variations in $\mathrm{CO}$ conversion and $\mathrm{CH}_{4}$ selectivity. Effects of varying the $\mathrm{H}_{2}$ pulse frequency (1-min $\mathrm{H}_{2}$ per 1,2 , and 4 hours) on the $\mathrm{CO}$ conversion and the $\mathrm{C}_{1}\left(\mathrm{CH}_{4}\right.$ and $\left.\mathrm{CO}_{2}\right)$ selectivity are shown in the composite plots of Figures $2 \mathrm{a}$ and $2 \mathrm{~b}$, respectively. These plots are composed of 10-hour segments of a series of sequential runs (typically lasting 48 hours, so as to collect sufficient amounts of oil + wax for the analysis), starting and ending with a base (no pulse) run. The data points correspond to measurements of the reactor effluent gas every 15 minutes.

A 1-min $\mathrm{H}_{2}$ pulse per 1-hour (10-20-hour segment in Figs. 2a and 2b) caused a significant increase in CO conversion (from $16 \%$ to ca. $30 \%$ ). The measured temperature of the catalyst bed also increased to $226^{\circ} \mathrm{C}$, indicating a strong reaction exotherm. The conversion of $\mathrm{CO}$ decreased gradually until

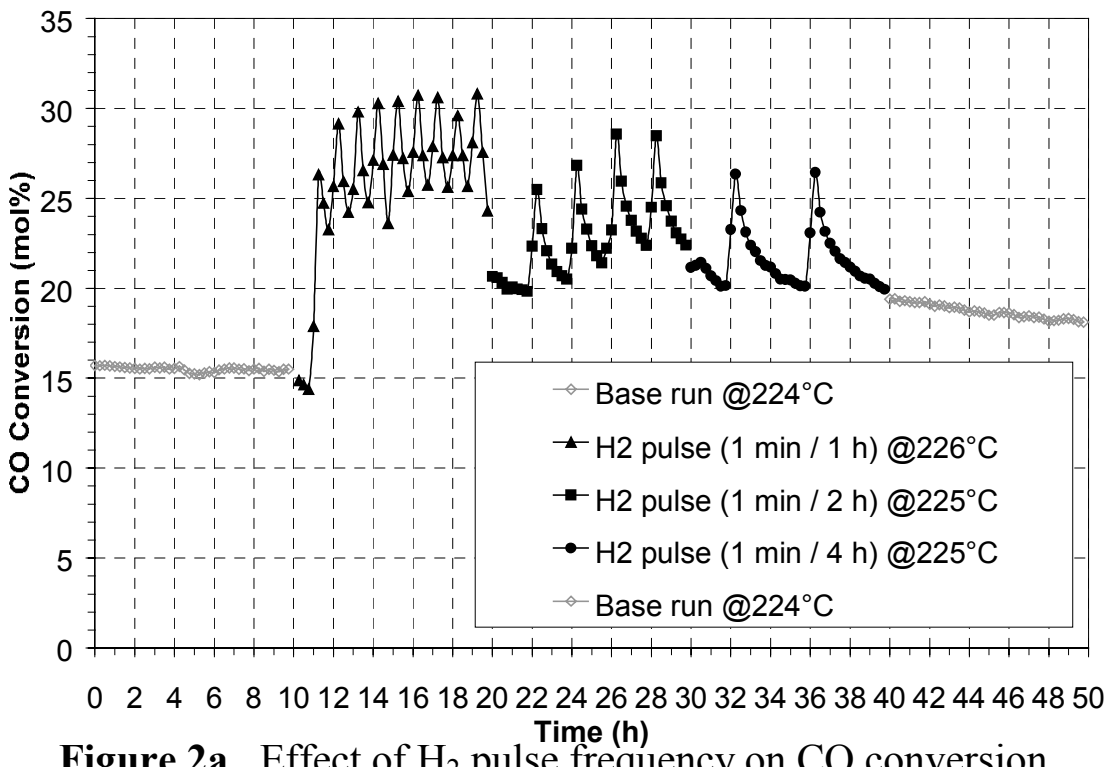

Figure 2a. Effect of $\mathrm{H}_{2}$ pulse frequency on $\mathrm{CO}$ conversion

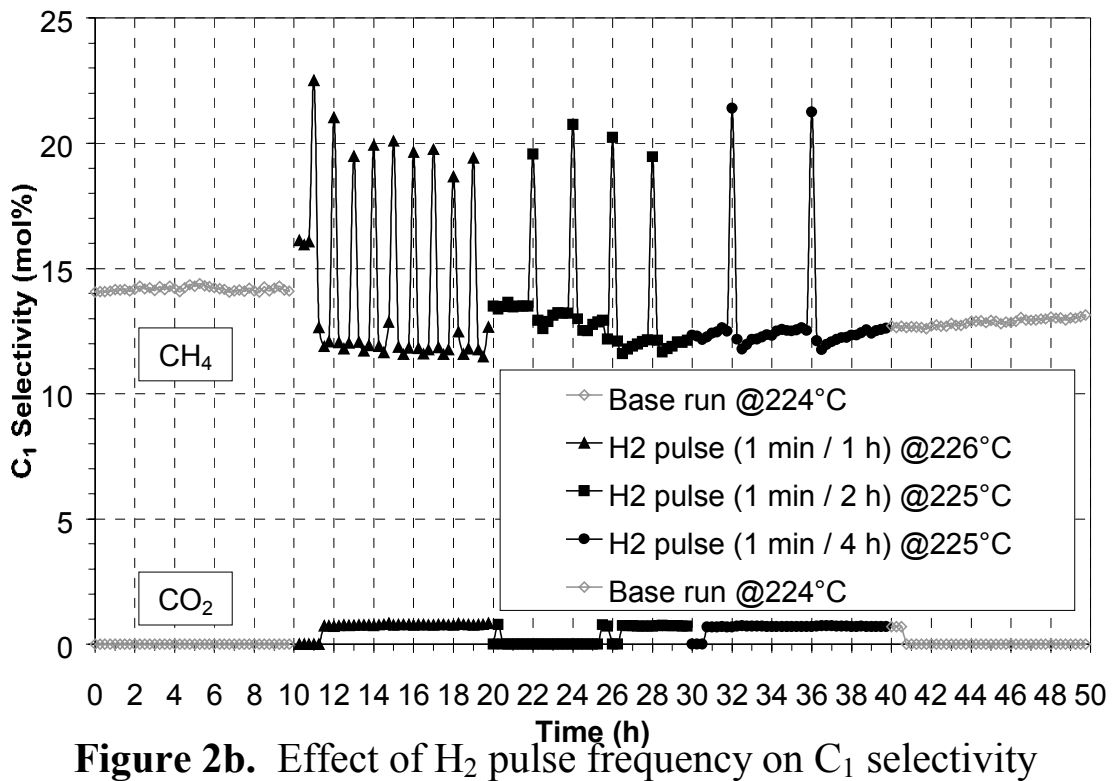
the next $\mathrm{H}_{2}$ pulse. A lesspronounced increase in $\mathrm{CO}$ conversion was also observed for the 1-min $\mathrm{H}_{2}$ pulse per $2-\mathrm{h}$ and $4-\mathrm{h}$ runs. The observed decrease in $\mathrm{CO}$ conversion after the pulse indicates that the activity tends to return to its steady state (comparing also the base runs before and after the 3 pulse runs). The measured changes in $\mathrm{CO}$ conversion cannot be attributed to variations in the inlet $\mathrm{CO}$ concentration since the conversion was based on comparing the inlet and outlet ratios of $\mathrm{CO}$ to the inert Ar (fed at a fixed ratio from a single gas cylinder).

The selectivity to $\mathrm{CH}_{4}$ was observed to increase instantaneously after each $\mathrm{H}_{2}$ pulse (from $13-14 \%$ to ca. $20 \%$ for all examined pulse runs). It was then quickly restored to its base value (Fig. 2b). Thus, $\mathrm{H}_{2}$ pulsing increases catalytic activity while only briefly increasing the undesirable formation of $\mathrm{CH}_{4}$. 


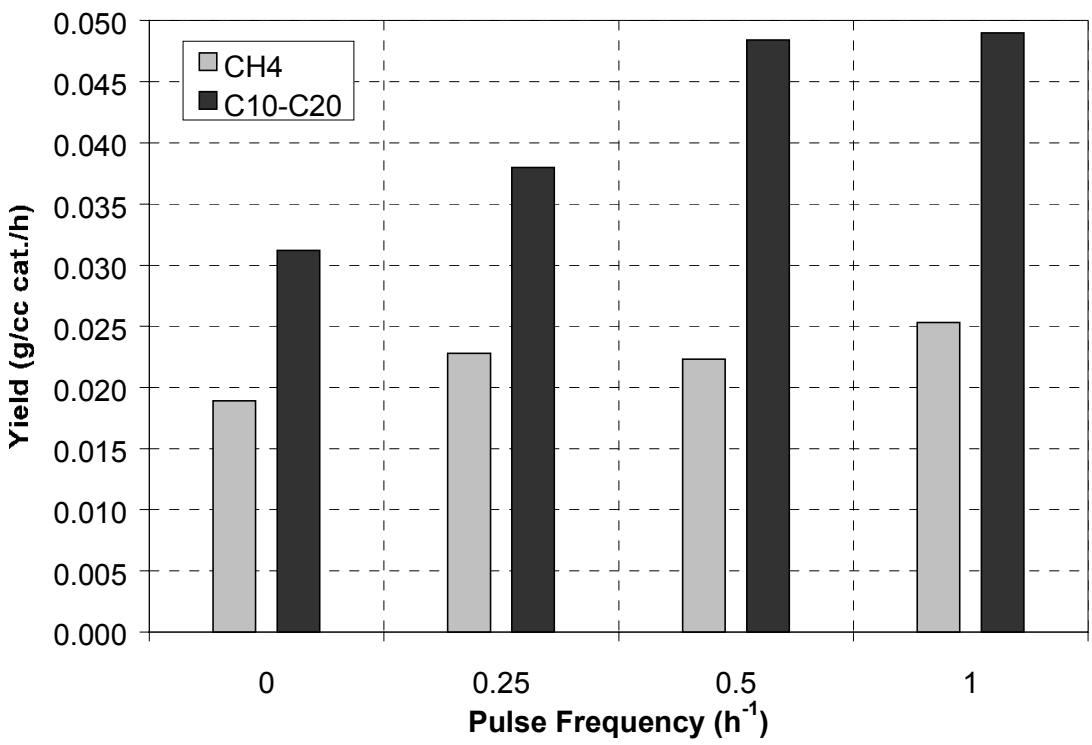

Figure 3. Effect of $\mathrm{H}_{2}$ pulse frequency on product yield
The effect of varying $\mathrm{H}_{2}$ pulse frequency on the desired $\mathrm{C}_{10}-\mathrm{C}_{20}$ yield vs. the undesired $\mathrm{CH}_{4}$ yield is shown in Figure 3. Pulse frequencies of $1,0.5$, and $0.25, \mathrm{~h}^{-1}$ correspond to a 1-min $\mathrm{H}_{2}$ pulse per 1, 2, and 4 hours, respectively. The zero pulse frequency corresponds to the average of the two no-pulse (base) runs before and after the 3 pulse runs.

Both $\mathrm{C}_{10}-\mathrm{C}_{20}$ and $\mathrm{CH}_{4}$ yields increase with $\mathrm{H}_{2-}$ pulse frequency (and so does the yield of $\mathrm{C}_{21+}$ ), obviously due to the enhancement in catalytic activity caused by the pulsing (Fig. 2a). As seen in Fig. 3, the effect of the 1-min $\mathrm{H}_{2}$ pulse per 1 hour compared to the (average) base run was to increase the $\mathrm{C}_{10}-\mathrm{C}_{20}$ yield by ca. $57 \%$, while the $\mathrm{CH}_{4}$ yield only increased by ca. $34 \%$. Although this comparison entails a temperature change (from $224^{\circ} \mathrm{C}$ to $226^{\circ} \mathrm{C}$ ), the increase in the $\mathrm{C}_{10}-\mathrm{C}_{20}$ yield is more than what could be accounted for solely by a $2^{\circ} \mathrm{C}$ increase in reaction temperature. The $\mathrm{CH}_{4}$ selectivity in the pulse runs $(13-14 \%$ on molar basis) is lower than that of the base runs (15.5\%), whereas the selectivity to $\mathrm{C}_{10}-\mathrm{C}_{20}$ and $\mathrm{C}_{21+}$ compounds is higher (28-32\% vs. $27 \%$, and $23-24 \%$ vs. $20 \%$, respectively). The $\boldsymbol{\alpha}$ values of the pulse runs (based on the molar fractions of $\mathrm{C}_{10}-\mathrm{C}_{65}$ products) are found to be essentially identical to that of the base runs $(0.890 \pm 0.005)$. Thus, the applied $\mathrm{H}_{2}$ pulsing apparently does not alter the SFA distribution.

Within the examined pulse frequency range, the greater difference between the yields of the desirable $\mathrm{C}_{10}-\mathrm{C}_{20}$ and the undesirable $\mathrm{CH}_{4}$ is obtained at the intermediate pulse frequency of $0.5 \mathrm{~h}^{-1}$ (1-min $\mathrm{H}_{2}$ per 2 hours). Also, upon extrapolating to higher $\mathrm{H}_{2}$-pulse frequencies, we could expect a stronger reaction exotherm and thus an increase in reaction temperature, which is known to cause a shift in FTS product distribution to lower molecular weight compounds and to enhance the methanation reaction [4]. Higher pulse frequencies would thus tend to increase the $\mathrm{CH}_{4}$ yield much more than the $\mathrm{C}_{10}-\mathrm{C}_{20}$ yield. An optimum $\mathrm{H}_{2}$-pulse frequency (depending on catalyst and reaction conditions) would therefore be required for maximizing the $\mathrm{C}_{10}-\mathrm{C}_{20}$ yield without substantially increasing the $\mathrm{CH}_{4}$ yield.

Another series of $\mathrm{H}_{2}$-pulse runs on the $\mathrm{Co}-\mathrm{ZrO}_{2} / \mathrm{SiO}_{2}$ catalyst examined the effect of $\mathrm{H}_{2}$ pulse duration on activity and product distribution, by varying the pulse duration (1, 2, 4-min of $\left.\mathrm{H}_{2}\right)$ at a fixed pulse frequency $\left(0.5 \mathrm{~h}^{-1}\right)$. The results of this study (not included here) are qualitatively similar to those of the variable-pulse-frequency study presented here: higher $\mathrm{H}_{2}$ pulse duration causes an increase in both $\mathrm{C}_{10}-\mathrm{C}_{20}$ and $\mathrm{CH}_{4}$ yield, and the greater difference between these yields is obtained at the intermediate pulse duration of $2 \mathrm{~min}$. Consequently, optimization of the pulse duration is also important in maximizing the formation of dieselrange FT products. 


\section{CONCLUSIONS}

In contrast to "blank" or inert $\left(\mathrm{N}_{2}\right)$ pulsing, pulsing with $\mathrm{H}_{2}$ has a significant impact on the activity and selectivity of the examined $\mathrm{Co}-\mathrm{ZrO}_{2} / \mathrm{SiO}_{2}$ catalyst. $\mathrm{H}_{2}$ pulsing causes significant increase in $\mathrm{CO}$ conversion, along with an observed enhanced reaction exotherm. Then, the $\mathrm{CO}$ conversion decreases gradually until the next $\mathrm{H}_{2}$ pulse, indicating that the catalyst activity tends to return slowly to its steady state, as measured in base (no-pulse) runs. On the other hand, the selectivity to $\mathrm{CH}_{4}$ increases instantaneously after each $\mathrm{H}_{2}$ pulse, and gets quickly restored to its steady-state value.

Increasing $\mathrm{H}_{2}$-pulse frequency has a positive effect on the yield of both $\mathrm{CH}_{4}$ and $\mathrm{C}_{10}-\mathrm{C}_{20}$. The selectivity to $\mathrm{C}_{10}-\mathrm{C}_{20}$ and $\mathrm{C}_{21+}$ compounds increases with $\mathrm{H}_{2}$ pulsing compared to the base runs, but the chain-growth probability $\boldsymbol{\alpha}$ is essentially unaffected. An optimum set of $\mathrm{H}_{2}$-pulse parameters (frequency and duration) appears to be needed to maximize the $\mathrm{C}_{10}-\mathrm{C}_{20}$ yield without substantially increasing the $\mathrm{CH}_{4}$ yield.

\section{ACKNOWLEDGEMENTS}

Funding for this work (in part) by the US Department of Energy under Contract No. DEFG26-99FT40680 is gratefully acknowledged.

\section{REFERENCES}

19. R.B. Anderson, The Fischer-Tropsch Synthesis, Acad. Press, New York, 1984.

20. M.E. Dry, Appl. Catal. A, 138 (1996) 319.

21. A.A. Adesina, Appl. Catal. A, 138 (1996) 345.

22. M.E. Dry, The Fischer-Tropsch Synthesis, in Catalysis - Science and Technology 1 (J.R. Ander and M. Boudart, eds.), Springer-Verlag, New York, 1981.

23. G. Parkinson, Chem. Eng., 4 (1997) 39.

24. C.D. Chang, W.H. Lang, and A.J. Silvestri, J. Catal., 56 (1979) 268.

25. R.J. Gormley, V.U.S. Rao, R.R. Anderson, R.R. Schehl, and R.D.H. Chi, J. Catal., 113 (1988) 195.

26. S. Bessell, Appl. Catal. A, 126 (1995) 235.

27. K. Jothimurugesan and S.K. Gangwal, Ind. Eng. Chem. Res., 37(4) (1998) 1181.

28. D.L. King, J.A. Cusamano, and R.L. Garten, Catal. Rev. Sci. Eng., 23(1-2) (1981) 233.

29. A.A. Adesina, R.R. Hudgins, and P.L. Silveston, Can. J. Chem. Eng., 25 (1995) 127.

30. J.W. Dun, and E. Gulari, Can. J. Chem. Eng., 64(2) (1986) 260.

31. G. Beer, Gas Conversion Process Using a Chain-Limiting Reactor, WO Patent No. 98/ 19979 (1997).

32. E. Peacock-Lopez and K. Lindenberg, J. Phys. Chem., 88 (1984) 2270.

33. E. Peacock-Lopez and K. Lindenberg, J. Phys. Chem., 90 (1986) 1725.

34. A.A. Khodadadi, R.R. Hudgins, and P.L. Silverston, Canadian J. Chem. Eng., 74 (1996) 695.

35. F.M. Dautzenberg, J.M. Heller, R.A. van Santen, and H. Berbeek, J. Catal., 50 (1977) 8.

36. A. Hoek, M.F.M. Post, J.K. Minderhoud, and P.W. Lednor, Process for the Preparation of a Fischer-Tropsch Catalyst and Preparation of Hydrocarbons from Syngas, US Patent No. 4,499,209 (1985). 